Universidad de Lima

Facultad de Ciencias Empresariales y Económicas

Carrera de Contabilidad

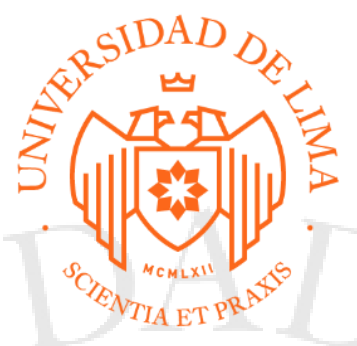

\title{
ANÁLISIS E INTERPRETACIÓN DE LOS ESTADOS FINANCIEROS. CASO \\ CORPORACIÓN LINDLEY S.A. PERIODOS
}

\section{$2015-2017$}

Trabajo de suficiencia profesional para optar el Título Profesional de Contador Público

\section{Lorena Romina Patri Carbajal}

Código 20102602

\section{Asesor}

Carlos Guillermo Paredes Reátegui

$$
\text { Lima - Perú }
$$

Octubre 2018 


\section{ANÁLISIS E INTERPRETACIÓN DE LOS ESTADOS FINANCIEROS. CASO CORPORACIÓN LINDLEY S.A. PERIODOS}

2015 - 2017 


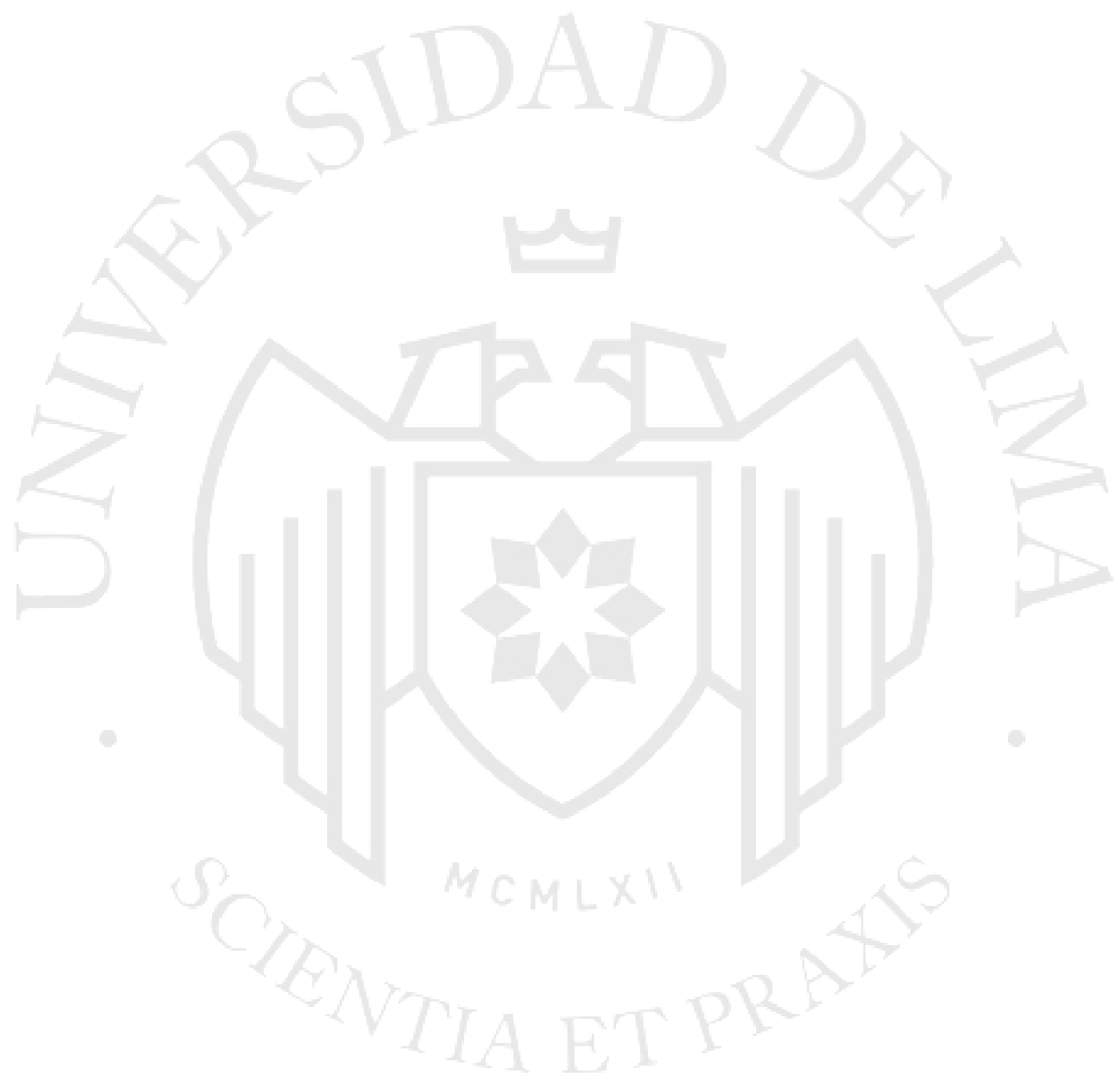




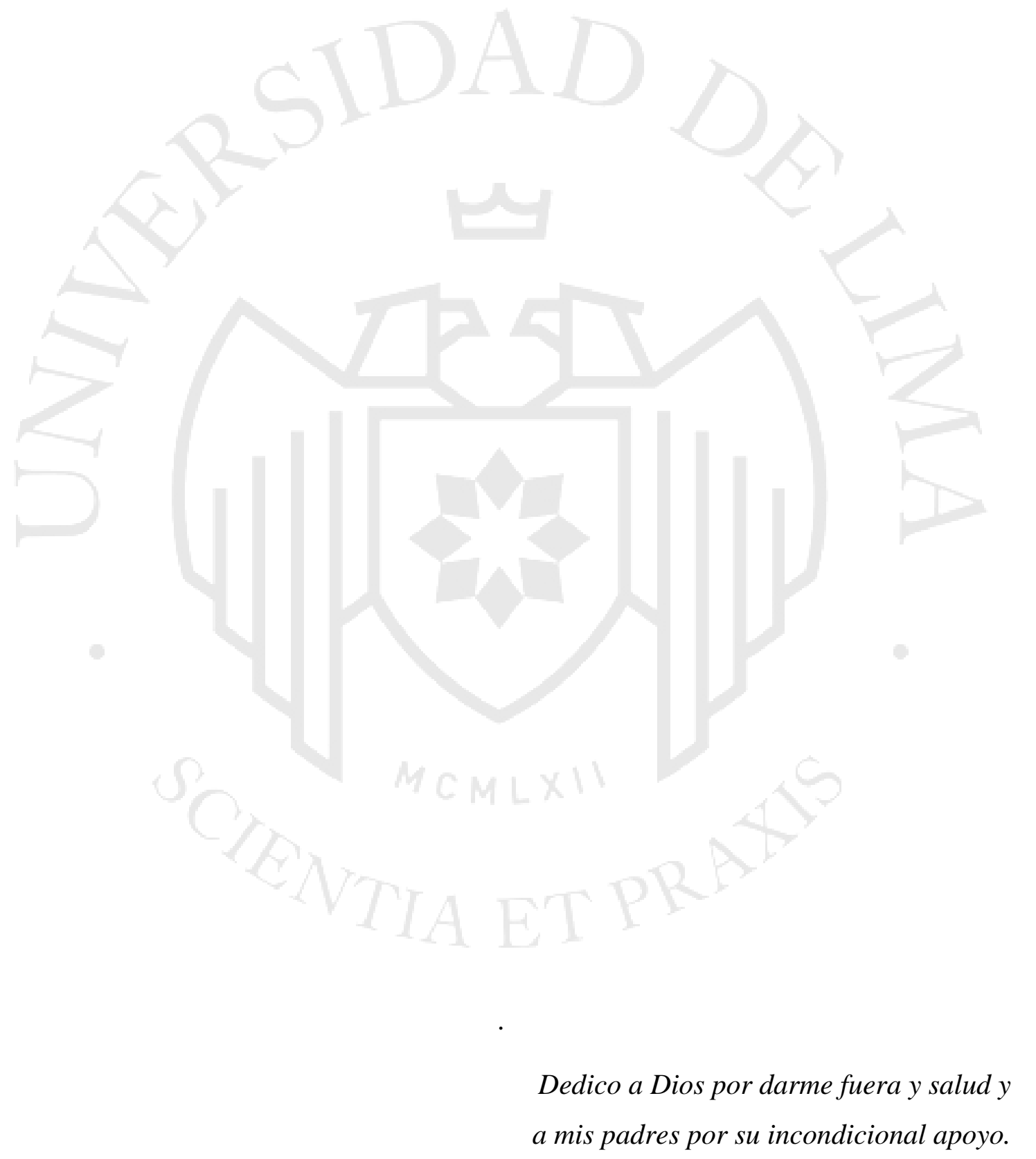

TABLA DE CONTENIDO 


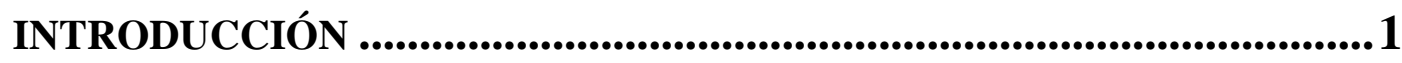

CAPITULO I: ANTECEDENTES DE LA ENTIDAD .................................3

1.1 Identificación y actividad económica ...................................................

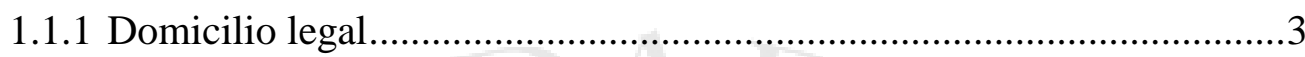

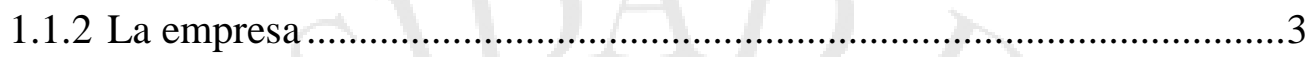

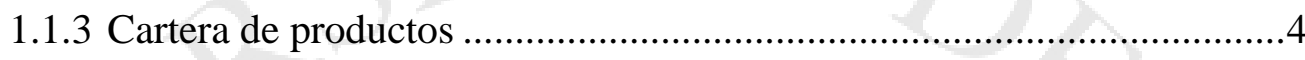

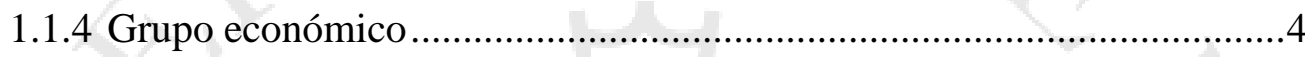

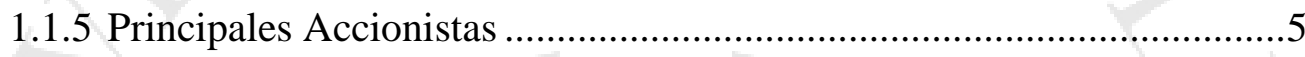

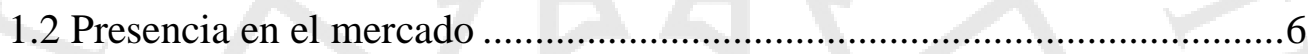

CAPITULO II: DESCRIPCION Y OBJETIVOS ......................................8

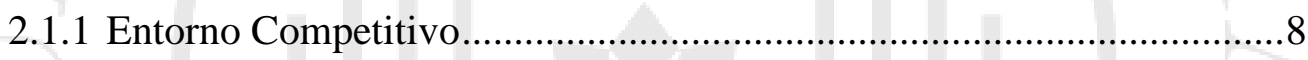

2.2 Descripción del caso de investigación.....................................................10

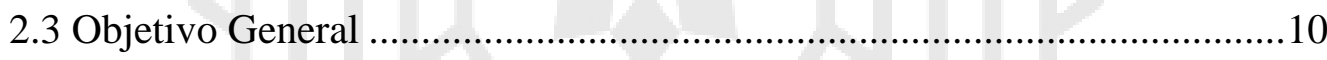

2.4 Objetivos Específicos .................................................................... 10

CAPITULO III: MARCO METODOLOGICO ...................................................10

3.1 Metodología de recolección de información ............................................11

3.2 Metodología de análisis de la información.............................................11

CAPITULO IV: ANALISIS, PRESENTACION DE RESULTADOS.............11

4.1 Análisis de la información...................................................................12

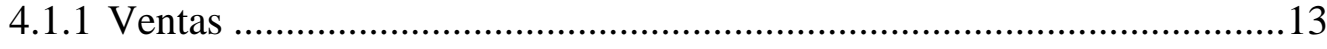

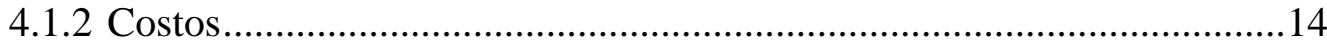

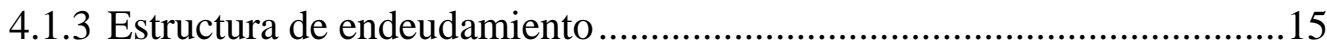

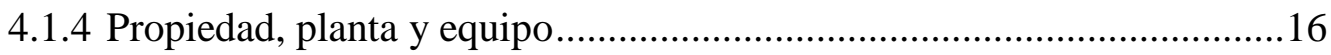


4.1.5 Arrendamientos. .19

4.1.6 Aplicación NIIF 16 Arrendamientos ..................................................24

4.1.7 Emisión de bonos corporativos internacionales......................................34

4.1.8 Instrumentos Financieros derivados y actividades de cobertura.............35

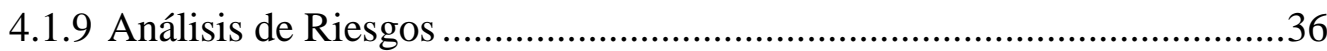

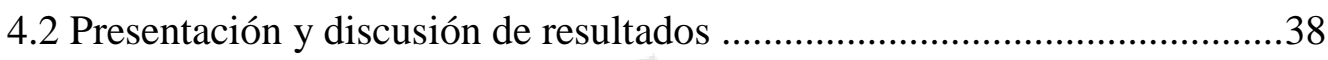

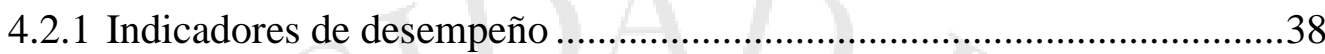

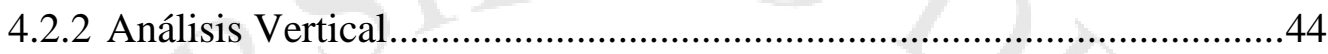

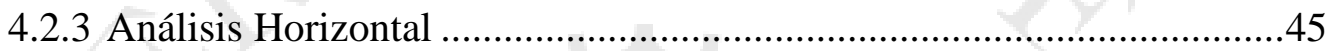

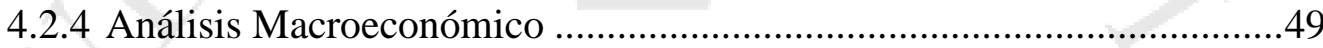

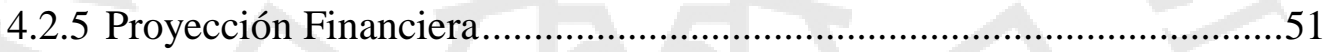

4.2.6 Proyección financiera con efecto IFRS 16 Arrendamientos ....................58

4.2.7 Ratios financieros proyectados con NIIF 16 .....................................63

4.2.8 Aplicación de NIIF 15 Ingreso de Actividades Ordinarias procedentes

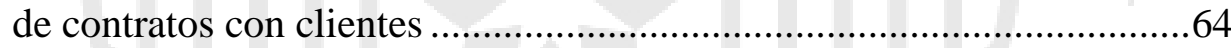

4.2.9 Aplicación de NIIF 9 Instrumentos Financieros ..................................66

CAPITULO V: CONCLUSIONES Y RECOMENDACIONES....................67

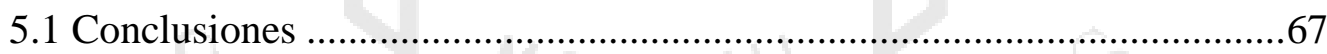

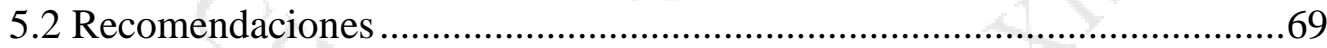

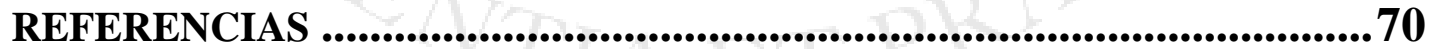

ANEXOS 


\section{INDICE DE TABLAS}

Tabla 1.1 Composición del accionariado Arca Continental Lindley ..........................6

Tabla 1.2 Participación de accionistas ....................................................................6

Tabla 2.1 Demanda de bebidas por categoría ......................................................8

Tabla 4.1 Variación de las ventas ............................................................................... 13

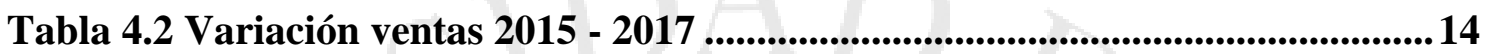

Tabla 4.3 Variación costo de ventas .................................................................15

Tabla 4.4 Variación Costo de Ventas ......................................................................15

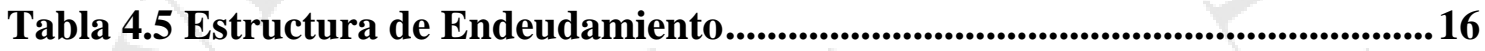

Tabla 4.6 Vida útil estimada PPE....................................................................17

Tabla 4.7 Variación Propiedad, Planta y Equipo _........................................................17

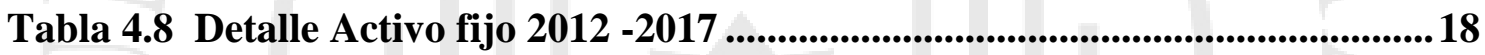

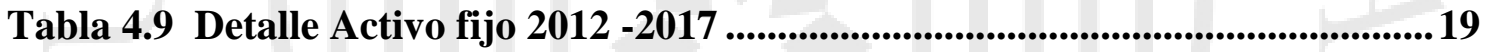

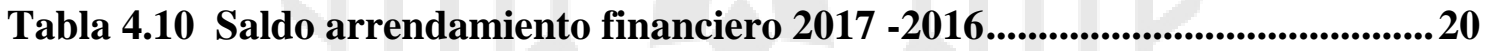

Tabla 4.11 Ejemplo arrendamiento financiero NIC 17 ...........................................21

Tabla 4.12 Calculo de cuotas y amortización Anual................................................21

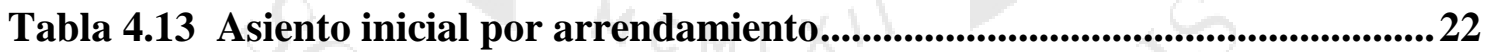

Tabla 4.14 Asiento por costos adicionales de adquisición ...........................................22

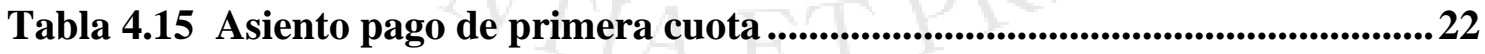

Tabla 4.16 Depreciación vida útil plazo del contrato ..............................................23

Tabla 4.17 Asientos pagos mensuales por arrendamiento operativo......................23

Tabla 4.18 Modificación en arrendamientos operativos ...........................................227

Tabla 4.19 Supuestos Arrendamiento operativo..................................................................28

Tabla 4.20 Pagos por arrendamiento primero año..........................................................29 


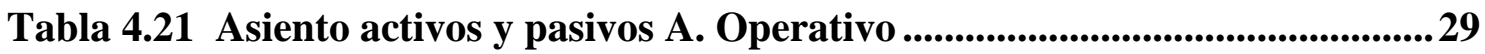

Tabla 4.22 Asiento activos y pasivos A. Operativo ................................................30

Tabla 4.23 Asientos de gastos por depreciación............................................................30

Tabla 4.24 Asiento de pago de cuota del principal ...........................................................30

Tabla 4.25 Resumen cuentas $T$ - Primero año..............................................................31

Tabla 4.26 Pagos por arrendamiento segundo año..............................................31

Tabla 4.27 Resumen cuentas $T$ - Segundo año ......................................................32

Tabla 4.28 Pagos por arrendamiento tercer año ..................................................32

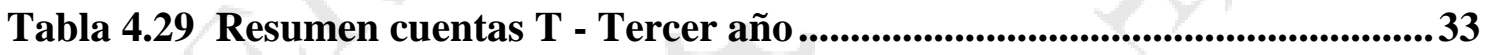

Tabla 4.30 Diferencias en el Reconocimiento EE.RR..........................................33

Tabla 4.31 Obligaciones financieras al 31 de Diciembre del 2017...........................34

Tabla 4.32 Detalle instrumentos financieros derivados. .......................................36

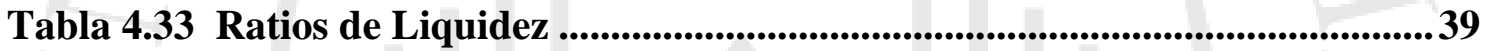

Tabla 4.34 Ratios de Solvencia. ........................................................................ 40

Tabla 4.35 Ratios de Gestión ............................................................................41

Tabla 4.36 Ratios de Rentabilidad .................................................................................42

Tabla 4.37 Indicador Deuda/Ebitda...................................................................44

Tabla 4.38 Análisis Horizontal - Activos .............................................................46

Tabla 4.39 Propiedad, planta y equipo neto y Propiedades de Inversión ...............47

Tabla 4.40 Análisis Horizontal Pasivos y Patrimonio …..............................................47

Tabla 4.41 Otros Ingresos y gastos operativos .................................................48

Tabla 4.42 Análisis Horizontal Estado de Resultados. .............................................4 49

Tabla 4.43 Crecimiento Ventas últimos 10 años .............................................52

Tabla 4.44 Proyección ventas 2018, 2019,2020.........................................................53

Tabla 4.45 Estados de Resultados Proyectados........................................................53

Tabla 4.46 Análisis Vertical Variación - Activos................................................................554 
Tabla 4.47 Análisis Vertical Variación - Pasivos y Patrimonio ...............................54

Tabla 4.48 Estados de Situación Financiera Proyectado - Activos ..........................55

Tabla 4.49 Estado de Situación Financiera Proyectado - Pasivos y Patrimonio...56

Tabla 4.50 Estado de Resultados Proyectados .....................................................55

Tabla 4.51 Premisas de Arrendamiento Operativo ................................................58

Tabla 4.52 Evolución de Pasivo por arrendamiento..............................................58

Tabla 4.53 Asiento Arrendamiento Año 2019 ..........................................................60

Tabla 4.54 Asiento Arrendamiento Año 2020 ...................................................61

Tabla 4.55 Asiento Arrendamiento Año 2020.........................................................62

Tabla 4.56 Estado de Situación Financiera - Activos ...........................................62

Tabla 4.57 Estado de Resultados .....................................................................63

Tabla 4.58 Estado de Situación Financiera - Pasivos y Patrimonio ........................ 63

Tabla 4.59 Ratios Financieros - Diferencias ........................................................64 


\section{INDICE DE FIGURAS}

Figura 1.1 Grupo económico AC Bebidas .......................................................................5

Figura 1.2 Posicionamiento de la marca ...............................................................

Figura 4.1 Variación Propiedad, Planta y Equipo......................................................... 18

Figura 4.2 Comparativa arrendamiento financiero y operativo ...............................25

Figura 4.3 Reconocimiento en los EEFF...................................................................26

Figura 4.4 Variación Ratios de Gestión ...............................................................42

Figura 4.5 Variación de ROA y ROE ...........................................................................443

Figura 4.6 Crecimiento histórico PBI ............................................................................50

Figura 4.7 Crecimiento consumo de bebidas gaseosas ...............................................51

Figura 4.8 Regresión lineal Ventas.......................................................................52 


\section{TABLA DE ANEXOS}

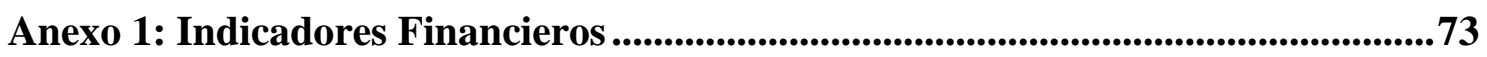

Anexo 2: Análisis vertical y horizontal de activos ................................................... 74

Anexo 3: Análisis vertical y horizontal pasivos y patrimonio....................................75

Anexo 4: Análisis vertical y horizontal de estado de resultados ...............................76

Anexo 5: Propiedad, planta y equipo ............................................................................ 77

Anexo 6: ESF Proyectado con NIIF 16 - Activos ....................................................78

Anexo 7: ESF Proyectado con NIIF 16 - Pasivos y Patrimonio ..................................79

Anexo 8: Estado de Resultados Proyectado con NIIF 16 ............................................80 


\section{INTRODUCCIÓN}

El mercado de bebidas no alcohólicas como gaseosas, aguas de bebida, energizantes, y bebidas saborizadas, es un mercado altamente competitivo debido a los distintos productos, marcas, presentaciones y sabores. Las marcas que ahora compiten en el rubro de estas bebidas son Backus, AJEPER y PEPSICO, donde Corporación Lindley es uno de los líderes en el sector a pesar de que la competencia tiene productos similares de menor precio; sin embargo, los productos de la compañía son percibidos como mejor calidad. Así mismo, la compañía ha tenido que realizar fuertes campañas de publicidad, marketing, y de fidelización con el consumidor al igual que con sus canales minoristas como tiendas y bodegas. Actualmente, Corporación Lindley es la embotelladora y distribuidora de The Coca Cola Company en el Perú y la segunda más grande en Latinoamérica después de México, por lo que ha sido necesaria la expansión y una fuerte inversión de capital para poder afrontar la demanda de las diferentes marcas de la cartera de productos. Debido a ello, se han emitido bonos nacionales e internacionales, así como préstamos con bancos locales. Con los fondos de estos pasivos, la compañía ha invertido en dos mega plantas de distribución como Pucusana y Huachipa, y en el mejoramiento de la planta de distribución de Villa el Salvador. Adicionalmente, se han adquirido distintos equipos para maximizar la eficiencia del llenado de bebidas, equipos de frio para entregar en comodato a sus canales de venta como tiendas, bodegas, autoservicios, supermercados, restaurantes, centros comerciales, cines, y otros establecimientos, los cuales sirven para almacenar, refrigerar y dispensar las bebidas; se adquirieron también más vehículos de distribución.

El presente trabajo busca analizar y comprender el funcionamiento y gestión de la compañía, en base a los Estados Financieros publicados en la Superintendencia de Mercado y Valores, según las memorias anuales, informes auditados, entrevistas a los principales directivos realizadas por diarios nacionales, y cuestionarios a personas que laboran en la empresa. Por otro lado, se ha realizado un análisis de indicadores financieros, así como de los Estados de Situación Financiera y Estado de Resultados y en base a la información historia de los años 2008 al 2017. Se ha podido proyectar los 
Estados Financieros en base a la información histórica hacia el año 2020 y la aplicación de la NIIF 16 así como los cambios contables que tendrá que realizar la compañía. 


\section{CAPITULO I: ANTECEDENTES DE LA ENTIDAD}

\subsection{Identificación y actividad económica}

\subsubsection{Domicilio legal}

La compañía se encuentra ubicada en la Avenida Javier Prado Este N 6210 piso 10 en el distrito de la Molina, ciudad de Lima.

\subsubsection{La empresa}

Corporación Lindley SA, es una empresa peruana constituida el 03 de Noviembre de 1928 por Joseph R Lindley e Hijos. Fundadora y creadora de la marca de gaseosas Inca Kola, la cual fue lanzada a la venta en el año 1935. Caracterizado por un nombre y color amarillo, que hacía referencia a los incas, fue la bebida con más acogida y que, sin duda, obtenía más ganancias que sus marcas competidoras de la época hasta la actualidad. A mediados del año 2015, integra sus operaciones con Arca Continental SAB CV, la segunda mayor embotelladora de la empresa The CocaCola Company en México, el suroeste de Estados unidos y América Latina (Ecuador y Argentina) así como la tercera más grande del mundo. El objetivo de ambas empresas con esta alianza, era aumentar el crecimiento de sus respectivas compañías; para Arca continental, la unión con la principal marca de gaseosas en el Perú fue potencial para incrementar sus ventas de sesenta y dos millones de pesos en el 2014 a cien millones en el 2017; así también, para Lindley fue beneficioso para sus planes de expansión, inversión, y alcance, para llevar más bebidas a más peruanos. Por su parte, José Borda, actual gerente general de Corporación Lindley dijo a Semana Económica lo siguiente: "Con la alianza, invertiremos recursos agresivamente, para apoyar el crecimiento y desarrollo del negocio. Para los siguientes años estimamos un cápex de alrededor de 11\% de las ventas netas". (Peru-retail, 2015, párr. 4).

Actualmente, Corporación Lindley, es socio y embotellador autorizado de Coca Cola Company. Comparten la producción y embotellamiento de distintos tipos de gaseosas, aguas, aguas saborizadas, jugos, isotónicos y cuenta con alrededor de 8 plantas de producción a nivel nacional, 4 de ellas se encuentran ubicadas en la 
ciudad de Lima (Planta Callao, Planta Zarate, Planta Huacho, Planta Pucusana) y 4 distribuidos los departamentos del Perú (Planta Trujillo, Planta Sullana, Planta Arequipa y Planta Cusco). Es ahora la tercera embotelladora más importante para CocaCola a nivel mundial. (AC Lindley, 2017).

\subsubsection{Cartera de productos}

Además de la emblemática marca de Lindley, Inka Kola, se ha añadido al portafolio de la compañía alrededor de 12 marcas pertenecientes a The CocaCola Company y otras marcas, mediante contratos de embotellador como Corporacion Inka Kola Peru SRL. y Schewpes Holdings Limited.

La cartera de productos de Corporación Lindley se conforma por las siguientes marcas:

- Bebidas carbonatadas: Conformada por las marcas Fanta, Kola Inglesa, Crushs, Schweppes, Sprite, Inca Kola y Coca Cola (también en versiones Zero).

- Néctares de frutas: Marca Frugos, Frugos Light, Kapó.

- Bebidas isotónicas: Marca Powerade, Powerade Zero.

- Bebidas energizantes: Marca Burn, Monster.

- Agua embotellada: Marca San Luis, San Luis saborizada (con gas y sin gas).

\subsubsection{Grupo económico}

Corporación Lindley forma parte del grupo económico de AC Bebidas SRL de CV (México), quien tiene el control de empresas que realizan la producción comercialización y distribución de bebidas licenciadas por The CocaCola Company en el país de México, Ecuador, Argentina Y Estados Unidos, la cual es a su vez subsidiaria de Arca Continental $\mathrm{SAB}$ de CV.

A nivel local, Corporación Lindley tiene como empresas subsidiarias a:

- Embotelladora La Selva SA (ELSSA), donde Corporación Lindley tiene el 93.16\% de participación y está ubicada en el Departamento de Loreto. Realiza la producción y comercialización de bebidas no alcohólicas de marcas autorizadas por The CocaCola Company en la zona de la selva del Perú.

- Empresa comercializadora de Bebidas SAC (ECOBESA), donde Lindley tiene el 
100\% de participación y está ubicada en el Departamento de Lima. Realiza la comercialización, distribución importación de alimentos, concentrados de fruta y bebidas alcohólica y no alcohólica en territorio nacional.

Figura 0.1

Grupo económico AC Bebidas

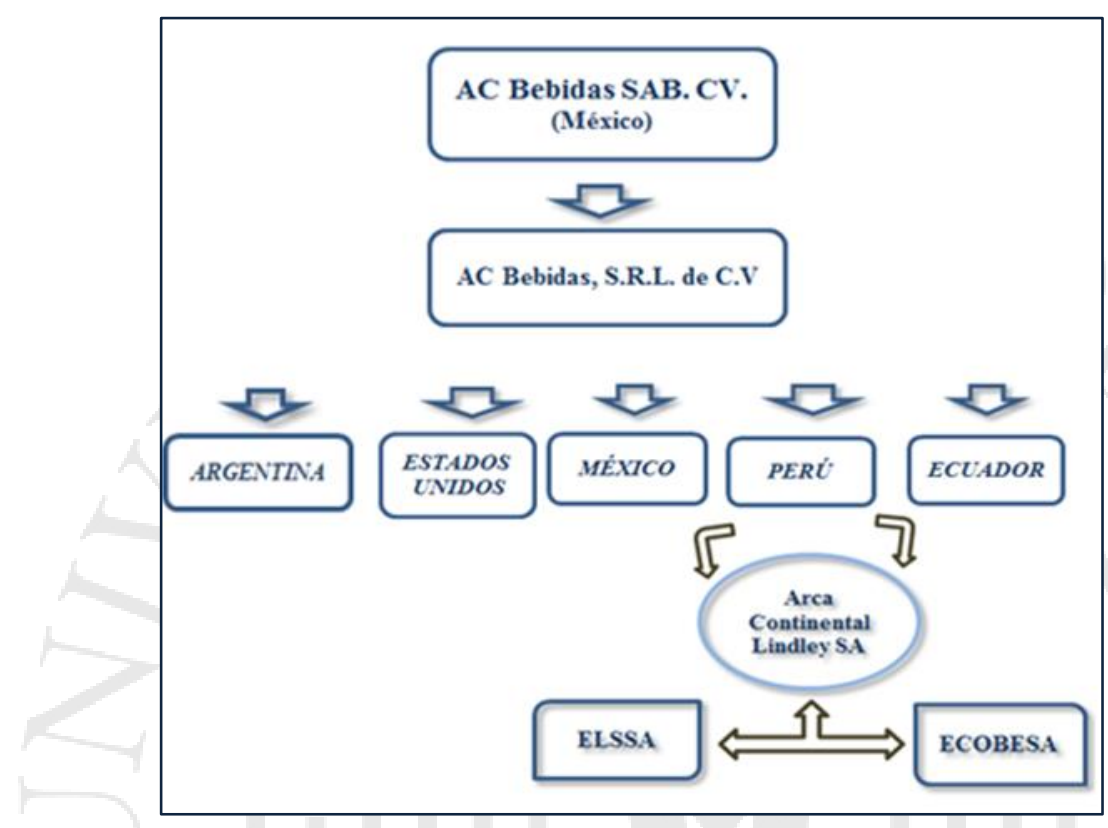

Fuente: Corporación Lindley (2017).

Elaboración propia

\subsubsection{Principales Accionistas}

Corporación Lindley SA, a fecha del 31 de diciembre del 2017, cuenta con 340 accionistas con derecho a voto, con un total de 580,981459 acciones comunes suscritas y pagadas al valor nominal de S/ 1.00 por acción. Total, las acciones comunes tienen los mismos derechos y obligaciones salvo por las siguientes diferencias. Las acciones de Serie A que representan un $35.52 \%$ del total de acciones tienen el poder de designar al gerente financieros dos directos titulares y dos alternos, mientras que las series $\mathrm{B}$ y $\mathrm{C}$ pueden designar al Gerente general y al resto de directores.

La composición de accionistas se conforma según el cuadro a continuación: 
Tabla 0.1

Composición del accionariado Arca Continental Lindley

\begin{tabular}{|l|l|r|r|l|}
\hline \multicolumn{1}{|c|}{ Tipo de Acciones } & \multicolumn{1}{|c|}{ Accionista } & $\begin{array}{c}\text { Número de } \\
\text { Acciones }\end{array}$ & \multicolumn{1}{c|}{$\%$} & Nacionalidad \\
\hline Comunes A & Peru Baverage Limitada SRL & $223,774,704$ & $38.52 \%$ & Peruana \\
\hline Comunes B & AC Bebidas SRL de CV & $329,870,528$ & $56.78 \%$ & Mexicana \\
\hline \multirow{2}{*}{ Comunes C } & AC Bebidas SRL de CV & $26,032,590$ & $4.48 \%$ & Mexicana \\
\cline { 2 - 5 } & Otros & $1,303,637$ & $0.22 \%$ & \\
\cline { 2 - 5 } & TOTAL & $\mathbf{5 8 0 , 9 8 1 , 4 5 9}$ & $\mathbf{1 0 0 \%}$ & \\
\cline { 2 - 3 } & &
\end{tabular}

Fuente: Corporación Lindley (2017).

Así mismo, la compañía cuenta con un total de 71'522,816 acciones de inversiones suscritas en la Bolsa de Valores de Lima (BVL) con un valor de S/4.10 por acción al 31 de diciembre del 2017.

Tabla 0.2

Participación de accionistas

\begin{tabular}{|l|c|c|c|}
\hline $\begin{array}{l}\text { Tenencia acciones con } \\
\text { derecho a voto }\end{array}$ & $\begin{array}{c}\text { Número de } \\
\text { tenedores }\end{array}$ & $\begin{array}{c}\text { Número de } \\
\text { acciones }\end{array}$ & $\begin{array}{c}\text { \% de } \\
\text { participació } \\
\text { n }\end{array}$ \\
\hline Accionistas con más de 10\% & 2 & $579^{\prime} 677,822$ & $99.78 \%$ \\
\hline Accionistas con 5\% a 10\% & 0 & & \\
\hline Accionistas con 1\% a 5\% & 0 & & \\
\hline Accionistas menores a 1\% & 338 & $11^{\prime} 303,637$ & $0.22 \%$ \\
\hline Total & 340 & $580^{\prime} 981,459$ & $100 \%$ \\
\hline
\end{tabular}

Fuente: Corporación Lindley (2017).

\subsection{Presencia en el mercado}

Corporación Lindley se encarga de la producción fabricación embotellamiento, venta y distribución de bebidas gaseosas carbonatadas y no carbonatadas, jugos de frutas, aguas de bebida energizantes. Compite en el mercado con marcas como AJEPER, BACKUS y PEPSICO sector en el cual lidera con $74 \%$ en bebidas gaseosas y $58.1 \%$ respecto a la industria de bebías no alcohólicas según la memoria anual de Lindley 2017.

Así mismo, según una reciente encuesta hecha por la empresa Arellano Marketing, se revela que las marcas con mayor preferencia y recordación son Inka Kola y Coca Cola en las dos categorías, siendo Inka Kola la marca que los peruanos más recuerdan y escogen a la hora de comprar, sobre todo los jóvenes y mujeres amas de casa. 
Figura 0.2

Posicionamiento de la marca

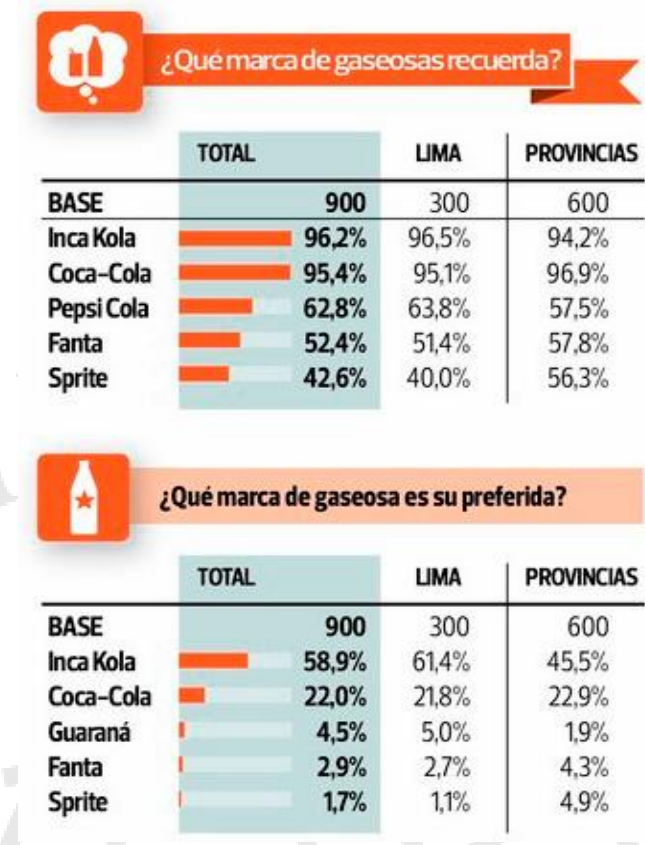

Fuente: Arellano Marketing (2014)

Para el mercado extranjero, Corporación Lindley tiene una unidad de negocio de agro exportación a 8 países como: Alemania, Holanda, Estados Unidos, Canadá, Francia, Puerto Rico e Israel, a los cuales se les vende pulpa de frutas de durazno, mango, y maracuyá, los cuales son comprados a agricultores peruanos, que posteriormente son producidas en planta del Huacho. Cabe resaltar que estos ingresos solo representan el $1 \%$ de las ventas, según testimonios de colaboradores del área.

Adicionalmente, la compañía también importa productos Premium de la Marca CocaCola Company como gaseosa en latas de las marcas Fanta, CocaCola, Inca Kola y Sprite. 


\section{CAPITULO II: DESCRIPCION Y OBJETIVOS}

\subsubsection{Entorno Competitivo}

Según un estudio de la empresa Euromonitor, el cual fue compartido con el diario peruano El Comercio, el consumo per-cápita de bebidas no alcohólicas entre los años 2012 y 2017 fue el siguiente:

Para bebidas energizantes hubo un crecimiento del $82.6 \%$ en 5 años. El consumo per cápita paso de 3.8 1t. a 6.4 lt. en el 2017 entre las marcas Gatorade, Sporade y Paworade (Lindley). Respecto al sector jugos, el segmento creció un 12\% entre los años 2012 y 2017. El consumo per cápita pasó de 11,7 litros a 12,3 litros. Las marcas más vendidas fueron Frugos (Lindley), Cifrut y Pulp. Así mismo, las aguas de bebida tuvieron un crecimiento de 52.3\%. Las marcas más bebidas fueron Cielo, San Luis y Aquarius. Sin embargo, en bebidas gaseosas solo crecieron en consumo un $16 \%$ de 47,6 litros en el 2012 a 51.5 litros en el 2017. Las marcas de bebidas gaseosas más vendidas fueron: Inca Cola Coca Cola y Kola Real. (El Comercio, 2018).

Tabla 0.1

Demanda de bebidas por categoría

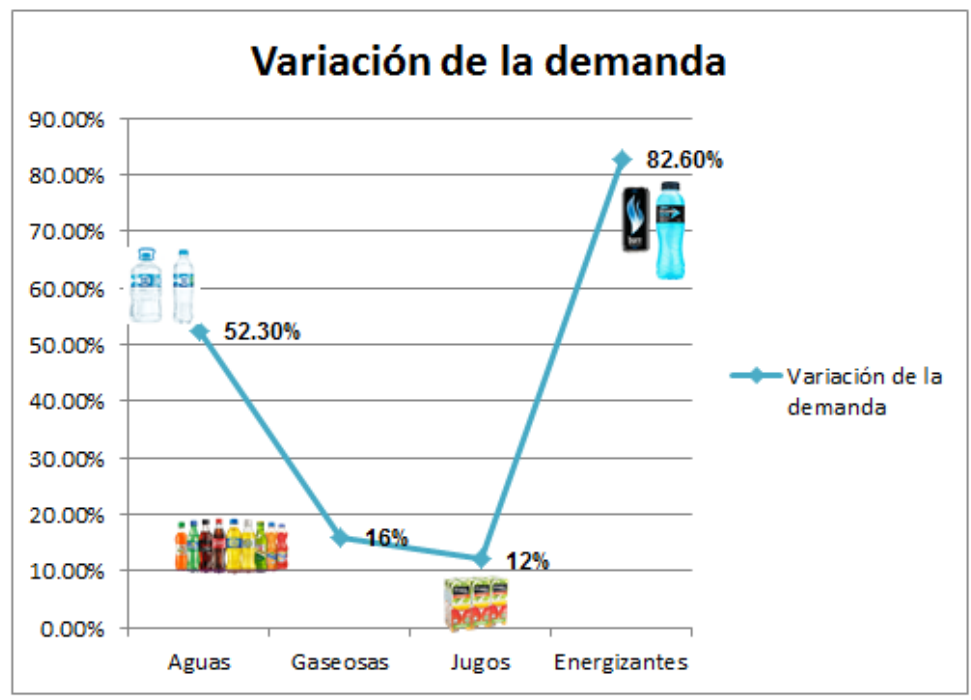

Fuente: El Comercio (2018).

Elaboración propia

Cabe resaltar, que la tendencia de los consumidores en los últimos años, se ha tornado más saludable, donde las comidas y bebidas con menos persevantes, azucares o 
grasas han tenido mayor crecimiento, como en el caso de las aguas embotelladas y energizaste. Sin embargo, las bebidas carbonatas no han disminuido, solo se han mantenido con un leve incremento.

Perú ocupa el segundo lugar en Latinoamérica, detrás de México (59\%), con más adeptos a dietas bajas en grasa (49\%), la preferencia de los peruanos sigue con la alimentación bajas en azúcar (35\%) y en carbohidratos (23\%). Sin embargo, de acuerdo con el $67 \%$ de los encuestados, sus necesidades dietéticas se encuentran parcialmente cubiertas por los productos ofrecidos en el mercado, mientras que el $23 \%$ dice tenerlas totalmente cubiertas y solo el $10 \%$ indica que no están siendo satisfechas en lo absoluto. Este resultado revela las oportunidades para minoristas y fabricantes que se ocupan de ofrecer a los consumidores productos que se ajusten a sus preferencias. (FMCG \& RETAIL, 2010)

En consecuencia, se desarrollaron las versiones Light o Zero de las marcas de gaseosa de la corporación, pues contienen menos cantidad de azúcares. Adicionalmente, está en proceso de creación de contenido y marca la línea de productos de tés fríos embotellados, que también se encuentran dentro del rubro saludable llamado "Fuze Tea", la cual es una marca creada por CocaCola Company que será distribuida por Corporación Lindley y formará parte de su cartera de productos.

Ante las variaciones del cambio en la demanda en cierto tipo de productos, es siempre recomendable tener un portafolio diversificado en caso de que las tendencias como las nuevas "modas light" (demandan más bebidas de agua embotella y refrescos) o nuevas regulaciones fiscales, como el incremento del ISC para aquellos productos que afectan la salud afecten el giro de empresa.

De la mano con el Ministerio de Salud, se ha creado un nuevo rango en el ISC a las bebidas azucaradas para reducir los incentivos a consumir aquellas bebidas que tengan una mayor concentración de azúcar y por lo tanto tengan un efecto más perjudicial sobre la salud. Esta medida se encuentra en línea con la experiencia exitosa de modificación impositiva en México. Así, todas aquellas bebidas que tengan menos de 6 gramos por 100 mililitros de azúcar mantendrán una tasa de $17 \%$ y las que contengan una cantidad mayor a esta se les aplicará una tasa de 25\%. (MEF, 2018). 


\subsection{Descripción del caso de investigación}

El presente trabajo de investigación está orientado al análisis y proyección de estados financieros de Corporación Lindley SA por los periodos del 2015 al 2017. Es importante hacer un análisis previo de los Estados financieros, ya que, los mismos reflejan la gestión de la compañía y si es que genera resultados. Así como se analiza la información historia para evaluar la gestión, también se puede proyectar en base a datos históricos y factores externos actuales (macroeconómicos) el porvenir de los subsiguientes años. Se analizará también las principales normas contables aplicables al modelo de negocio de la compañía como la NIC 17.

\subsection{Objetivo General}

Analizar y comprender la gestión de negocio y gestión contable de la corporación Lindley, así como también, determinar la situación financiera en que se encuentra Corporación Lindley SA al 31 de diciembre del 2017.

\subsection{Objetivos Específicos}

- Realizar un análisis de estados financieros, proyectarlos y hacer un análisis integrar acerca de la gestión y reconocimiento contable en sus actividades y partidas más significativas.

- Realizar técnicas de análisis de la información financiera en base a los estados financieros brindados año a año por la compañía al público general.

- Comprender mediante los indicadores financieros como ratios de liquidez, gestión, solvencia y rentabilidad; la capacidad en que se encuentra la empresa para hacer frente a sus operaciones de corto, mediano y largo plazo.

- La aplicación de la Norma Internacional de Información Financiera 16 (NIIF) que sustituye a la Norma Internacional de Contabilidad 17 (NIC) Arrendamientos, así como los principales cambios que conlleva su aplicación.

\section{CAPITULO III: MARCO METODOLOGICO}




\subsection{Metodología de recolección de información}

Se recolectó información en base a los estados financieros, dictámenes de auditoria realizados por PriceWaterhouse Coopers (PWC) y las memorias anuales de la compañía de publicados en la Superintendencia de Mercado y Valores (SMV), de los cuatro últimos años (2017-2015). Así mismo, se buscó información coyuntural en diarios y revistas económicas web de entrevistas con los gerentes y dueños de la compañía, acerca de las gestiones, nuevas innovaciones, proyectos y la reciente fusión con Arca Continental.

\subsection{Metodología de análisis de la información}

Se trabajó con apoyo de hojas de cálculo para el análisis de los ratios por los años comprendidos entre el 2015 y 2017, y las proyecciones financieras de la compañía a fecha 2020 tomando como año base el histórico al 2017. Asimismo, se utilizó datos estadísticos proporcionados por la página web del Instituto Nacional de Estadística e Información (INEI) para analizar la variación del Producto Bruto Interno (PBI) y PBI per cápita como también las cotizaciones en la Bolsa de Valores de Lima (BVL) de la corporación Lindley.

\section{CAPITULO IV: ANÁLISIS Y PRESENTACIÓN DE RESULTADOS}




\subsection{Análisis de la información}

Se ha recuperado y analizado los Estados Financieros (Estado de Situación Financiera, Estado de Resultados, Estados de Cambios en el Patrimonio, Estado de Flujos de Efectivo y Notas Explicativas) por los años comprendidos entre el 01 de enero del 2015 al 31 de diciembre del 2017.

En el ejercicio 2015, la compañía tuvo una pérdida de S/ 88,909 (miles), a pesar de tener muy buenos resultados operativos. Estos se vieron afectados por una gran pérdida por diferencia en cambio de S/ 230,360 (miles) debido a la alta depreciación de la moneda local de S/ 2.99 el dólar a S/3.41, los cuales impactan de manera directa los pasivos que mantiene la empresa en moneda extranjera, esto debido a la parte de la deuda expuesta no coberturada.

Sin embargo, para el año 2016, se obtiene una utilidad de 240,196 (miles), gracias al incremento en ventas por descuentos y promociones, y nuevos productos "light y zero"; la reducción de gastos administrativos, y venta de propiedades de inversión y propiedad planta y equipo, así como una leve ganancia por tipo de cambio por la fluctuación de la parte expuesta no coberturada, como también la reducción de intereses por la recompra parcial de bonos internacionales.

Para el 2017, los resultados del ejercicio se mantuvieron en positivo, con una utilidad de S/163,656 (miles). A pesar de obtener ganancias por tipo de cambio de $\mathrm{S} / 25,188$ (miles), aumentaron los gastos operativos en un $5.48 \%$ respecto al ejercicio anterior principalmente por las inversiones en construcción de la mega planta de Huachipa, adquisición de equipos fríos y mejoras en las líneas de producción. 


\subsubsection{Ventas}

Las ventas de Corporación Lindley tienen a diciembre del 2017 un valor de S/ 2,514,204 (miles) con un margen operativo del 14\%. Cabe resaltar, que, en los últimos 3 años, las ventas han crecido con un promedio de $5.1 \%$ con una pequeña desaceleración al 2017 producto de factores macroeconómicos y sociales, así mismo, el retorno de ventas sobre activos ha sido un promedio de 0.73 , es decir, por casa sol invertido, se obtiene 0.73 de ingresos, en consecuencia, la rotación de activos es adecuada.

Tabla 0.1

Variación de las ventas

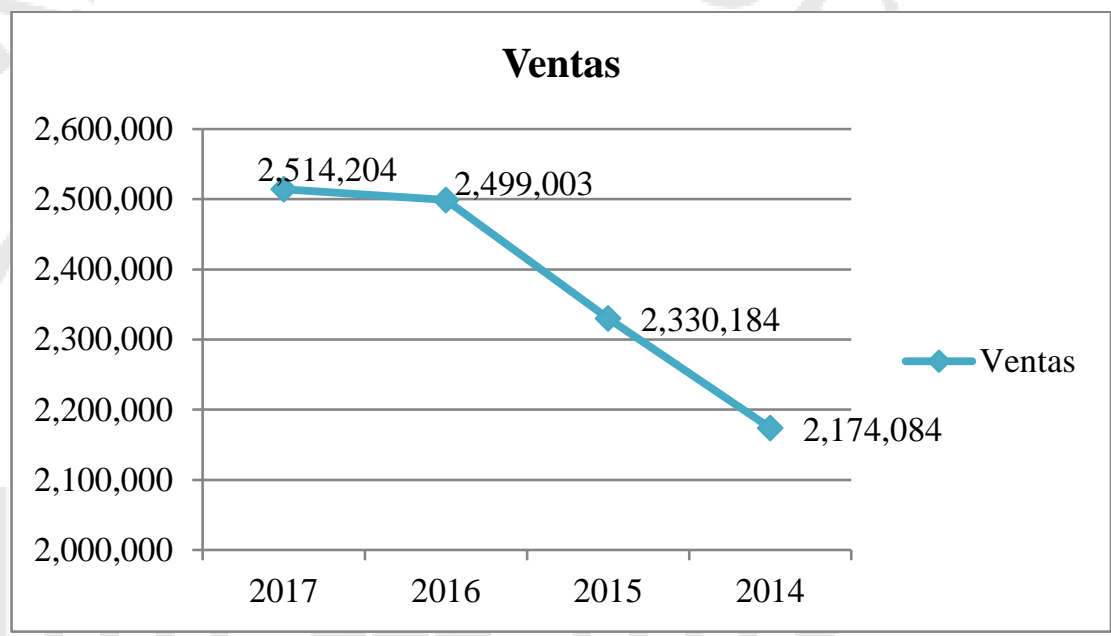

Fuente: Corporación Lindley $(2017,2016,2015,2014)$.

Elaboración propia.

Los motivos de este crecimiento se deben continuamente a las actividades de publicidad y marketing como: participación en eventos y activaciones, promociones como "tapisoles", "promoción vale otra" y presentaciones de gaseosas de 330ml PET más económicas. Así mismo, se refuerzan los canales de distribución los cuales son: Bodegas, fast-foods, cines, supermercados, restaurantes, y mercados de abastos. A modo de ejemplo, en el caso de las bodegas se cuenta con el plan de "la bodega elegida" donde se busca hacer respetar el precio de venta al público, a cambio de descuentos exclusivos a estos canales. Sin embargo, para el año 2017 las ventas en volumen de Arca Continental Lindley tuvieron un descenso de $0.6 \%$, después de 3 años de crecimiento continuo. Este resultado estuvo influenciado por factores externos a la operación, como el impacto del fenómeno El Niño. "El Niño Costero, el cual dejó serios daños en infraestructura pública, 
impactó en la desaceleración en la canasta de consumo masivo que decreció -3.29\% y en bebidas no alcohólicas $-4.7 \%$, donde la categoría de aguas fue la más afectada" (AC Lindley, 2018, p.17).

Tabla 0.2

Variación ventas 2015 - 2017

\begin{tabular}{|c|c|c|c|c|c|c|c|c|c|}
\hline \multicolumn{4}{|l|}{ ESTADO DE RESULTADOS } & \multicolumn{3}{|c|}{ VARIACION } & \multicolumn{3}{|c|}{ TENDENCIA(\%) } \\
\hline Cuenta & 2017 & 2016 & 2015 & 2017 & 2016 & 2015 & 2017 & 2016 & 2015 \\
\hline Ingresos de Actividades Ordinarias & $2,514,204$ & $2,499,003$ & $2,330,184$ & 15,201 & 168,819 & 156,100 & $0.61 \%$ & $7.24 \%$ & $7.18 \%$ \\
\hline
\end{tabular}

Fuente: Corporación Lindley (2017, 2016, 2015,2014).

Elaboración propia.

A pesar de los factores externos, aun se ha mantenido el crecimiento en ventas, por promociones, marketing, publicidad, mayor alcance del producto gracias a más cadenas de distribución.

Así mismo, mediante la ampliación de plantas como Pucusana y Huachipa, y la implementación de nuevas maquinarias, se ha podido aumentar la producción en volumen como también ampliar la capacidad de almacenamiento para su distribución.

\subsubsection{Costos}

La empresa busca mantener un margen promedio de $60 \%$ de costo sobre las ventas, que desde el 2014 al 2017 se ha logrado disminuir de 63\% a 60\%. Sin embargo, entre los años 2016 y 2017 no se ha logrado mejorar la gestión de diminución de costos debido a variables externas vistas en el análisis de ventas. 
Tabla 0.3

Variación costo de ventas

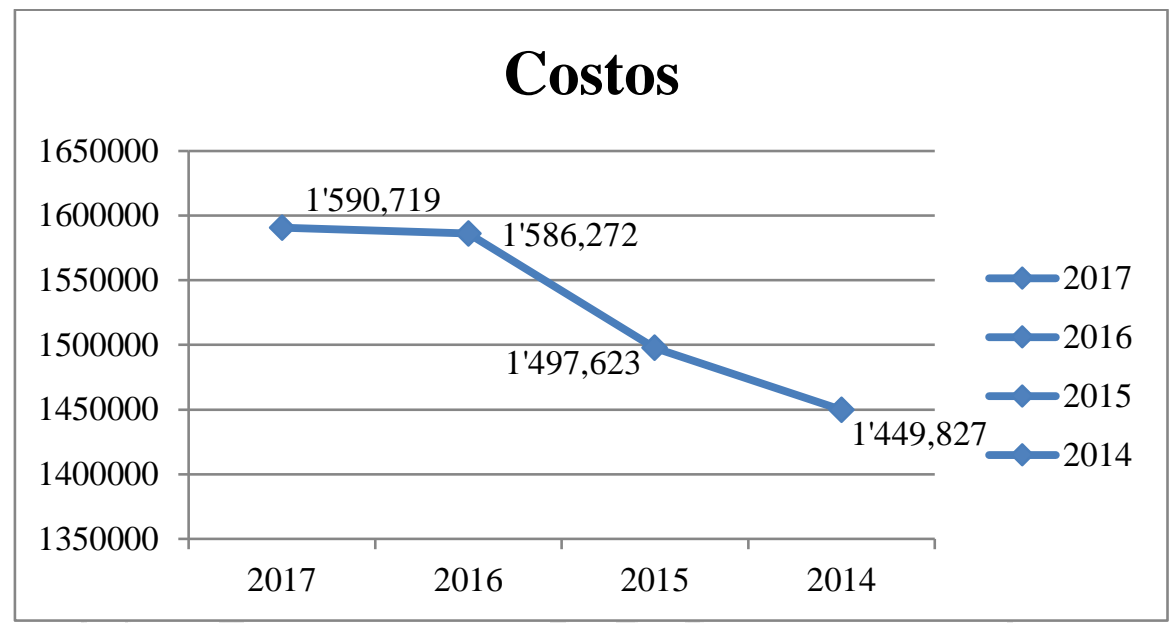

Fuente: Corporación Lindley, (2017, 2016, 2015,2014).

Elaboración propia.

Los costos de las materias primas han tenido un comportamiento variable, para el caso de los envases de tereftalato de polietileno (PET), la baja en el precio del petróleo ayudo a que el precio de los productos PET se redujeran en un $16 \%$ y a la actualidad siguen bajando debido a mayores producciones a nivel mundial, lo que ciertamente favorece también a la baja del precio de combustible, de igual modo, hay un similar comportamiento con el azúcar, que se ha mantenido en descenso a excepción del año 2016 , donde tuvo un incremento promedio del precio del $18 \%$ debido a problemas con el principal proveedor de azúcar casa grande (empresa del grupo Gloria SA) la cual paralizo una cosecha de 30 mil toneladas por problemas con el sindicato de trabajadores, los cuales exigían mejoras salariales y condiciones laborales. La variación de costos del 2016 respecto al 2015 es de s/ 88,649 (miles).

Tabla 0.4

Variación Costo de Ventas

\begin{tabular}{|c|c|c|c|c|c|c|c|c|c|}
\hline \multicolumn{4}{|c|}{ ESTADO DE RESULTADOS } & \multicolumn{3}{|c|}{ VARIACION } & \multicolumn{3}{|c|}{ TENDENCIA(\%) } \\
\hline Cuenta & 2017 & 2016 & 2015 & 2017 & 2016 & 2015 & 2017 & 2016 & 2015 \\
\hline Costo de Ventas & $-1,590,719$ & $-1,586,272$ & $-1,497,623$ & $-4,447$ & $-88,649$ & $-47,796$ & $0.28 \%$ & $5.92 \%$ & $3.30 \%$ \\
\hline
\end{tabular}

Fuente: Corporación Lindley $(2017,2016,2015,2014)$.

Elaboración propia.

\subsubsection{Estructura de endeudamiento}


Una estructura óptima de capital significaría reducir el riesgo de impago y disminuir el costo de capital de las empresas maximizando su valor. La estructura de endeudamiento de Lindley se centra en un sistema de estructura de capital $30 \%$ y $70 \%$ deuda, salvo en el 2015 y 2014 cuando llego a $20 \%$ de capital y $80 \%$ de deuda, la cual fue descendiendo para los subsiguientes años con el fin de reducir el sobreendeudamiento.

Tabla 0.5

Estructura de Endeudamiento

\begin{tabular}{|c|c|c|c|c|c|c|c|c|}
\hline & 2017 & Razón & 2016 & Razón & 2015 & Razón & 2014 & Razón \\
\hline \multicolumn{9}{|l|}{ Otros Indicadores } \\
\hline Deuda & $2,363,788$ & $72 \%$ & $2,395,826$ & $76 \%$ & $2,880,724$ & $83 \%$ & $2,722,080$ & $81 \%$ \\
\hline Patrimonio & 905,625 & $28 \%$ & 776,491 & $24 \%$ & 582,198 & $17 \%$ & 634,680 & $19 \%$ \\
\hline Deuda + Patrimonio & $3,269,413$ & $100 \%$ & $3,172,317$ & $100 \%$ & $3,462,922$ & $100 \%$ & $3,356,760$ & $100 \%$ \\
\hline
\end{tabular}

Fuente: Corporación Lindley (2017, 2016, 2015,2014).

Elaboración propia.

Corporación Lindley maneja una gestión de deuda inversión, donde los fondos recuperados de apalancamientos a mediano y largo plazo son para cancelar deudas pasadas y reinvertirlo en activos que a un futuro ayudaran a la empresa a generar mayores ingresos, como las construcciones de nuevas plantas, modernización e implementación de equipos, inversión en investigación de nuevos productos como el que próximamente será aplicado, máquinas de sellado en caliente para jugos naturales, donde el principal objetivo es disminuir la cantidad de preservantes en los productos de pulpa de fruta.

\subsubsection{Propiedad, planta y equipo}

Los activos pertenecientes a propiedad, planta y equipo de la compañía, se encuentran valuadas al costo menos la depreciación acumulada. El costo de adquisición comprende todos los costos necesarios para que el activo esté listo para su uso, así mismo la depreciación se calcula por el método de línea recta con las siguientes vidas útiles estimadas. 
Tabla 0.6

Vida útil estimada PPE

\begin{tabular}{|c|c|}
\hline & Años \\
\hline Edificios y otras construcciones & 40 \\
\hline Maquinaria y equipo & 5 a 30 \\
\hline Unidades de transporte & 5 \\
\hline Equipos de frío & 8 \\
\hline Botellas, cajas y tarimas & 2.5 y 10 \\
\hline Equipos de cómputo y diversos & 4 a 30 \\
\hline Muebles y enseres & 10 \\
\hline
\end{tabular}

Fuente: PWC (2018).

Cabe resaltar que las botellas retornables de plástico y de vidrio se encuentran registradas al costo y sigue una depreciación bajo el método de línea recta con una vida útil de 2 años y medio para las botellas de plástico y de 4 años para las botellas de vidrio. (PWC, 2018).

La empresa ha realizado una fuerte inversión en activo fijo en los últimos 3 años. Hay un incremento de equipos en frio dado al plan estratégico de la compañía de mejorar el abastecimiento de productos en el mercado, así mismo, la compra de botellas de envases, líneas de llenado, cajas plásticas, y unidades de transporte para mayor circulación de las bebidas debido al incremento de la demanda del mercado, además de las inversiones en el mega almacén de villa el salvador.

Tabla 0.7

Variación Propiedad, Planta y Equipo

\begin{tabular}{|c|c|c|c|c|c|c|c|c|c|}
\hline \multirow{2}{*}{\multicolumn{4}{|c|}{ ESTADO DE SITUACION FINANCIERA }} & \multirow{2}{*}{\multicolumn{3}{|c|}{ VARIACION }} & \multirow{2}{*}{\multicolumn{3}{|c|}{ TENDENCIA(\%) }} \\
\hline & & & & & & & & & \\
\hline Cuenta & 2017 & 2016 & 2015 & 2017 & 2016 & 2015 & 2017 & 2016 & 2015 \\
\hline \multicolumn{10}{|l|}{ Activos No Corrientes } \\
\hline Total Activos No Corrientes & $2,707,547$ & $2,620,886$ & $2,614,352$ & 86,661 & 6,534 & 91,346 & & & \\
\hline TOTAL DE ACTIVOS & $3,269,413$ & $3,172,317$ & $3,462,922$ & 97,096 & $-290,605$ & 106,162 & & & \\
\hline
\end{tabular}

Fuente: Corporación Lindley (2017, 2016,2015).

Elaboración propia.

Se ha Recuperado información a partir de los EE.FF. auditados de los años 2012 al 2017, para analizar la inversión en activo fijo para los últimos 6 años. Se puede observar que hay una fuerte inversión en el rubro de Edificios y construcciones sobre todo a partir del año 2015, año en que Arca Continental absorbe a Lindley bajo fusión por absorción e integran operaciones. Como ya ha sido explicado anteriormente, la unión de estas dos grandes distribuidoras, origino la necesidad de expandirse para cubrir la 
mayor demanda. De la misma manera que las edificaciones, hubo un aumento de inversión en maquinaria y equipo por los equipos en frio, los equipos de krones, etc.

Figura 0.1

\section{Variación Propiedad, Planta y Equipo}

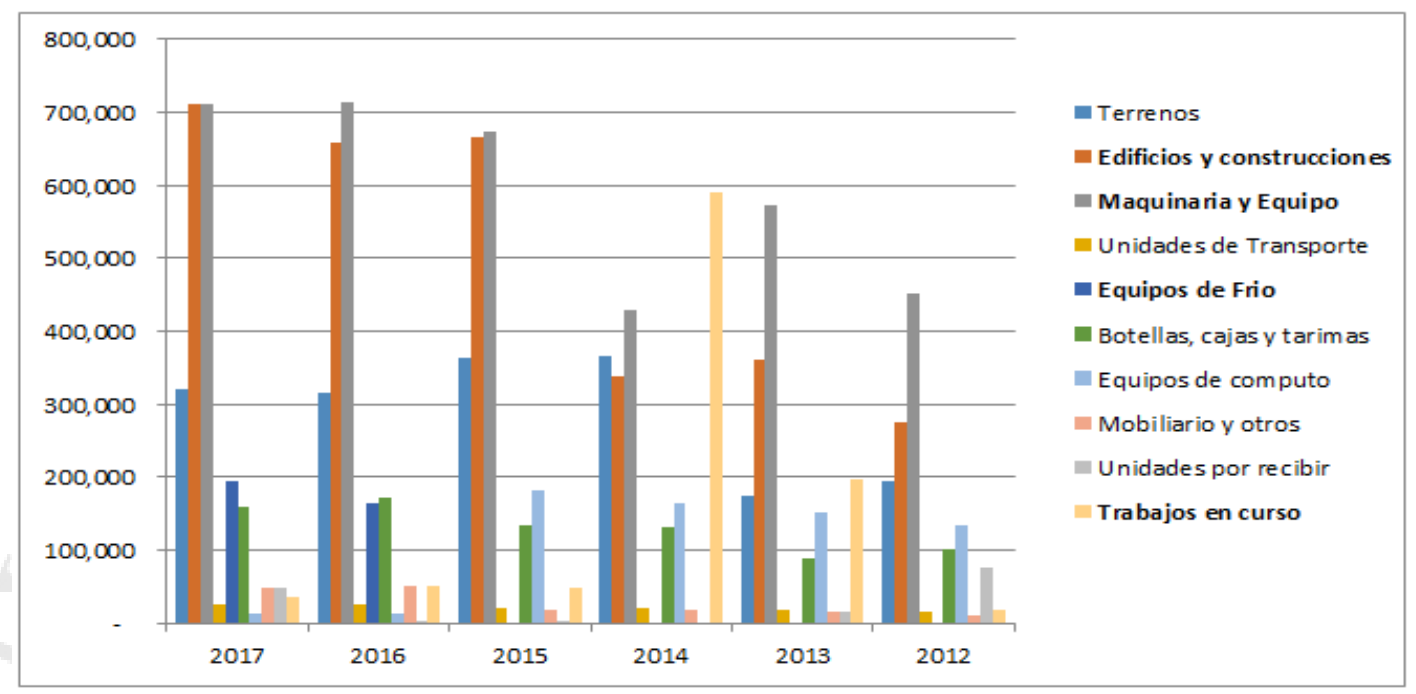

Fuente: PWC (2017, 2016, 2015, 2014, 2013).

Elaboración propia.

Respecto a trabajos en curso, se observa un pico de crecimiento en el año 2014, debido a que se realizaba la construcción de la mega planta de Pucusana con una inversión de doscientos millones de dólares y un área de 100,000 metros cuadrados, la cual incorpora plantas de producción, de alancen de productos terminados y dos plantas ecológicas del tratamiento de agua de alta tecnología. (AC Lindley, 2015).

Tabla 0.8

Detalle Activo fijo $2012-2017$

\begin{tabular}{|c|c|c|c|c|c|c|}
\hline & 2017 & 2016 & 2015 & 2014 & 2013 & 2012 \\
\hline Terrenos & 321,159 & 316,323 & 363,844 & 366,798 & 173,509 & 195,383 \\
\hline Edificios y construcciones & 710,083 & 658,628 & 664,842 & 338,806 & 361,749 & 274,368 \\
\hline Maquinaria y Equipo & 712,201 & 714,144 & 672,934 & 429,317 & 573,615 & 451,396 \\
\hline Unidades de Transporte & 26,143 & 26,715 & 19,519 & 20,011 & 16,880 & 14,261 \\
\hline Equipos de Frio & 195,630 & 163,362 & - & $-\quad$ & & \\
\hline Botellas, cajas y tarimas & 157,875 & 170,468 & 134,655 & 131,098 & 87,507 & 101,136 \\
\hline Equipos de computo & 13,380 & 11,872 & 182,345 & 165,128 & 151,989 & 133,687 \\
\hline Mobiliario y otros & 47,876 & 50,654 & 18,218 & 17,070 & 14,116 & 9,423 \\
\hline Unidades por recibir & 48,730 & 2,407 & 1,371 & - & 16,305 & 77,081 \\
\hline Trabajos en curso & 35,939 & 51,644 & 47,349 & 589,437 & 197,179 & 17,702 \\
\hline Total & $2,269,016$ & $2,166,217$ & $2,105,077$ & $2,057,665$ & $1,592,849$ & $1,274,437$ \\
\hline
\end{tabular}

Fuente: PWC (2017, 2016, 2015, 2014, 2013).

Elaboración propia. 
Respecto a trabajos en curso, se observa un pico de crecimiento en el año 2014, debido a que se realizaba la construcción de la mega planta de Pucusana con una inversión de doscientos millones de dólares y un área de 100,000 metros cuadrados, la cual incorpora plantas de producción, de alancen de productos terminados y dos plantas ecológicas del tratamiento de agua de alta tecnología. (AC Lindley, 2015).

Tabla 0.9

Detalle Activo fijo $2012-2017$

\begin{tabular}{|c|c|c|c|c|c|c|}
\hline & 2017 & 2016 & 2015 & 2014 & 2013 & 2012 \\
\hline Terrenos & 321,159 & 316,323 & 363,844 & 366,798 & 173,509 & 195,383 \\
\hline Edificios y construcciones & 710,083 & 658,628 & 664,842 & 338,806 & 361,749 & 274,368 \\
\hline Maquinaria y Equipo & 712,201 & 714,144 & 672,934 & 429,317 & 573,615 & 451,396 \\
\hline Unidades de Transporte & 26,143 & 26,715 & 19,519 & 20,011 & 16,880 & 14,261 \\
\hline Equipos de Frio & 195,630 & 163,362 & - & - & & \\
\hline Botellas, cajas y tarimas & 157,875 & 170,468 & 134,655 & 131,098 & 87,507 & 101,136 \\
\hline Equipos de computo & 13,380 & 11,872 & 182,345 & 165,128 & 151,989 & 133,687 \\
\hline Mobiliario y otros & 47,876 & 50,654 & 18,218 & 17,070 & 14,116 & 9,423 \\
\hline Unidades por recibir & 48,730 & 2,407 & 1,371 & - & 16,305 & 77,081 \\
\hline Trabajos en curso & 35,939 & 51,644 & 47,349 & 589,437 & 197,179 & 17,702 \\
\hline Total & $2,269,016$ & $2,166,217$ & $2,105,077$ & $2,057,665$ & $1,592,849$ & $1,274,437$ \\
\hline
\end{tabular}

Fuente: PWC $(2017,2016,2015,2014,2013)$.

Elaboración propia.

\subsubsection{Arrendamientos}

Los arrendamientos son aquellos contratos en donde el arrendador sede al arrendatario el uso de un activo por un periodo de tiempo determinado. Entonces, un arrendamiento financiero se origina cuando se transfieren todos los riesgos y beneficios sobre la propiedad del activo arrendado (ejemplo: usándolo, manteniéndolo o subarrendándolo), mientras que el arrendamiento operativo, es cualquier otro arrendamiento distinto al financiero (definido bajo NIC17). En pocas palabras, el arrendatario tiene el control del uso del activo arrendado durante un periodo de tiempo, teniendo el uso exclusivo del activo y la capacidad para dirigir su uso.

Los arrendamientos financieros de la compañía se encuentran suscritos con diferentes entidades bancarias como el banco continental (BBVA), Interbank y Banco de Crédito del Perú (BCP), con las cuales se realizó los contratos de arrendamiento para las máquinas de quipos de frio (cámaras frigoríficas para el almacenamiento de bebidas las cuales se entregan a las bodegas, supermercados, restaurantes y autoservicios en calidad de comodato bajo el cumplimiento de ciertos lineamientos), vehículos para distribución de productos terminados; así mismo, ha arrendado por leasing, dos inmuebles para las oficinas administrativas en el distrito de La Molina (piso 10 y 11). 
Tabla 0.10

Saldo arrendamiento financiero 2017 -2016

\begin{tabular}{|c|c|c|c|c|}
\hline \multicolumn{5}{|c|}{ Al 31 de diciembre, el valor de los bienes en arrendamiento financiero comprende: } \\
\hline & \multicolumn{3}{|l|}{2017} & \multirow{2}{*}{$\begin{array}{l}2016 \\
\text { Valor } \\
\text { neto } \\
\mathrm{S} / 000\end{array}$} \\
\hline & $\frac{\text { Costo }}{\text { S/000 }}$ & $\begin{array}{l}\text { Depreciación } \\
\text { acumulada } \\
\mathrm{S} / 000\end{array}$ & $\begin{array}{l}\text { Valor } \\
\text { neto } \\
\text { S/000 }\end{array}$ & \\
\hline Edificaciones & 12,232 & 357) & 11,875 & 12,232 \\
\hline Unidades de transporte & 1,710 & 993) & 717 & 1,032 \\
\hline Equipos de frio & 6.023 & 5.226) & 797 & 1,144 \\
\hline & 19,965 & $6,576)$ & 13,389 & 14,408 \\
\hline
\end{tabular}

Fuente: PWC (2018).

Cuenta con arrendamientos operativos de equipos de envasado como llenadora aséptica que realiza envasados en condiciones más estériles y con mayor hermetismo, la cual emplea llenado en frio para reducir el efecto del calor en los productos, conservando el sabor y las propiedades nutritivas del mimo. Así también, un inmueble de más de setecientos metros cuadrados, en la ciudad de Lima como almacén de productos terminados, adicionalmente, vehículos para el transporte de mercaderías y de logística agrícola, además de otros equipos de tecnología de información como computadoras, impresoras, etc., líneas de embotellado de krones, los cuales realizan embotellado de botellas PET con una producción de hasta 81,000 envases por hora y capacidad de envasado de 144 horas seguidas de forma separada o combinada, optimizado horas y capacidad de producción y montacargas para la carga y desplazamiento de materiales pesados.

Actualmente, la compañía se rige por la norma aún vigente NIC 17 Arrendamientos, la cual clasifica a los arrendamientos en operativos y financieros los cuales tienen tratamientos contables diferentes. Bajo esta NIC, los activos y pasivos provenientes de leasing financiero o arrendamiento financiero, se deben contabilizar como si el arrendatario hubiera realizado la compra del activo con un préstamo del arrendador. En consecuencia, se registra en base al valor del activo por la "compra" y de un pasivo por el "préstamo" por el mismo importe al valor razonable del bien o al valor actual de los pagos mínimos (el menor), considerando la tasa de interés implícita del arrendamiento o de no poder determinarse, se aplicará la tasa incremental por préstamos del arrendatario. Así mismo, se considerarán todos los costos directos iniciales en el reconocimiento del arrendamiento financiero. (IASC, 2006). 
A modo de ejemplo, si se adquiriese un arrendamiento financiero por el valor de 145,000 soles, a tasa implícita anual del $12 \%$ y considerando los demás datos de la tabla 10.1 se realizarán los siguientes asientos contables:

Tabla 0.11

Ejemplo arrendamiento financiero NIC 17

\begin{tabular}{|lr|}
\hline Valor del Activo & 145,000 \\
\hline Fecha de contrato & $01 / 01 / 2017$ \\
\hline Duracion del contrato & 3 años \\
\hline Amortizacion de capital & Anuales \\
\hline$N^{\circ}$ de Amortizaciones & 3 \\
\hline Valor de cuota & 60,000 \\
\hline Tasa de interes implicta - anual & $12 \%$ \\
\hline Vida util & 10 años \\
\hline Opcion de compra & 1,250 \\
\hline
\end{tabular}

Elaboración propia.

Se desarrollan las cuotas por cada periodo considerando el pago de interés e igv. El saldo anual es la diferencia de la cuota con el saldo del ejerció anterior; así como la amortización del capital que es el resultado de restar el interés a la cuota anual. Se considera al fin de los tres periodos la compra del activo subyacente por el valor de 1,250 soles.

Tabla 0.12

Calculo de cuotas y amortización Anual

\begin{tabular}{|c|c|c|c|c|c|c|}
\hline \multirow{2}{*}{ PERIODO } & \multirow{2}{*}{ SALDO } & \multicolumn{2}{|c|}{ AMORTIZACION } & \multirow{2}{*}{ TOTAL CUOTA } & \multirow{2}{*}{ IGV } & \multirow{2}{*}{ TOTAL } \\
\hline & & CAPITAL & INTERES & & & \\
\hline 0 & 145,000 & & & & & \\
\hline 1 & 102,400 & 42,600 & 17,400 & 60,000 & 10,800 & 70,800 \\
\hline 2 & 54,688 & 47,712 & 12,288 & 60,000 & 10,800 & 70,800 \\
\hline 3 & 1,251 & 53,437 & 6,563 & 60,000 & 10,800 & 70,800 \\
\hline OPCION DE COMPRA & & 1,250 & & 1,250 & 225 & 1,475 \\
\hline TOTAL & & 144,999 & 36,251 & 181,250 & 32,625 & 213,875 \\
\hline
\end{tabular}

Elaboración propia.

Se registra la adquisición del activo en arrendamiento financiero al valor razonable del bien arrendado en el año cero. 
Tabla 0.13

Asiento inicial por arrendamiento

\begin{tabular}{|l|c|c|}
\hline CUENTAS & DEBE & HABER \\
\hline Activos adquiridos por arrendamiento f. - PPE & 145,000 & \\
\hline Obligaciones financieras & & 145,000 \\
\hline
\end{tabular}

Elaboración propia.

Así mismo, si se incurriese en costos directos iniciales en la adquisición del bien, también deberán ser registrados como parte del costo del activo

Tabla 0.14

Asiento por costos adicionales de adquisición

\begin{tabular}{|l|c|c|}
\hline CUENTAS & DEBE & HABER \\
\hline Activos adquiridos por arrendamiento f. - PPE & 10,000 & \\
\hline Cuentas por pagar diversas & & 10,000 \\
\hline
\end{tabular}

Elaboración propia.

Amanera de valoración posterior, los pagos mínimos se dividirán en las cargas financieras y la reducción de la deuda. Los gastos financieros se distribuyen entre los años del plazo del arrendamiento y los pagos contingentes se cargan en el ejercicio en el que se incurren. (IASC, 2006). Entonces, siguiendo con el ejemplo, el pago de la primera cuota originara asientos en la cuenta de obligaciones financieras por el pago del interés y gastos financieros por parte del pago del capital.

Tabla 0.15

Asiento pago de primera cuota

\begin{tabular}{|l|c|c|}
\hline CUENTAS & DEBE & HABER \\
\hline Gastos financieros & 42,600 & \\
\hline Obligaciones financieras & 17,400 & \\
\hline Efectivo y equivalente de efectivo & & 60,000 \\
\hline
\end{tabular}

Elaboración propia.

Respecto a la depreciación, se depreciará según las políticas que tenga la empresa para los demás activos depreciables que posea según la NIC 16; si no hay certeza razonable de la compra del activo al final de periodo, se deprecia hasta el fin de la vida útil o hasta el plazo del arrendamiento (el menor). De lo contrario, si existiese certeza razonable de la compra del activo, la depreciación será por la vida útil del activo o del plazo de arrendamiento lo que resulte menor. Esto a su vez origina un gasto por depreciación y un cargo por gasto financiero. Cabe resaltar que, para las evaluaciones de 
deterioro de los activos, se aplicara la NIC 36 deterioros del valor de los activos. Siguiendo el ejemplo planteado, para una vida útil de 3 años (regido bajo el periodo del contrato) y sin valor residual, se realiza la depreciación en línea recta de la siguiente manera:

Tabla 0.16

Depreciación vida útil plazo del contrato

\begin{tabular}{|c|c|c|}
\hline Periodo & Tasa depreciacion \% & \multicolumn{1}{c|}{ Importe } \\
\hline 1 & $33 \%$ & 48,333 \\
\hline 2 & $33 \%$ & 48,333 \\
\hline 3 & $33 \%$ & 48,333 \\
\hline & &
\end{tabular}

Elaboración propia.

En el caso de arrendamientos operativos, la norma indica que se deben reconocer un gasto de manera lineal por los pagos de los alquileres, así como los pagos correspondientes a las cuotas del arrendamiento. Por ejemplo, si se contrajese un contrato por arrendamiento operativo por el valor de S/ 40,000 a un plazo de 4 años, entonces los gastos mensuales a registrar serian $\mathrm{S} / 833$ (S/ 40,000 / 48 meses).

Tabla 0.17

Asientos pagos mensuales por arrendamiento operativo.

\begin{tabular}{|l|r|r|}
\hline CUENTAS & DEBE & HABER \\
\hline Gastos financieros & & 833 \\
\hline Efectivo y equivalente de efectivo & & 833 \\
\hline
\end{tabular}

Elaboración propia.

Por otro lado, la NIIF 7 instrumentos financieros, pide revelaciones acerca del plazo, los pagos, intereses, y periodicidad del arrendamiento operativo.

Además de los requisitos informativos fijados en la NIIF 7 instrumentos financieros: información a revelar, los arrendatarios revelarán, en sus estados financieros, la siguiente información referida a los arrendamientos operativos:

(a) el total de pagos futuros mínimos del arrendamiento, derivados de contratos de arrendamiento operativo no cancelables, que se vayan a satisfacer en los siguientes plazos:

(i) hasta un año; 
(ii) entre uno y cinco años;

(iii) a más de cinco años.

(b) el importe total de los pagos futuros mínimos por subarriendo que se espera recibir, en la fecha del balance, por los subarriendos operativos no cancelables.

(c) cuotas de arrendamientos y subarriendos operativos reconocidas como gastos del ejercicio, revelando por separado los importes de los pagos mínimos por arrendamiento, las cuotas contingentes y las cuotas de subarriendo.

(d) una descripción general de los acuerdos significativos de arrendamiento concluidos por el arrendatario, donde se incluirán, sin limitarse a ellos, los siguientes datos:

(i) las bases para la determinación de cualquier cuota de carácter contingente que se haya pactado;

(ii) la existencia y, en su caso, los plazos de renovación o las opciones de compra y las cláusulas de actualización o escalonamiento; y

(iii) las restricciones impuestas a la entidad en virtud de los contratos de arrendamiento, tales como las que se refieran a la distribución de dividendos, al endeudamiento adicional o a nuevos contratos de arrendamiento. (IASC, 2006, p.9).

\subsubsection{Aplicación NIIF 16 Arrendamientos}

La NIIF 16, será aplicada por la compañía el 01 de enero del 2019, la cual está realizando las evaluaciones para la aplicación y posibles impactos de la misma en los Estados Financieros.

La compañía estará aplicando una nueva norma contable donde, bajo la NIC 8 Políticas Contables, Cambios en las estimaciones contables y Errores; tendría que realizar un tratamiento retroactivo, ajustando los saldos iniciales de cada componente afectando el patrimonio neto del ejercicio anterior más antiguo que se presente y revelará información acerca de los demás importes comparables para cada ejercicio anterior 
presentado, como si siempre se hubiera aplicado esta nueva política contable (IASC, 1993). Sin embargo, la norma también indica que cuando sea impracticable, se puede determinar el efecto acumulado al 01 de enero del 2019 (fecha en la cual la norma entra en vigencia), cuando sea efectiva la aplicación.

Los principales cambios que realiza esta norma afectan más a los arrendamientos operativos, pues la NIIF 16 tiene un tratamiento por igual con respecto al arrendamiento financiero, a excepción de aquellos arrendamientos con periodicidad menos a 12 meses y aquellos que tengan menor valor, los cuales serán reconocidos como gastos de manera lineal a lo largo del plazo de arrendamiento y en los estados de flujos de efectivo en actividades de operación o financiamiento.

Figura 0.2

Comparativa arrendamiento financiero y operativo

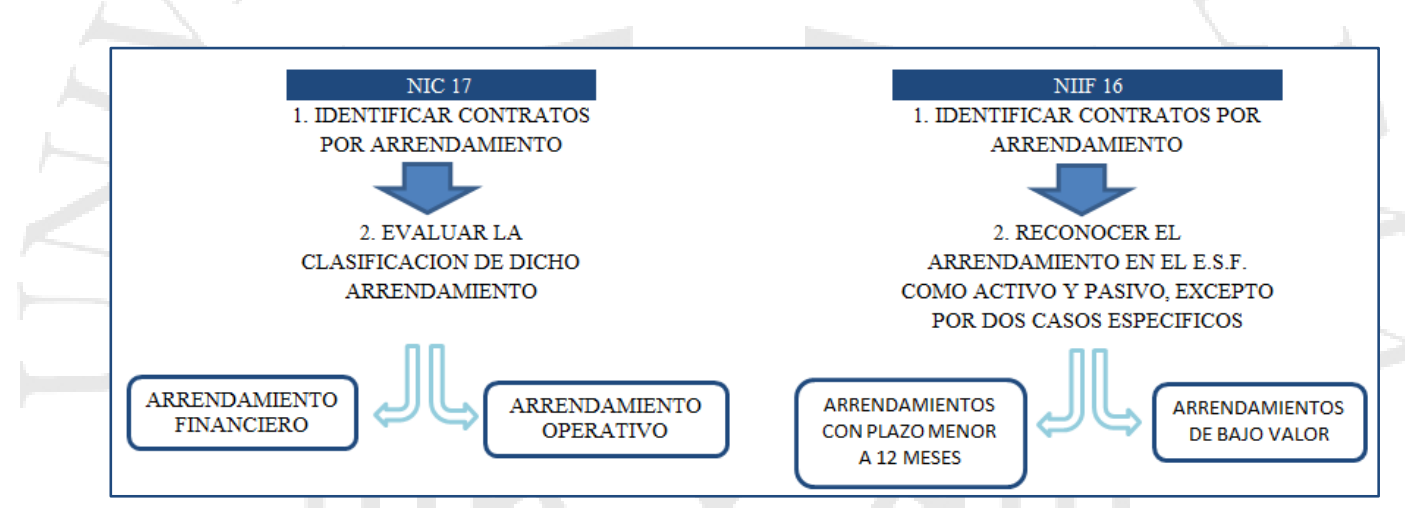

Fuente: IASB (2016).

Elaboración propia.

Esta nueva norma, reconoce el activo y pasivos en maneras distintas. Se reconocerá un activo por derecho de uso y un pasivo por arrendamiento. Los activos deberán medirse al costo, el cual comprende el valor de la medición inicial del pasivo por arrendamiento más los pagos realizados antes o a partir de la fecha de arrendamiento menos incentivos recibidos, los costos directos iniciales incurridos y otros costos que se incurran para que el activo esté operativo y a disposición del arrendatario. Por su parte, los pasivos se registrarán inicialmente al valor presente de los pagos por arrendamiento que aún no se han pagado, usando la tasa de interés implícito o la incremental si esta primera no puede determinarse. (IASB, 2016, p. 29). 
Figura 0.3

Reconocimiento en los EEFF

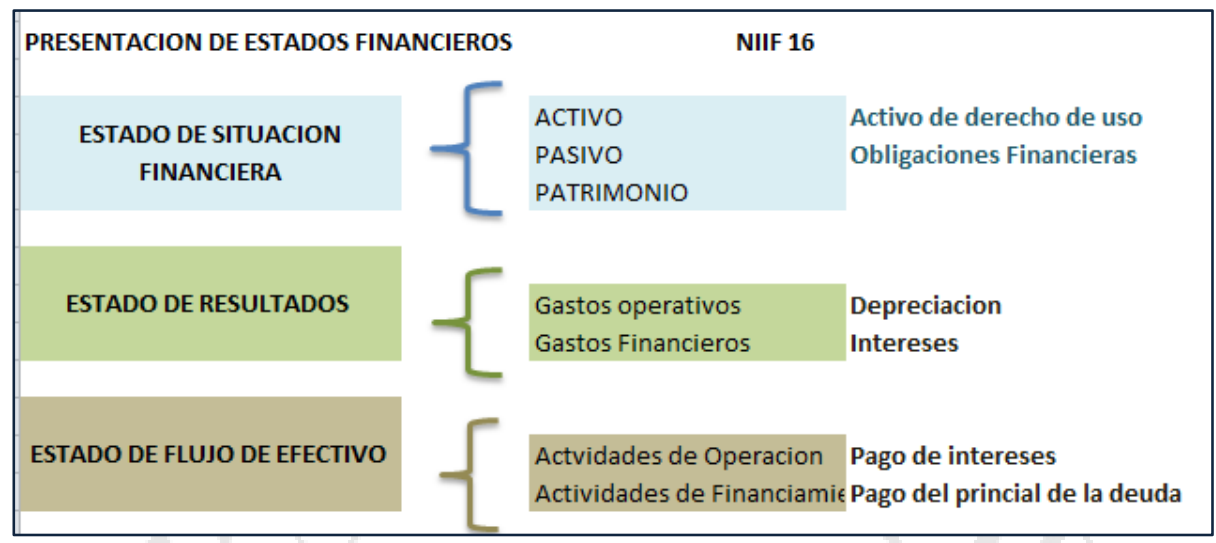

Fuente: IASB (2016).

Elaboración propia

Valoración posterior.

Para los activos se utilizará el modelo del costo, restando la depreciación acumulada y ajustando cualquier nueva medición del pasivo según el método valor razonable a aquellos activos por arrendamiento clasificados en propiedades de inversión bajo la NIC 40 o bajo la NIC 16 si el arrendamiento aplica el modelo de revaluación. Así mismo, para los pasivos, se aumentará el valor del mismo, reflejando los intereses sobre el saldo restante del pasivo. Del mismo modo, se reducirá para reflejar el pago de las deudas en cada ejercicio y se medirá nuevamente para reflejar modificaciones o nuevas mediciones.

Se realizarán nuevas mediciones para medir los pasivos en el caso de que haya algún cambio en el plazo de arrendamiento o algún cambio en la evaluación de la opción de compra, como también, cambios en los importes a pagar esperados debido un cambio de índice o tasa, o en los importes a pagar relacionados con una garantía del valor residual del bien.

Se registrará los pagos de las cuotas afectando el gasto por intereses y disminuyendo el pasivo periódicamente. Así como también el gasto por depreciación dependiendo si es en base al plazo del contrato o a la vida útil del activo. Esto permitirá identificar al usuario de la información tener una imagen más real de los financiamientos y gastos de la empresa. 
Respecto a la depreciación, se aplicará bajo los lineamientos de la NIC 16. En caso de que haya certeza de la compra del activo arrendado, se depreciara hasta el final de la vida útil del activo, de lo contrario, se depreciara hasta el final de la vida útil o hasta el fin del plazo del arrendamiento, el que ocurra primero. Así mismo, la valuación por deterioro se efectúa bajo la NIC 36.

La aplicación de la norma supondrá cambios en los ratios financieros como el EBITDA, índices de apalancamiento, rotación de activos y cobertura de intereses ya que eran derechos y obligaciones de los arrendamientos operativos que se encontraban fuera de balance.

Tabla 0.18

Modificación en arrendamientos operativos

\begin{tabular}{|c|c|c|c|}
\hline \multirow{3}{*}{ PARTIDAS } & \multicolumn{2}{|c|}{ NIC 17} & NIIF16 \\
\hline & \multicolumn{2}{|c|}{ ARRENDAMIENTO } & \multirow{2}{*}{$\begin{array}{c}\text { TODOS LOS } \\
\text { ARRENDAMIENTOS }\end{array}$} \\
\hline & FINANCIEROS & OPERATIVOS & \\
\hline \multicolumn{4}{|l|}{ Ingresos } \\
\hline Gastos operativos & \multicolumn{2}{|r|}{ Gasto por alquiler } & \\
\hline EBITDA & & & \\
\hline Amortizacion y Depreciacion & Depreciacion & $\longrightarrow$ & Depreciacion \\
\hline Gastos Financieros & Gasto por Intereses & $\longrightarrow$ & Gasto por Intereses \\
\hline Utilidad antes de Impuestos & & & \\
\hline Utilidad Bruta & & & \\
\hline
\end{tabular}

Fuente: IASB (2016).

Elaboración propia.

Si un arrendatario opta por aplicar esta Norma de acuerdo con el párrafo C5(b): (a) Reconocerá un pasivo por arrendamiento en la fecha de aplicación inicial para los arrendamientos anteriormente clasificados como un arrendamiento operativo utilizando la NIC 17. El arrendatario NIIF 16 medirá ese pasivo por arrendamiento al valor presente de los pagos por arrendamientos restantes, descontados usando la tasa incremental por préstamos del arrendatario en la fecha de aplicación inicial.

(b) Reconocerá un activo derecho de uso en la fecha de aplicación inicial para los arrendamientos anteriormente clasificados como un arrendamiento operativo utilizando la NIC 17. El arrendatario optará, 
arrendamiento por arrendamiento, por medir el activo por derecho de uso:

(i) su importe en libros como si la Norma se hubiera aplicado desde la fecha de comienzo, pero descontado usando la tasa incremental por préstamos del arrendatario en la fecha de aplicación inicial; o

(ii) un importe igual al pasivo por arrendamiento, ajustado por el importe de cualquier pago por arrendamientos anticipado o acumulado (devengado) relacionado con ese arrendamiento reconocido en el estado de situación financiera inmediatamente antes de la fecha de aplicación inicial. (IASB, 2016)

La compañía, cuenta con un saldo neto por arrendamiento financiero al 2017 de S/ 14,408 (miles) y arrendamientos operativos con un valor aproximado de S/ 3,200 (miles) con periodicidad mayor a un año, pero menos de 5 años, además arrendamientos por S/2,500 (miles) aproximadamente menores a un año, que se encuentran registrados en gastos operativos en el Estado de Resultado. No se cuenta con la información exacta del valor en arrendamientos operativos puesto que es información que la compañía no ha revelado de manera pública, sin embargo, se encuentra plasmada en los gastos del ejercicio.

A modo de ejemplo, suponiendo un arrendamiento operativo por el periodo de tres años de una maquinaria con una tasa de descuento anual de $8 \%$ y un valor de cuota anual de 72,000 soles, el reconocimiento seria el siguiente:

\section{Tabla 0.19}

\section{Supuestos Arrendamiento operativo}

\begin{tabular}{|lc|}
\hline Cuota anual & 72,000 soles \\
\hline Plazo contrato & 3 años \\
\hline Tasa de descuento anual & $8 \%$ \\
\hline Tasa de descuento mensual & $0.64 \%$ \\
\hline Depreciacion & Plazo del Contrato \\
\hline
\end{tabular}

Elaboración propia

La tasa de descuento mensual seria $0.64 \%$ considerando la fórmula de $[(1+$ Tasa descuento anual $)^{\wedge}(1 / 12$ meses $\left.)\right]-1$ para convertir a tasa de descuento mensual. Así también el plazo del contrato seria 36 meses y el valor actual neto seria de S/ 192,260 
utilizando las cuotas mensuales de S/ 6,000 y la tasa de descuento mensual de $0.64 \%$, se obtienen las siguientes obligaciones mensuales.

Tabla 0.20

Pagos por arrendamiento primero año

\begin{tabular}{|c|c|c|c|c|c|}
\hline \multirow{2}{*}{ Periodo } & \multicolumn{3}{|c|}{ PASIVO POR ARRENDAMIENTO } \\
\cline { 2 - 5 } & Capital & Amortización & Intereses & \multicolumn{1}{c|}{ Cuota } \\
\hline Valor Actual Neto & $\mathbf{1 9 2 , 2 6 0 . 0}$ & & \\
\hline 0 & $192,259.99$ & & & \\
\hline 1 & $187,496.99$ & $4,762.99$ & $1,237.01$ & 6,000 \\
\hline 2 & $182,703.36$ & $4,793.64$ & $1,206.36$ & 6,000 \\
\hline 3 & $177,878.88$ & $4,824.48$ & $1,175.52$ & 6,000 \\
\hline 4 & $173,023.35$ & $4,855.52$ & $1,144.48$ & 6,000 \\
\hline 5 & $168,136.59$ & $4,886.76$ & $1,113.24$ & 6,000 \\
\hline 6 & $163,218.39$ & $4,918.20$ & $1,081.80$ & 6,000 \\
\hline 7 & $158,268.54$ & $4,949.85$ & $1,050.15$ & 6,000 \\
\hline 8 & $153,286.84$ & $4,981.70$ & $1,018.30$ & 6,000 \\
\hline 9 & $148,273.10$ & $5,013.75$ & 986.25 & 6,000 \\
\hline 10 & $143,227.09$ & $5,046.01$ & 953.99 & 6,000 \\
\hline 11 & $138,148.62$ & $5,078.47$ & 921.53 & 6,000 \\
\hline 12 & $133,037.47$ & $5,111.15$ & 888.85 & 6,000 \\
\hline ANO 1 & $\mathbf{1 , 9 2 6 , 6 9 9}$ & $\mathbf{5 9 , 2 2 3}$ & $\mathbf{1 2 , 7 7 7}$ & $\mathbf{7 2 , 0 0 0}$ \\
\hline
\end{tabular}

Elaboración propia

El registro del primer año de arrendamiento operativo según los lineamientos de la NIIF 16, son los siguientes:

Se registra el derecho de uso del activo por el valor del pasivo más costos iniciales menos cualquier incentivo (en este supuesto no se ha considerado la existencia de estos dos últimos). El pasivo registra el valor presente de los pagos por el arrendamiento, el asiento contable sería el siguiente:

Tabla 0.21

Asiento activos y pasivos A. Operativo

\begin{tabular}{|l|l|l|}
\hline Cuenta Contable & Debe & Haber \\
\hline Activo por derecho de uso & 192,260 & \\
\hline Pasivo por Arrendamiento & & 192,260 \\
\hline
\end{tabular}

Elaboración propia

Por los gastos de intereses provenientes del arrendamiento operativo, para el primer año, el asiento seria el siguiente: 
Tabla 0.22

Asiento activos y pasivos A. Operativo

\begin{tabular}{|l|l|l|}
\hline Cuenta Contable & Debe & Haber \\
\hline Gasto financiero & 12,777 & \\
\hline Intereses por Pagar & & 12,777 \\
\hline
\end{tabular}

Elaboración propia

Por los gastos de depreciación originados por el activo arrendado se obtiene S/ 64,087 de la por la vida útil del activo de 3 años en base al valor de S/ 192,260. Se reconoce en el Estado de Resultados y en el Estado de Situación Financiera como depreciación acumulada.

Tabla 0.23

Asientos de gastos por depreciación

\begin{tabular}{|l|l|l|}
\hline Cuenta Contable & \multicolumn{1}{|l|}{ Debe } & Haber \\
\hline Gasto por Depreciacion & 64,087 & \\
\hline Depreciacion Acumulada & & 64,087 \\
\hline
\end{tabular}

Elaboración propia

Finalmente, las cuotas por pago del principal son reconocidas disminuyendo la cuenta de efectivo o caja y los pasivos por pagar del principal.

Tabla 0.24

Asiento de pago de cuota del principal

\begin{tabular}{|l|l|l|}
\hline Cuenta Contable & Debe & Haber \\
\hline Cuota por pagar & 72,000 & \\
\hline Efectivo y Equivalente & & 72,000 \\
\hline
\end{tabular}

Elaboración propia

El resumen de los asientos contables por el periodo del primero año de arrendamiento es plasmado en las siguientes cuentas " $\mathrm{T}$ ": 
Tabla 0.25

Resumen cuentas T - Primero año

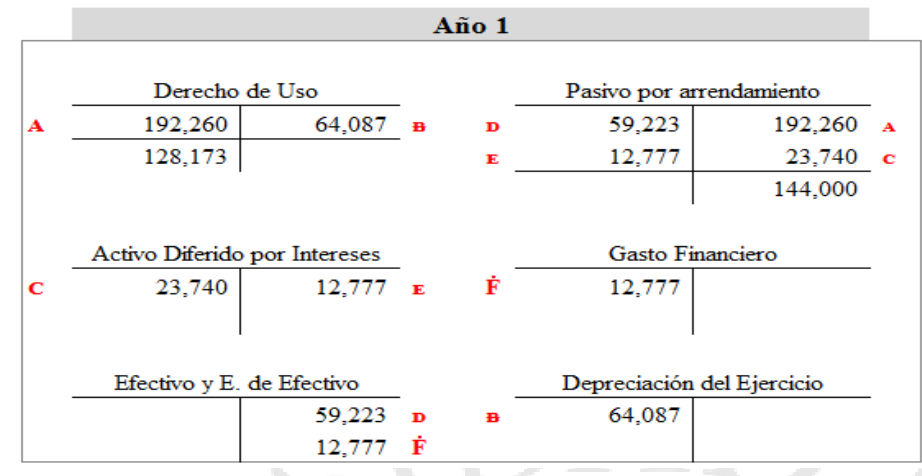

Elaboración propia

En el segundo año de operaciones, los pasivos por arrendamientos serán de S/72,000 por el pago de la cuota, S/8,040 por el pago de intereses y un saldo de S/63,960 de amortización del capital. El detalle de los pagos mensuales se detalla en la tabla 4.26.

Tabla 0.26

Pagos por arrendamiento segundo año

\begin{tabular}{|l|c|c|c|}
\hline \multirow{2}{*}{ Periodo } & \multicolumn{3}{|c|}{ PASIVO POR ARRENDAMIENTO } \\
\cline { 2 - 3 } & Capital & Amortización Intereses & Cuota \\
\hline
\end{tabular}

\begin{tabular}{|c|c|c|c|c|}
\hline 13 & $127,893.44$ & $5,144.03$ & 855.97 & 6,000 \\
\hline 14 & $122,716.31$ & $5,177.13$ & 822.87 & 6,000 \\
\hline 15 & $117,505.87$ & $5,210.44$ & 789.56 & 6,000 \\
\hline 16 & $112,261.90$ & $5,243.96$ & 756.04 & 6,000 \\
\hline 17 & $106,984.20$ & $5,277.70$ & 722.30 & 6,000 \\
\hline 18 & $101,672.54$ & $5,311.66$ & 688.34 & 6,000 \\
\hline 19 & $96,326.70$ & $5,345.84$ & 654.16 & 6,000 \\
\hline 20 & $90,946.47$ & $5,380.23$ & 619.77 & 6,000 \\
\hline 21 & $85,531.62$ & $5,414.85$ & 585.15 & 6,000 \\
\hline 22 & $80,081.94$ & $5,449.69$ & 550.31 & 6,000 \\
\hline 23 & $74,597.19$ & $5,484.75$ & 515.25 & 6,000 \\
\hline 24 & $69,077.15$ & $5,520.04$ & 479.96 & 6,000 \\
\hline AÑO 2 & $1,185,595$ & 63,960 & 8,040 & 72,000 \\
\hline
\end{tabular}

Elaboración propia

De la misma manera que el año anterior, se registra la depreciación del activo arrendado por $\mathrm{S} / 64,087$, los gastos por intereses por $\mathrm{S} / 8,040$ y los pagos de la cuota del principal de S/72,000. 
Tabla 0.27

Resumen cuentas T - Segundo año

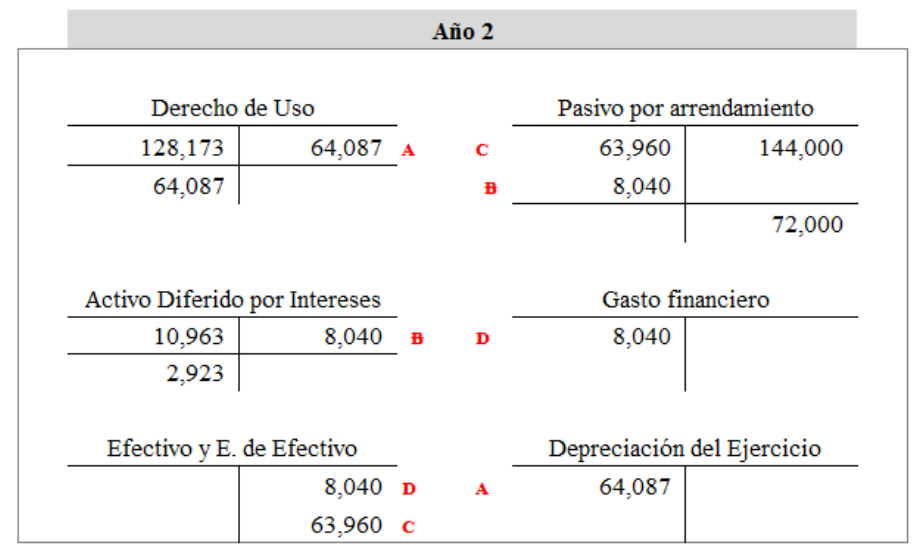

Elaboración propia

Finalmente, para el año 3 de arrendamiento, al igual que los años anteriores, se reconoce los gastos de depreciación, intereses y disminución del pasivo por el pago de la deuda. La tabla 4.28 muestra el detalle de los pasivos mensuales por el arrendamiento operativo, así como el gasto totalizado al final de los 3 periodos.

Tabla 0.28

Pagos por arrendamiento tercer año

\begin{tabular}{|c|c|c|c|c|}
\hline \multirow{2}{*}{ Periodo } & \multicolumn{4}{|c|}{ PASIVO POR ARRENDAMIENTO } \\
\hline & Capital & Amortización & Intereses & Cuota \\
\hline 25 & $63,521.59$ & $5,555.56$ & 444.44 & 6,000 \\
\hline 26 & $57,930.29$ & $5,591.30$ & 408.70 & 6,000 \\
\hline 27 & $52,303.02$ & $5,627.27$ & 372.73 & 6,000 \\
\hline 28 & $46,639.54$ & $5,663.48$ & 336.52 & 6,000 \\
\hline 29 & $40,939.62$ & $5,699.92$ & 300.08 & 6,000 \\
\hline 30 & $35,203.02$ & $5,736.59$ & 263.41 & 6,000 \\
\hline 31 & $29,429.52$ & $5,773.50$ & 226.50 & 6,000 \\
\hline 32 & $23,618.87$ & $5,810.65$ & 189.35 & 6,000 \\
\hline 33 & $17,770.83$ & $5,848.04$ & 151.96 & 6,000 \\
\hline 34 & $11,885.17$ & $5,885.66$ & 114.34 & 6,000 \\
\hline 35 & $5,961.64$ & $5,923.53$ & 76.47 & 6,000 \\
\hline 36 & - & $5,961.64$ & 38.36 & 6,000 \\
\hline AŇO 3 & 385,203 & 69,077 & 2,923 & 72,000 \\
\hline Total & & 192,260 & 23,740 & 216,000 \\
\hline
\end{tabular}

Elaboración propia

Para el tercer año de arrendamiento operativo, el activo se encuentra completamente depreciado, las obligaciones por arrendamiento ya han sido cubiertas y los gastos financieros por intereses ya se encuentran pagados como detalla el resumen de cuentas T de la tabla 4.26. 
Tabla 0.29

Resumen cuentas T - Tercer año

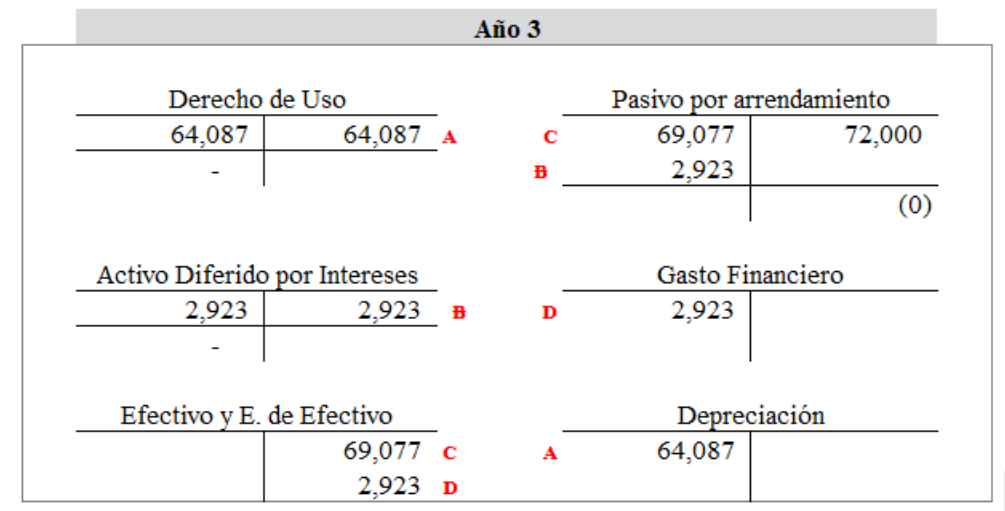

Elaboración propia

Por otro lado, se puede observar en la tabla 4.30 las diferencias como efecto del cambio de registro de la NIC 17 y NIIF 16. Los gastos se incrementan para los primeros años de arrendamiento y van disminuyendo al final del contrato. En contraste, la NIC 17, solo permitía el registro de los pagos de las cuotas en el Estado de Resultados de manera lineal.

Tabla 0.30

Diferencias en el Reconocimiento EE.RR.

Reconocimiento en Estado de Resultados

\begin{tabular}{l|l|l} 
NIC 17 & NIIF 16 & Diferencia
\end{tabular}

$\left.\begin{array}{|r|c|r|}\hline 72,000 & 76,864 & (4,864) \\ \hline 72,000 & 72,126 & (126) \\ \hline 72,000 & 67,010\end{array}\right]$

Elaboración propia

\section{Efecto de aplicación}

- En el Estado de Situación Financiera, se verá afectado por un aumento de endeudamiento, debido a que se incluye en los pasivos las obligaciones por arrendamientos operativos que bajo la NIC 17 eran reconocidos como gastos en el ejercicio.

- Se originará un mayor gasto por el pago de intereses los primeros años del arrendamiento.

- En el Estado de Resultados, hay nuevos reconocimientos por pagos de intereses y 
depreciación, lo que conlleva a la variación de ratios o indicadores como el EBITDA, deuda / EBITDA, ratios de solvencia, entre otros que sirven para las entidades financieras como indicadores del rendimiento de las empresas.

\subsubsection{Emisión de bonos corporativos internacionales}

La empresa cuenta al 31 de diciembre del 2017 con un saldo en deuda por emisión de bonos de $S / 1,229,055$, los cuales fueron emitidos a fecha 23 de noviembre del 2011 por un valor de US\$320,000,000 a tasa de $6.75 \%$ anual y vencimiento al 23 de Noviembre del 2021; de igual forma, el 12 de abril del 2013 se realizó una segunda emisión de bonos internacionales por US\$260,000,000 a una tasa de $4.625 \%$ anual y con vencimiento del 12 de Abril del 2023. Los fondos Recuperados de estas demisiones de bonos, fueron utilizados para la implementación y construcción de las plantas de Pucusana, Arequipa, Trujillo, Huachipa y Lima), la cancelación de préstamos bancarios y la recompra de bonos locales.

Tabla 0.31

Obligaciones financieras al 31 de Diciembre del 2017

\begin{tabular}{|c|c|}
\hline \multicolumn{2}{|c|}{ PRESTAMOS Y OBLIGACIONES } \\
\hline NOMBRE & IMPORTE \\
\hline Bonos C. Internacionales & $1,229,055,000$ \\
\hline Bonos C. Nacionales & $150,000,000$ \\
\hline Prestamos Bancos Locales & $100,000,000$ \\
\hline Arrendamientos Financieros & $12,866,000$ \\
\hline Financiamiento Prima Call Spread & $11,728,000$ \\
\hline
\end{tabular}

Fuente: Corporación Lindley (2017).

Así mismo, para reducir la exposición al tipo de cambio, la compañía realizo la recompra de bonos internacionales por un valor nominal de S/ 655,400,000 el cual equivale a US $\$ 200,000,000$, US $\$ 70,000,000$ y US $\$ 130,000,000$ del bono a vencimiento 2021 y 2023 respectivamente. El impacto de la recompra fue de S/ 60,133,000 reconocido en el estado separado de resultados. (PWC, 2018)

Cabe resaltar que la recompra de bonos o también denominados "Callable Bonds", que a diferencia de los bonos que finalizan con el vencimiento, estos concluyen a la fecha de amortización o pago de la deuda a una fecha determinada. Es una opción que ofrece el inversionista al emisor de retirar los bonos después de cierto tiempo, pagando un interés ligeramente más alto que un bono convencional a forma de 
compensación. Este tipo de título de deuda es atractivo para ambas partes, ya que, para el inversor, incrementa el interés recibido y para el emisor acorta el tiempo de deuda junto con el costo de intereses a una fecha futura si las tasas de interés bajan.

La compañía también ha Recuperado préstamos en bancos locales y emisión de bonos corporativos nacionales para la restructuración de pasivos, es decir, para mejorar las condiciones de deuda actuales por unas más favorables. Así mismo, también presenta préstamos por arrendamiento financiero o leasing para la compra de maquinarias, camiones de distribución, equipos en frio, montacargas entre otros.

Las emisiones de bonos y demás préstamos han sido reconocidas inicialmente bajo su valor razonable después de descontar los costos incurridos por la transacción; posteriormente, han sido registrados a su costo amortizado.

\subsubsection{Instrumentos Financieros derivados y actividades de cobertura}

Según la definición contenida en la NIC 32 los instrumentos financieros son aquellos contratos que dan lugar a un activo o pasivo financiero que o instrumento de patrimonio en otra entidad. Así mismo, se encuentras divididas en instrumentos financieros primarios; tales como las cuentas por cobrar, por pagar e instrumentos de patrimonio. Así también, los instrumentos financieros derivados como las opciones financieras, futuros y contratos a plazo, permutas de tipo de interés y de divisas.

Bajo la NIC 39, la empresa reconoce los instrumentos financieros derivados a su valor razonable en la fecha que se celebra el contrato; así mismo, la compañía cubre sus principales riesgos con coberturas de valor razonable y coberturas de flujo de efectivo.

El cambio de un valor razonable de un derivado que sea instrumento de cobertura se reconoce en el estado de resultados como gasto financiero, así como el cambio del valor razonable de la partida cubierta se registra como parte del valor en libros y a su vez en el estado de resultados como gasto financiero.

Para las coberturas de flujos de efectivo que tiene la corporación, se reconoce en Estados de Resultados Integrales la porción efectiva de cambios en el valor razonable de derivados de coberturas de flujos de efectivo como los Swaps de azúcar. Sin embargo, se reconoce en Estado de Resultados, la ganancia o pérdida de la porción infectiva del valor razonable de estos flujos. 
Los instrumentos financieros derivados con los que se cobertura la compañía son:

- Cross Currency Swap

- Call Spread

- Swaps del Azúcar

\section{Cross Currency Swap.}

Son dereivados que permiten a las emrpesas intercambiar principal e intereses en una divisa diferente a un tipo de cambio e interes pactado. Esta modalidad de swaps se realiza para aprovechar las tasas de interes de bancos nacionales.

\section{Call Spread.}

Este tipo de derivado cubre la volatilidad de flujos por variaciones en el tipo de cambio respecto a la deuda de bonos internacionales.

\section{Contratos Swaps del azúcar.}

Son instrumentos financieros derivados con la función de cubrir la volatilidad del precio del azúcar a fechas futuras, asegurando con un precio de mercado a la fecha de transacción.

Tabla 0.32

Detalle instrumentos financieros derivados.

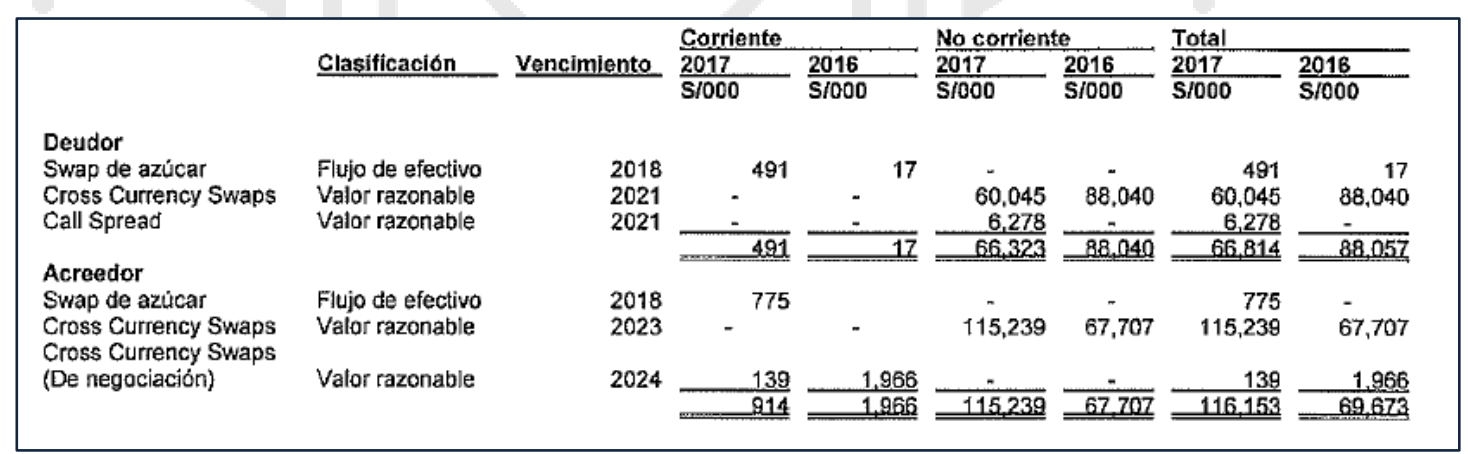

Fuente: PWC (2018)

\subsubsection{Análisis de Riesgos}

La compañía se encuentra expuesta a dos tipos de riesgo debido al tipo de negocio y gestiones que realiza los órganos de gobierno de la empresa como financiamiento a largo plazo. 


\section{Riesgo de Mercado.}

a) Riesgo de tipo de cambio.

La moneda funcional de la compañía es El Sol (S/), pero también realiza operaciones con el extranjero como préstamos a largo plazo y contratos de futuros con entidades financieras externas de las que se obtienen flujos en diferentes divisas además de las exportaciones e importaciones (dólar estadounidense y euro) que se convierten a moneda local a fecha de transacción. La conversión a moneda funcional de estas operaciones se realiza con el tipo de cambio publicado por la Superintendencia de Banca y Seguros (SBS). El principal riesgo de tipo de cambio es la deuda a mediano plazo por bonos que fue emitida en el año 2011 y 2013, además de las coberturas para mitigar este tipo de riesgo por un valor de 100 millones de dólares.

\section{b) Riesgos de Precios.}

Uno de los principales componentes de las bebidas que comercializa corporación Lindley, es el azúcar. El cual se ve afectado por las variaciones de precio del mercado de su principal materia prima el azúcar.

Para poder asegurar el precio y que la compañía no se vea afectada por estas fluctuaciones, se contratan los seguros Forward o "swaps del azúcar, el cual consiste en pactar la compra a futuro de la materia prima, a un precio fijado, esto permite mitigar la volatilidad de los precios que podrían afectar los costos de ventas. La empresa ha adquirido contratos futuros (hacia el 31 de diciembre de 2015, el valor razonable de dichos contratos fue de S/ 2.824.000) y swaps de azúcar (Over-The-Counter Liquity swaps) para coberturar el riesgo.

\section{c) Riesgo de Tasa de interés.}

El riesgo de que las tasas de interés del mercado suban o bajen, afectando los flujos futuros de caja, para mitigar este riesgo, la compañía pacta tasas de intereses fijas en la obtención de deudas, así como la suscripción de contratos "interest rate swaps" que intercambia las tasas de interés variables por fijas.

Un swap de tasa de interés es un tipo de contrato derivado a través del cual dos contrapartes acuerdan intercambiar una corriente de pagos de intereses futuros por otra, con base en un monto de capital específico. En la mayoría de los casos, los swaps de tasas de interés incluyen el 
intercambio de una tasa de interés fija por una tasa flotante .Al igual que con otros tipos de swaps, los swaps de tasas de interés no se negocian en las bolsas públicas, solo de venta libre (OTC). (Corporate Finance Institute, párr. 1).

\section{Riesgo de liquidez.}

Según el informe auditado por PWC, la compañía monitorea su riesgo de liquidez mediante flujos de caja proyectados a corto y largo plazo. Manteniendo una continuidad de fondos, mediando fuentes de crédito comprometidas y la capacidad de liquidar transacciones de endeudamiento. Además, que la compañía cuenta con record crediticio por el pago de sus obligaciones antes del vencimiento.

\subsection{Presentación y discusión de resultados}

\subsubsection{Indicadores de desempeño}

Los ratios financieros son una herramienta de medida que sirve para analizar la gestión y resultados de la empresa a nivel histórico comparativo. Como su nombre lo dice, es la razón de dos o más variables del Estado de Situación Financiera.

En líneas generales, la empresa puede afrontar sus obligaciones al corto plazo gracias al endeudamiento a largo plazo que tiene con bancos nacionales e internacionales, además de tener un crecimiento ininterrumpido de ingresos y una rotaciones inventario alta, no es de preocupación que sus ratios de liquidez sean más bajos que los esperado puesto que los fondos provienen del apalancamiento que son compensados con las utilidades operativas, así mismo son altos los costos de financiamiento debido a las emisiones de bono, y prestamos además de los contratos de cobertura.

A continuación, se analizará cada razón o ratio de los estados financieros:

- Ratios de Liquidez

- Ratios de Solvencia

- Ratios de Actividad

- Ratios de Rentabilidad 


\section{Ratios de Liquidez.}

Los ratios de liquidez muestran la capacidad que tiene la empresa de hacer frente a sus obligaciones a corto plazo, es decir, como puede transformar sus activos en efectivo o equivalente de efectivo de manera rápida. Los ratios mostradas a continuación, señalan una razón muy por debajo de uno, eso quiere decir, que los pasivos corrientes superan a los activos corrientes y podría presumirse que la empresa se encuentra demasiado apalancada como para asumir sus obligaciones al corto plazo; sin embargo, la corporación logra hacer frente y cumplir con sus pasivos inmediatos con los fondos recuperados por endeudamientos a largo plazo.

Tabla 0.33

Ratios de Liquidez

\begin{tabular}{|c|c|c|c|c|}
\hline & & 2017 & 2016 & 2015 \\
\hline \multicolumn{5}{|l|}{ Ratios de Liquidez } \\
\hline Liquidez General & $\begin{array}{l}\text { A. Corriente/P. } \\
\text { Corriente }\end{array}$ & 0.77 & 0.71 & 1.02 \\
\hline Prueba Acida & $\begin{array}{l}\text { AC-Inventarios / } \\
\text { Pasivo corriente }\end{array}$ & 0.48 & 0.39 & 0.72 \\
\hline Prueba Defensiva & $\begin{array}{c}\text { Efectivo y E. / } \\
\text { Pasivo Corriente }\end{array}$ & 0.08 & 0.05 & 0.33 \\
\hline Capital de Trabajo & $\begin{array}{l}\text { Acorriente- } \\
\text { PCorriente }\end{array}$ & $-171,274$ & $-226,840$ & 19,447 \\
\hline
\end{tabular}

Fuente: Corporación Lindley (2017, 2016,2015).

Elaboración propia.

Los activos corrientes presentan mayores importes en las cuentas de inventarios, cuentas por cobrar comerciales y relacionas; pero son superadas largamente por los pasivos a corto los cuales se conforman principalmente por las cuentas por pagar comerciales, por la compra de materiales suministros, envases y embalajes de producción en moneda nacional y extranjera, tienen vencimientos corrientes y no generan intereses.

Las cuentas por pagar con relacionadas, CocaCola Chile SA; Corporación Inka Kola Perú SRL, CocaCola Servicios del Perú SA con el cual se maneja la compra de concentrados y bases; VEND SAC por la venta de productos para distribuir máquinas expendedoras y Vendtech SAC que presta servicio de mantenimiento de equipos en frio. Cabe resaltar, que las cuentas más representativas son la cuentas por pagar comerciales y el factoring con proveedores o también llamado "confirming" o "reverse factoring", el cual es un sistema donde los bancos ofrecen a sus clientes, la facilidad de gestionar sus pagos a proveedores antes de la fecha de vencimiento, es decir, el banco asegura el pago 
de esas deudas, de esta manera se mantiene la buena relación con los proveedores y se obtiene, por parte del banco, mayor plazo para pagar la obligación con cierto interés añadido.

Cabe resaltar que la calificación crediticia de la compañía es de A- luego de haber estado en $\mathrm{BBB}+$ dado por la clasificadora Fitch Ratings debido a su crecimiento y liderazgo en el mercado y desapalancamiento con entidades financieras.

Las categorías de clasificación se denominan con las letras AAA, AA, A, $\mathrm{BBB}, \mathrm{BB}, \mathrm{B}, \mathrm{C}, \mathrm{D}$ y E; siendo la categoría AAA la de más bajo riesgo y la D la de más alto riesgo. La categoría $\mathrm{E}$ se utiliza cuando se carece de información suficiente para clasificar a una compañía de seguros. (Comisión para el Mercado Financiero, S.F., párr. 3).

\section{Ratios de Solvencia.}

Se puede ver que casi la mayoría de fondos Recuperados por deudas a largo plazo se destina a propiedad planta y equipo además de cubrir deudas al corto plazo. Los pasivos no corrientes están confirmados en su mayoría por las emisiones de Bonos corporativos internacionales, Bonos Corporativos nacionales, préstamos bancarios, arrendamientos financieros, y financiamiento prima Call spread, los fondos Recuperados de estos préstamos financieros son utilizados para invertirlos en maquinaria, plantas de distribución y pago de obligaciones al corto plazo.

Tabla 0.34

Ratios de Solvencia.

\begin{tabular}{|c|c|c|c|c|}
\hline & & 2017 & 2016 & 2015 \\
\hline \multicolumn{5}{|l|}{ Ratios de Solvencia } \\
\hline Crecimiento en Ventas & & $0.61 \%$ & $7.24 \%$ & $7.18 \%$ \\
\hline Grado de Endeudamiento & Pasivo T/Activo & 0.72 & 0.76 & 0.83 \\
\hline Razon Deuda Patrimonio & $\begin{array}{l}\text { Pasivo } \mathrm{T} / \\
\text { Patrimonio } \mathrm{T}\end{array}$ & 2.61 & 3.09 & 4.95 \\
\hline Deuda Largo Plazo - Patrimonio & $\begin{array}{l}\text { Pasivo NC / } \\
\text { Patrimonio }\end{array}$ & 1.80 & 2.08 & 3.52 \\
\hline Cobertura de Intereses & $\begin{array}{l}\text { EBIT / Gastos } \\
\text { Finan }\end{array}$ & 2.44 & 2.29 & 1.48 \\
\hline Calidad de Deuda & Pasivo C/ Pasivo T & 0.31 & 0.32 & 0.29 \\
\hline Multiplicador del capital Contable & $\begin{array}{l}\text { Activo } \mathrm{T} / \\
\text { Patrimonio }\end{array}$ & 3.61 & 4.09 & 5.95 \\
\hline Margen Bruto & & $36.73 \%$ & $36.52 \%$ & $35.73 \%$ \\
\hline Margen Operativo & & $14.34 \%$ & $21.26 \%$ & $9.50 \%$ \\
\hline Margen Neto & & $6.51 \%$ & $9.61 \%$ & $-3.82 \%$ \\
\hline
\end{tabular}

Fuente: Corporación Lindley $(2017,2016,2015)$.

Elaboración propia.

Se aprecia que casi la mayoría de fondos Recuperados por deudas a largo plazo se destina a propiedad planta y equipo además de cubrir deudas al corto plazo. 
Los pasivos no corrientes están confirmados en su mayoría por las emisiones de Bonos corporativos internacionales, Bonos Corporativos nacionales, préstamos bancarios, arrendamientos financieros, y financiamiento prima Call spread, los fondos Recuperados de estos préstamos financieros son utilizados para invertirlos en maquinaria, plantas de distribución y pago de obligaciones al corto plazo.

\section{Ratios de Gestión.}

Se puede observar que, para la gestión de cobranza, la empresa mantiene hace efectivos los cobraros de ventas entre 15 a 30 días, del 2015 al 2017 hay una evidente mejora en la gestión de cobros, que permiten a la empresa tener liquidez en un mejor periodo de tiempo.

Tabla 0.35

Ratios de Gestión

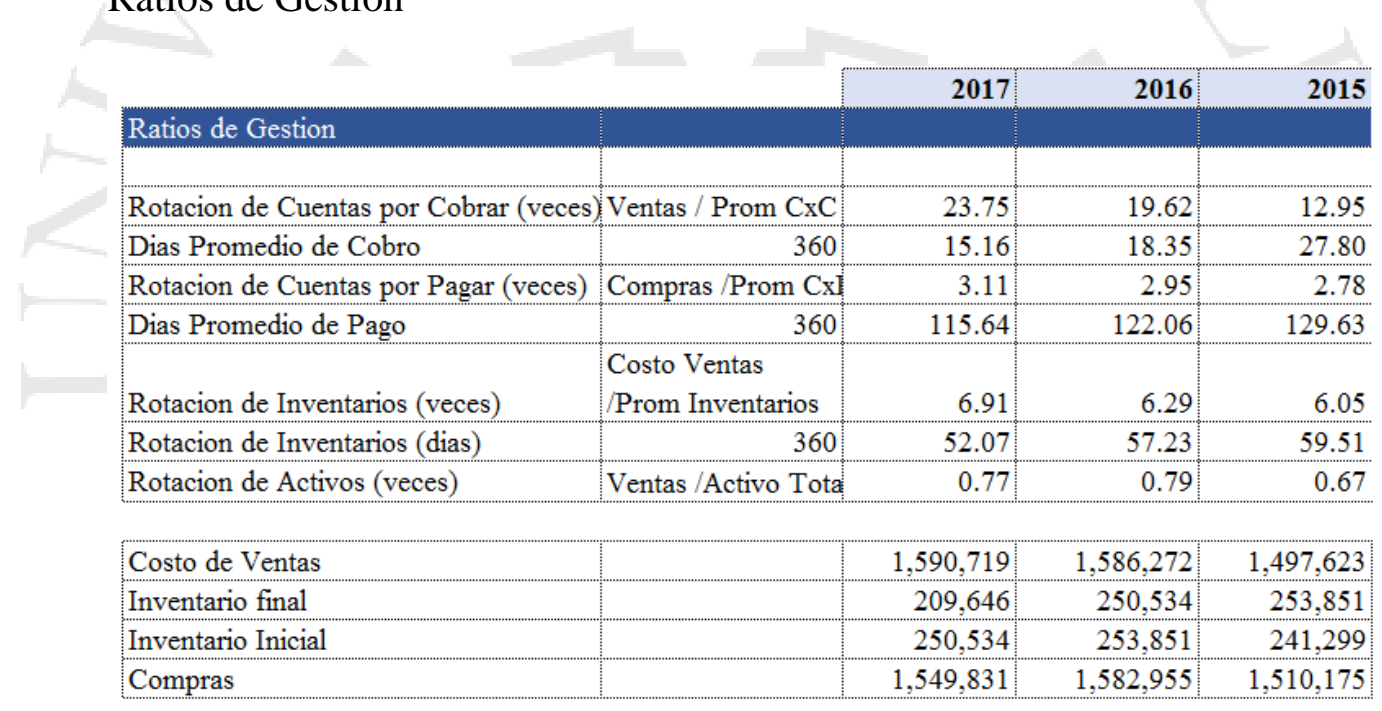

Fuente: Corporación Lindley $(2017,2016,2015)$.

Elaboración propia.

Para las cuentas por pagar a proveedores, se tiene un promedio de 100 a 130 días en que la empresa hace efectiva la cancelación de sus pasivos comerciales, lo cual le da el tiempo para disponer de ese efectivo para otras gestiones de operación hasta el cumplimiento del plazo de deuda. Por el lado de inventarios, tienen una rotación en promedio de 56 días, es decir, demora menos de dos meces en agotar el límite de stock de productos terminados, es un buen indicador reflejado también con el aumento de las ventas. 
Figura 0.4

Variación Ratios de Gestión

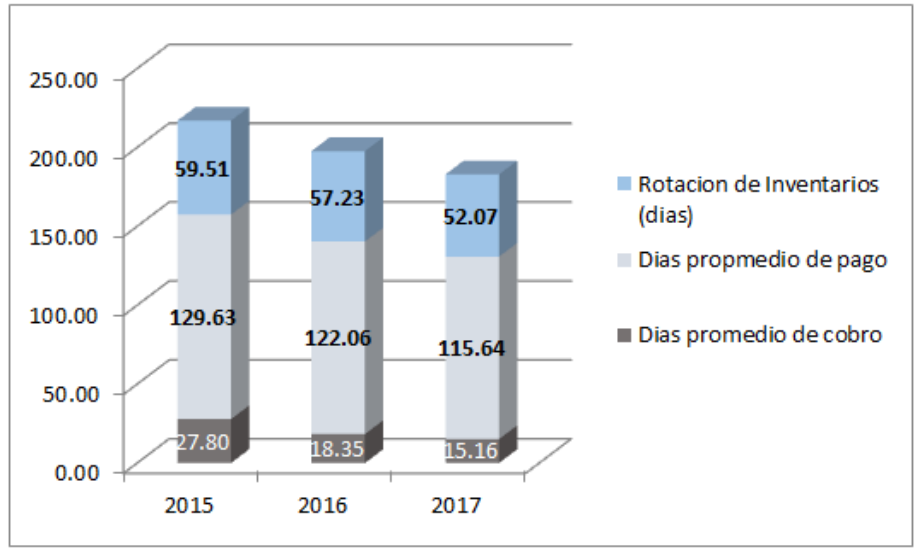

Fuente: Corporación Lindley, (2017, 2016,2015).

Elaboración propia.

\section{Ratios de Rentabilidad.}

Estos indicadores permiten evaluar la eficiencia de las operaciones, mediante la relación entre utilidad, ventas y patrimonio.

Tabla 0.36

Ratios de Rentabilidad

Ratios de Rentabilidad

\begin{tabular}{|c|c|c|c|c|}
\hline Rendimiento sobre los Activos (ROA) & Utilidad / Activos & $5.01 \%$ & $7.57 \%$ & $-2.57 \%$ \\
\hline Rendimiento sobre el Patrimonio (ROE) & Utilidad / Patrimoni & $18.07 \%$ & $30.93 \%$ & $-15.27 \%$ \\
\hline \multicolumn{5}{|l|}{ Otros Indicadores } \\
\hline EBIT & & 360,611 & 531,333 & 221,412 \\
\hline EBITDA & $\begin{array}{l}\mathrm{EBIT}+\mathrm{DEPREC}+ \\
\mathrm{AMORT}\end{array}$ & 561,270 & 718,399 & 381,051 \\
\hline
\end{tabular}

Fuente: Corporación Lindley $(2017,2016,2015$.

Elaboración propia.

El Rendimiento de Activos en la empresa se muestra en una situación favorable desde el año 2016, las pérdidas del año 2015, no permiten lograr un ratio positivo, a pesar que los Activos del año en mención tuvieron un aumento de S/106,162 (miles). Esto se debe principalmente a que se tuvo gastos por un valor de $\mathrm{S} / 230,360$ por diferencias de tipo de cambio por la parte expuesta no coberturada de la deuda, lo que. en consecuencia, 
arrojó pérdidas en la utilidad antes de impuestos de S/ 129,241 (miles). Sin embargo, para el año 2016 se logra superar estas pérdidas, con una utilidad neta de S/240,196 (miles) gracias a la gestión de contratos de cobertura (instrumentos financieros), ingresos operativos por venta de activos de inversión y una mejora en otros gastos operativos.

Figura 0.5

Variación de ROA y ROE

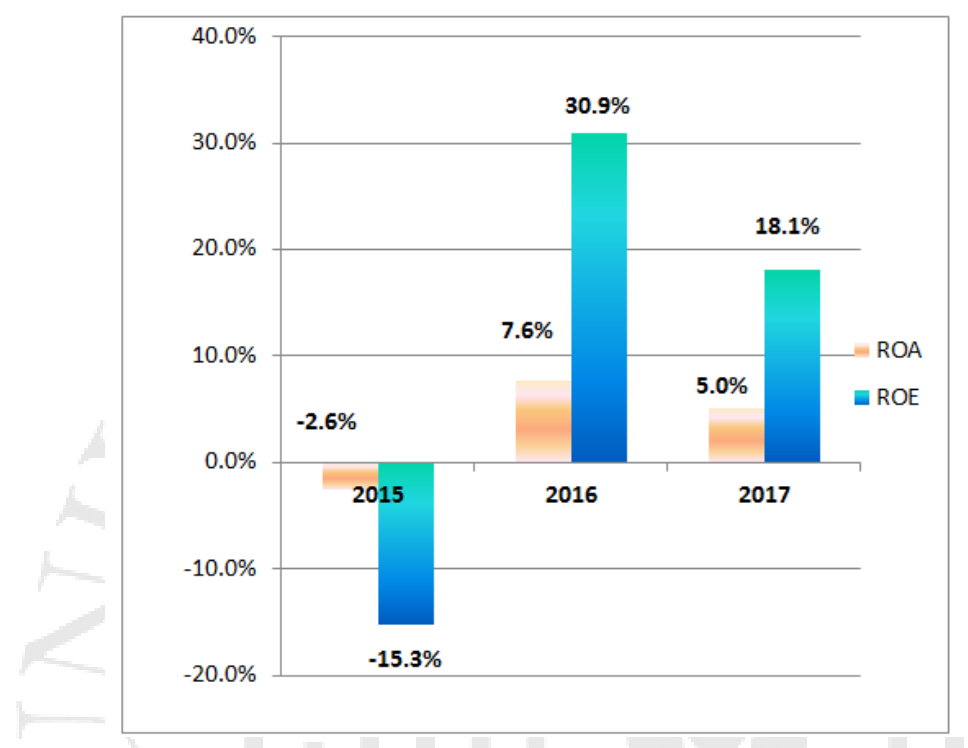

Fuente: Corporación Lindley $(2017,2016,2015)$.

Elaboración propia.

El indicador Earnings Before Interest, Taxes, Depreciation, and Amortization (EBITDA), es decir, Utilidad antes de intereses, impuestos, depreciación y amortización, es un indicador que muestra la liquidez con la que cuenta una empresa, los beneficios netos antes de impuestos con los que puede hacer frente a pasivos corrientes y no corrientes. Así mismo, la rentabilidad patrimonio mide el retorno del inversionista.

Dividiendo la deuda sobre el Ebitda, se observa una tendencia decreciente debido al desapalancamiento que la compañía trata de ejercer después de las inversiones para el crecimiento y expansión de la corporación. 
Tabla 0.37

Indicador Deuda/Ebitda

\begin{tabular}{|l|r|r|r|r|}
\hline & $\mathbf{2 0 1 7}$ & $\mathbf{2 0 1 6}$ & $\mathbf{2 0 1 5}$ & $\mathbf{2 0 1 4}$ \\
\hline Otros Indicadores & & & & \\
\hline EBITDA & 561,270 & 718,399 & 381,051 & 306,284 \\
\hline DEUDA & $2,363,788$ & $2,395,826$ & $2,880,724$ & $2,722,080$ \\
\hline DEUDA-EBITDA & 4.21 & 3.33 & 7.56 & 8.89 \\
\hline
\end{tabular}

Fuente: Corporación Lindley $(2017,2016,2015)$.

Elaboración propia.

Ha habido un mejoramiento del resultado de Ebitda año a año como también de la reducción de la deuda. A pesar de que el indicar deuda/ebitda se encuentre alto, se puede observar que la compañía trata de desapalancarse respecto a sus deudas de largo plazo que componen la mayor parte de sus pasivos. La deuda en el año 2017 es 4.21 veces el EBITDA a diferencia del año 2014 donde fue de 8.89.

\subsubsection{Análisis Vertical}

El análisis vertical muestra la participación de cada cuenta referente al total de activos, pasivos y patrimonio y a su vez, en el estadio de resultados, referente al total de las ventas, de esta manera se puede identificar que partida es más significativa, o las relaciones entre las mismas donde se pueden evidenciar las gestiones de inversión y financiamiento entre activos y pasivos.

\section{Estado de Situación Financiera.}

a) Activos.

Para los activos corrientes, Corporación Lindley muestra un incremento porcentual del $7.92 \%$ en comparativa con los demás años, que puede deberse a la inversión de Arca continental, la cual desembolso alrededor 760 millones de dólares a fines del año 2015.ç

Así mismo las cuentas más significativas son los inventarios que han venido disminuyendo gradualmente de $7.33 \%$ en el 2015 a $6.41 \%$ en el 2017 , lo cual refleja una mejora en las rotaciones de stock, de la misma manera, las cuentas por cobrar que al año 2016 tuvo una variación positiva respecto al 2015 de una razón de 4.17\% en el 2015 y de $3.10 \%$ en el 2017, es decir, se mejoró la gestión de cobranzas, considerando que las ventas han venido en aumento los últimos años. 
Respecto a los Activos no corrientes, se puede observar que se compone principalmente por Propiedad, planta y equipo el cual se conforma por: Edificaciones, equipos de frio, terrenos, unidades de transporte, maquinaria y equipo, botellas, cajas y tarimas, equipos, mobiliario, trabajos en curso, entre otros. La compañía invierte la mayor parte de sus fondos en reinversión para la empresa, ya que es parte de sus objetivos, las mejoras en equipamiento, almacenamiento y distribución para afrontar la demanda de años futuros.

b) Pasivos y Patrimonio.

Las principales obligaciones en los pasivos corrientes son las cuentas por pagar comerciales, originado por la compra de materiales, suministros, envases, embalajes, para el proceso productivo, en moneda nacional y extranjera. Estas cuentas por pagar son reconocidas inicialmente a su valor razonable y posteriormente al costo amortizado.

Los pasivos no corrientes, como se ha mencionado con anterioridad, se conforma en su mayoría por bonos internacionales al valor de S/ 1,229,055 al 2017, bonos locales por el valor de S/ 150,000,000 al 2017 suscrito el 29 de diciembre del 2016, prestamos con el banco nacional por S/ 100,000,000 y arrendamiento financiero por la adquisición de líneas de embotellado, krones (maquinaria que se encargar del llenado de bebidas), vehículos montacargas, y equipos de frio.

\section{c) Estado de Resultados.}

El costo de ventas se ha mantenido en el mismo nivel con una ligera tendencia a disminuir gracias a la gestión de mejora en costos y también a la baja de precios de materias primas.

Así mismo se ha se ha logrado en el 2016 gracias a una venta de propiedades de inversión de tres inmuebles por el valor de S/ 126,892 y de propiedad planta y equipo por baja de activos de la Planta de Rímac por el valor de S/ 216,950.

\subsubsection{Análisis Horizontal}

El análisis horizontal nos muestra la variación entre partidas año a año, se puede determinar la variación tanto en números como en porcentaje para obtener un resultado más específico, analizando las variaciones y determinando las causas respectivas. 


\section{Estado de Situación Financiera}

\section{a) Activos}

En Corporación Lindley, para el estado de situación financiera, se puede observar que los activos corrientes han tenido una fuerte disminución del año 2015 al 2016 cerca de un 54\% menos para luego volver a mantenerse en el 2017 principalmente por una fuerte variación en la cuenta de efectivo y equivalente de efectivo que al año 2015 fue de S/ 274,362 (miles) y para el año 2016 tuvo un valor de S/ 40,983, probablemente dado por la inversión de Arca continental en la fusión por absorción realizada en el cuarto trimestre el 2015, y el pago de obligaciones para el año 2016.

Tabla 0.38

Análisis Horizontal - Activos

\begin{tabular}{|c|c|c|c|c|c|c|}
\hline \multicolumn{4}{|l|}{ ESTADO DE SITUACION FINANCIERA } & \multicolumn{3}{|c|}{ TENDENCLA $(\%)$} \\
\hline Cuenta & 2017 & 2016 & 2015 & 2017 & 2016 & 2015 \\
\hline Efectivo y Equivalentes al Efectivo & 55,146 & 40,983 & 274,362 & $35 \%$ & $-85 \%$ & $\mathbf{2 3 5} \%$ \\
\hline Otros Activos Financieros & 491 & 17 & 0 & $2788 \%$ & & \\
\hline Cuentas por Cobrar Comerciales & 101,459 & 110,275 & 144,481 & $-8 \%$ & $-24 \%$ & $-33 \%$ \\
\hline Cuentas por Cobrar a Entidades Relacionadas & 124,677 & 55,112 & 57,697 & $126 \%$ & $-4 \%$ & $-72 \%$ \\
\hline Otras Cuentas por Cobrar & 45,581 & 55,285 & 72,679 & $-18 \%$ & $-24 \%$ & $32 \%$ \\
\hline Anticipos & 7,765 & 9,666 & 0 & $-20 \%$ & & $-100 \%$ \\
\hline Inventarios & 209,646 & 250,534 & 253,851 & $-16 \%$ & $-1 \%$ & $5 \%$ \\
\hline Activos por Impuestos a las Ganancias & 0 & 21,051 & 34,564 & $-100 \%$ & $-39 \%$ & $18 \%$ \\
\hline Otros Activos no Financieros & 3,193 & 8,508 & 10,936 & $-62 \%$ & $-22 \%$ & $231 \%$ \\
\hline $\begin{array}{l}\text { Activos no Corrientes o Grupos de Activos para su } \\
\text { Disposición Clasificados como Mantenidos para la Venta } \\
\text { o como Mantenidos para Distribuir a los Propietarios }\end{array}$ & 13,908 & 0 & 0 & & & \\
\hline Total Activos Corrientes & 561,866 & 551,431 & 848,570 & & & \\
\hline Otros Activos Financieros & 66,345 & 88,065 & 108,249 & $-25 \%$ & $-19 \%$ & \\
\hline $\begin{array}{l}\text { Inversiones en Subsidiarias, Negocios Conjuntos y } \\
\text { Asociadas }\end{array}$ & 11,401 & 11,401 & 7,401 & $0 \%$ & $54 \%$ & $0 \%$ \\
\hline Cuentas por Cobrar Comerciales & 0 & 0 & 0 & & & $-100 \%$ \\
\hline Otras Cuentas por Cobrar & 25,205 & 22,890 & 25,349 & $10 \%$ & $-10 \%$ & $-65 \%$ \\
\hline Anticipos & 1,206 & 2,143 & 0 & $-44 \%$ & & $-100 \%$ \\
\hline Propiedades de Inversión & 18,761 & 19,167 & 42,659 & $-2 \%$ & $-55 \%$ & $-1 \%$ \\
\hline Propiedades, Planta y Equipo & $2,269,016$ & $2,166,217$ & $2,102,547$ & $5 \%$ & $3 \%$ & $2 \%$ \\
\hline Activos Intangibles Distintos de la Plusvalia & 5,000 & 5,448 & 6,079 & $-8 \%$ & $-10 \%$ & $41 \%$ \\
\hline Activos por Impuestos Diferidos & 5,058 & 0 & 14,857 & & $-100 \%$ & \\
\hline Plusvalia & 305,555 & 305,555 & 305,555 & $0 \%$ & $0 \%$ & $0 \%$ \\
\hline Otros Activos no Financieros & 0 & 0 & 1,656 & & $-100 \%$ & \\
\hline Total Activos No Corrientes & $2,707,547$ & $2,620,886$ & $2,614,352$ & & & \\
\hline TOTAL DE ACTIVOS & $3,269,413$ & $3,172,317$ & $3,462,922$ & & & \\
\hline
\end{tabular}

Fuente: Corporación Lindley (2017, 2016,2015).

Elaboración propia.

La plusvalía no se ve modificada en ningún ejercicio, sin embargo, la cuenta de propiedades de inversión ha sufrido grandes cambios, del 2015 al 2016 un descenso del $55 \%$, por la venta de las mismas. A su vez, los activos fijos de Propiedad, Planta y Equipo van en aumento principalmente por la política de inversión y expansión de la compañía como las plantas de Pucusana, Huachipa, y nueva maquinaria para el envasado de bebidas 
antes ya mencionadas, como también construcciones de mega almacenes en Villa El Salvador y Lima Centro, remodelaciones de oficinas en la planta de Rímac. Así mismo, la compañía registra ventas de trece inmuebles no estratégicos y del piso 9 y 12 de oficinas ubicadas en la molina, que se encontraban registrados como Propiedad, planta y equipo y Propiedades de Inversión.

Tabla 0.39

Propiedad, planta y equipo neto y Propiedades de Inversión

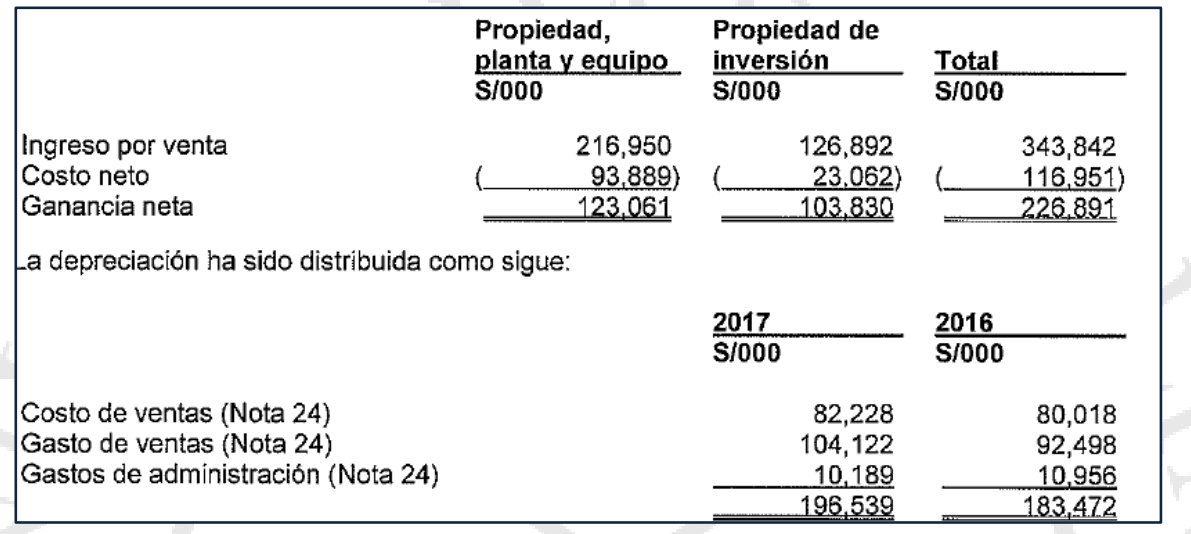

Fuente: PWC (2018)

b) Pasivos y Patrimonio.

Los pasivos corrientes hay una tendencia a reducir las cuentas por pagar comerciales y con relacionadas como pagos de factoring a proveedores en soles y dólares y por la compra de materiales directos para producción. Se encuentra el pasivo corriente de las deudas de corto largo plazo.

Tabla 0.40

Análisis Horizontal Pasivos y Patrimonio

\begin{tabular}{|c|c|c|c|c|c|c|}
\hline \multicolumn{4}{|l|}{ ESTADO DE SITUACION FINANCIERA } & \multicolumn{3}{|c|}{ TENDENCIA(\%) } \\
\hline Cuenta & 2017 & 2016 & 2015 & 2017 & 2016 & 2015 \\
\hline \multicolumn{7}{|l|}{ Pasivos y Patrimonio } \\
\hline \multicolumn{7}{|l|}{ Pasivos Corrientes } \\
\hline Otros Pasivos Financieros & 6,723 & 4,342 & 4,647 & $55 \%$ & $-7 \%$ & $-94 \%$ \\
\hline Cuentas por Pagar Comerciales & 474,749 & 520,909 & 552,496 & $-9 \%$ & $-6 \%$ & $3 \%$ \\
\hline Cuentas por Pagar a Entidades Relacionadas & 65,176 & 96,732 & 81,250 & $-33 \%$ & $19 \%$ & $-34 \%$ \\
\hline Otras Cuentas por Pagar & 80,599 & 84,214 & 115,923 & $-4 \%$ & $-27 \%$ & $12 \%$ \\
\hline Otras Provisiones & 27,160 & 25,462 & 22,132 & $7 \%$ & $15 \%$ & $-4 \%$ \\
\hline Pasivos por Impuestos a las Ganancias & 27,753 & 0 & 0 & & & $-100 \%$ \\
\hline Otros Pasivos no Financieros & 50,980 & 46,612 & 52,675 & $9 \%$ & $-12 \%$ & \\
\hline Total Pasivos Corrientes & 733,140 & 778,271 & 829,123 & & & \\
\hline \multicolumn{7}{|l|}{ Pasivos No Corrientes } \\
\hline Otros Pasivos Financieros & $1,613,079$ & $1,602,321$ & $1,975,097$ & $1 \%$ & $-19 \%$ & $14 \%$ \\
\hline Cuentas por Pagar Comerciales & 0 & 0 & 607 & & $-100 \%$ & \\
\hline Cuentas por Pagar a Entidades Relacionadas & 0 & 0 & 69,401 & & $-100 \%$ & $307 \%$ \\
\hline Otras Cuentas por Pagar & 17,569 & 12,764 & 6,496 & $38 \%$ & $96 \%$ & $-92 \%$ \\
\hline Pasivos por Impuestos Diferidos & 0 & 2,470 & 0 & $-100 \%$ & & $-100 \%$ \\
\hline Total Pasivos No Corrientes & $1,630,648$ & $1,617,555$ & $2,051,601$ & & & \\
\hline Total Pasivos & $2,363,788$ & $2,395,826$ & $2,880,724$ & & & \\
\hline
\end{tabular}

Fuente: Corporación Lindley (2017, 2016, 2015).

Elaboración propia. 
Los pasivos no corrientes se ven incrementados en el 2017 por el financiamiento de prima Call Spread por un valor aproximado de S/ 3,853 (miles), así mismo hay un incremento por impuesto a las ganancias comprendido por impuesto a la renta corriente y diferido, además de la ejecución en obras por impuestos por un importe de S/3,285 (soles) para la remodelación de un centro educativo de alrededor de 1000 alumnos ubicado en el distrito de Pucusana, cerca de la planta de distribución de la compañía.

Por parte del patrimonio, no varía en lo que respecta al capital emitido y acciones de inversión, salvo por las reservas de capital, resultados acumulados y otras reservas del patrimonio.

\section{c) Estado de Resultados.}

Además de las variaciones de ventas y costos, previamente mencionados, también se ve una disminución en gastos administrativos como una mejora en gestión de recursos por parte de la compañía. En otros ingresos por el año 2016 se ve un fuerte aumento de S/ 206,377 (miles) un equivalente a $231 \%$ respecto del año anterior, debido a la venta de inmuebles hechos por la compañía (clasificados como propiedades de inversión), ventas de camiones y ventas de propiedad, planta y equipo además de ventas de material publicitario, botellas y cajas plásticas, etc.

Tabla 0.41

Otros Ingresos y gastos operativos

\begin{tabular}{|c|c|c|c|}
\hline \multirow[t]{3}{*}{25} & $\begin{array}{l}\text { OTROS INGRESOS Y GASTOS } \\
\text { Este rubro comprende: }\end{array}$ & $\frac{2017}{\mathrm{~S} / 000}$ & $\frac{2016}{S / 000}$ \\
\hline & $\begin{array}{l}\text { Otros ingresos } \\
\text { Venta de servicios, materias primas y material publicitario } \\
\text { Convenio Corporativo Coca Cola Chile, CCS y CIKPSA (a) } \\
\text { Venta de inmueble, maquinaria y equipos (b) } \\
\text { Alquileres } \\
\text { Venta de botellas y cajas plásticas } \\
\text { Devolución de impuestos (c) } \\
\text { Varios }\end{array}$ & $\begin{array}{r}24,969 \\
32,986 \\
13,501 \\
10,115 \\
2,127 \\
8,197 \\
24,140 \\
116,035 \\
\end{array}$ & $\begin{array}{r}15,049 \\
12,416 \\
10,352 \\
5,573 \\
3,999 \\
-\quad 21,499 \\
68,888 \\
\end{array}$ \\
\hline & $\begin{array}{l}\text { Otros gastos } \\
\text { Provisiones para contingencias, cese de personal y diversas } \\
\text { Costo de venta de inmueble, maquinaria y equipos (b) } \\
\text { Provisión por deterioro de repuestos (Nota 11) } \\
\text { Baja de inventarios, botellas y cajas plásticas } \\
\text { Costo de venta de servicios, materias primas y material } \\
\text { publicitario }\end{array}$ & $\begin{array}{r}17,687 \\
11,447 \\
8,151 \\
1,049 \\
7,829 \\
46,163 \\
\end{array}$ & $\begin{array}{r}20,366 \\
14,150 \\
-\quad 842 \\
8,405 \\
43,763\end{array}$ \\
\hline
\end{tabular}

Fuente: PWC (2018) 
Y por los gastos, comprende costos de venta de propiedad, planta y equipo, baja de inventarios y materiales directos varios, y otros tipos de contingencias como cese de personal. Además de un ligero incremento del 5.48\% para el 2017, por provisiones de deterioro y baja de inventarios y materiales.

Tabla 0.42

Análisis Horizontal Estado de Resultados.

\begin{tabular}{|c|c|c|c|c|c|c|}
\hline \multicolumn{4}{|l|}{ ESTADO DE RESULTADOS } & \multicolumn{3}{|c|}{ TENDENCLA $(\%)$} \\
\hline Cuenta & 2017 & 2016 & 2015 & 2017 & 2016 & 2015 \\
\hline Ingresos de Actividades Ordinarias & $2,514,204$ & $2,499,003$ & $2,330,184$ & $1 \%$ & $7 \%$ & $7 \%$ \\
\hline Costo de Ventas & $-1,590,719$ & $-1,586,272$ & $-1,497,623$ & $0 \%$ & $6 \%$ & $3 \%$ \\
\hline Ganancia (Pérdida) Bruta & 923,485 & 912,731 & 832,561 & $1 \%$ & $10 \%$ & $15 \%$ \\
\hline Gastos de Ventas y Distribución & $-536,056$ & $-532,279$ & $-511,168$ & $1 \%$ & $4 \%$ & $22 \%$ \\
\hline Gastos de Administración & $-96,690$ & $-101,135$ & $-109,177$ & $-4 \%$ & $-7 \%$ & $6 \%$ \\
\hline Otros Ingresos Operativos & 116,035 & 295,779 & 89,402 & $-61 \%$ & $231 \%$ & $-55 \%$ \\
\hline Otros Gastos Operativos & $-46,163$ & $-43,763$ & $-80,206$ & $5.48 \%$ & $-45 \%$ & $-65 \%$ \\
\hline Ganancia (Pérdida) Operativa & 360,611 & 531,333 & 221,412 & $-32 \%$ & $140 \%$ & $31 \%$ \\
\hline Ingresos Financieros & 2,976 & 2,360 & 28,840 & $26 \%$ & $-92 \%$ & $826 \%$ \\
\hline $\begin{array}{l}\text { Ingresos por Intereses calculados usando el Metodo de } \\
\text { Interes Efectivo }\end{array}$ & 0 & 0 & 0 & & & \\
\hline Gastos Financieros & $-147,599$ & $-232,265$ & $-149,133$ & $-36 \%$ & $56 \%$ & $44 \%$ \\
\hline Diferencias de Cambio Neto & 25,188 & 15,504 & $-230,360$ & $62 \%$ & $-107 \%$ & \\
\hline Ganancia (Pérdida) antes de Impuestos & 241,176 & 316,932 & $-129,241$ & $-24 \%$ & $-345 \%$ & $494 \%$ \\
\hline Ingreso (Gasto) por Impuesto & $-77,520$ & $-76,736$ & 40,332 & $1 \%$ & $-290 \%$ & $70 \%$ \\
\hline Ganancia (Pérdida) Neta de Operaciones Continuadas & 163,656 & 240,196 & $-88,909$ & $-32 \%$ & $-370 \%$ & $-4537 \%$ \\
\hline Ganancia (Pérdida) Neta del Ejercicio & 163,656 & 240,196 & $-88,909$ & $-32 \%$ & $-370 \%$ & $4337 \%$ \\
\hline
\end{tabular}

Fuente: Corporación Lindley (2017, 2016,2015).

Elaboración propia.

Para el año 2015 hubo un fuerte gasto por diferencias de tipo de cambio de $\mathrm{S} / 230,360$ lo cual fue una de las razones por las que en ese ejercicio resultaron pérdidas netas de S/ 88,909, sin embargo, para el 2016 se logra mejorar esta cuenta con ingresos por S/15,504 (miles) y en el 2017 por S/ 25,188 (miles).

\subsubsection{Análisis Macroeconómico}

El crecimiento del PBI en los últimos años ha sido adecuado, considerando que somos uno de los países más estables de Sudamérica, en referencia a como nos vemos afectados por crisis macroeconómicas por países potencia como China y Estados Unidos, o como nuestros países limítrofes se han visto afectados en crisis internas económicas de inflación como Venezuela, Brasil y Argentina. 
Figura 0.6

Crecimiento histórico PBI
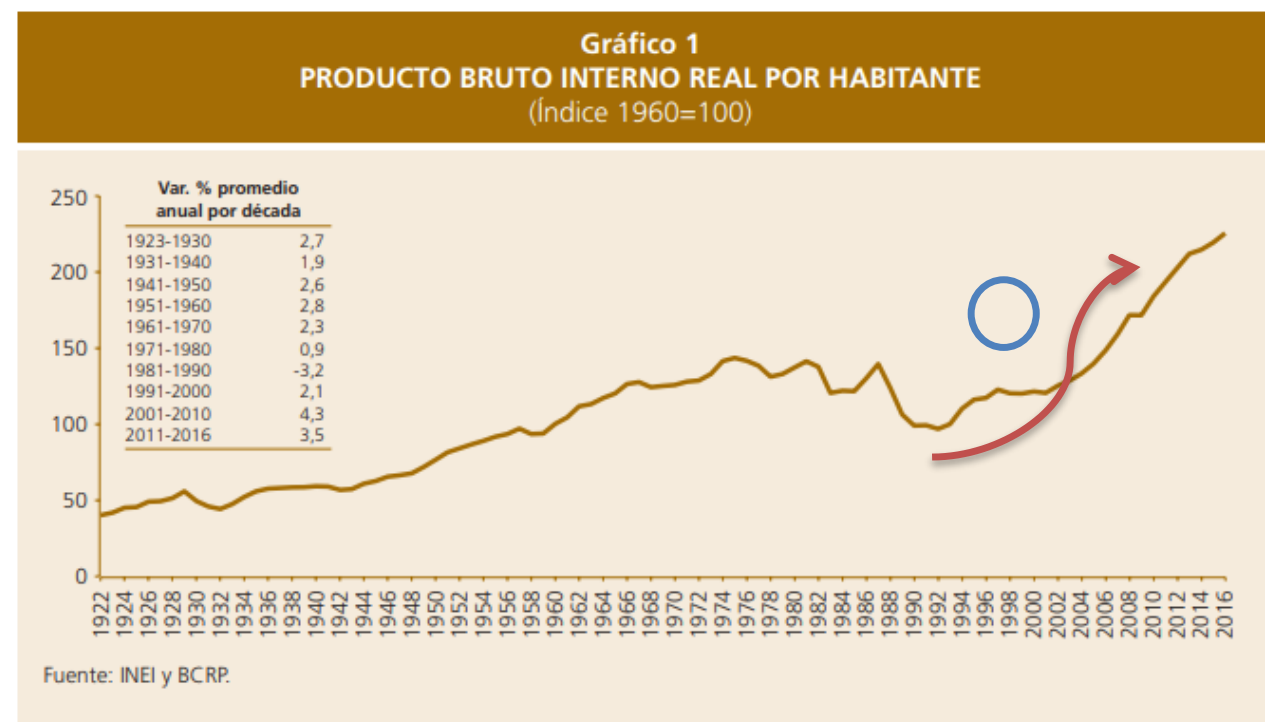

Fuente: BCRP (S.F.).

Desde el año 2000 en adelante se registra un largo crecimiento de la economía peruana, a excepción del 2009 por la crisis financiera mundial que afectó a varios países incluido el nuestro, sin embargo, no ha detenido el crecimiento económico para los subsiguientes años.

En 2016, el Producto Bruto Interno (PBI) registró una tasa de crecimiento mayor a la del año previo (3,9 por ciento versus 3,3 por ciento), impulsado por el crecimiento de los sectores primarios, especialmente la minería metálica, lo que impulsó el aumento de las exportaciones en 9,5 por ciento. La demanda interna registró una ligera expansión (0,9 por ciento) sostenida por el desempeño del consumo privado, que atenuó el impacto de las caídas de la inversión privada y del gasto público. (BCRP, S.F.)

Ahora bien, el crecimiento del consumo de bebidas gaseosas desde el 2014 al 2015 se encuentra en aumento año a año reflejado también en las ventas de la compañía. Según el Banco Central de Reserva del Perú, del año 2007 al 2016 se registra un promedio de crecimiento del consumo de bebidas gasificadas el 6.90\%. A pesar de las recientes tendencias saludables que se da en personas jóvenes y adultos mayores, el mercado de bebidas gasificadas y saborizadas aún no se ve tan afectado debido a la cultura y costumbres nacionales arraigadas. 
Figura 0.7

Crecimiento consumo de bebidas gaseosas

\begin{tabular}{|c|c|c|c|c|}
\hline \multicolumn{5}{|c|}{$\begin{array}{c}\text { Cuadro } 12 \\
\text { CRECIMIENTO DE LA MANUFACTURA NO PRIMARIA POR TIPO DE BIENES } \\
\text { (Variaciones porcentuales reales) }\end{array}$} \\
\hline & 2014 & 2015 & 2016 & $\begin{array}{l}\text { Promedio } \\
2007-2016\end{array}$ \\
\hline Consumo masivo & $-2,0$ & 0,3 & 0,9 & 4,7 \\
\hline proauctos lacteos & 1,4 & 3,1 & $-4,1$ & 4,3 \\
\hline Panadería & $-0,4$ & 1,2 & $-1,9$ & 1,3 \\
\hline Aceites y grasas & 4,6 & 4,5 & 2,3 & 3,9 \\
\hline Productos alimenticios diversos & $-5,5$ & $-8,0$ & $-6,2$ & 4,6 \\
\hline Cerveza y malta & 0,5 & $-0,4$ & $-0,8$ & 3,6 \\
\hline Bebidas gaseosas & 1,7 & 9,1 & 7,2 & 6,9 \\
\hline Prendas de vestir & $-9,0$ & $-8,7$ & $-4,2$ & $-0,2$ \\
\hline Muebles & $-6,3$ & 7,8 & 5,7 & 11,5 \\
\hline Otros artículos de papel y cartón & 110 & 12.5 & -7.0 & 71 \\
\hline Productos de tocador y limpieza & 2,0 & $-1,9$ & 9,8 & 6,6 \\
\hline Productos farmacéuticos & $-1,7$ & $-20,4$ & 10,1 & $-0,4$ \\
\hline Manufacturas diversas & $-7,2$ & $-6,0$ & $-9,9$ & 0,3 \\
\hline
\end{tabular}

Fuente BCRP (S.F.)

Por otro lado, dentro de nuevas leyes y regulaciones que podrían afectar las operaciones de la compañía se encuentra el decreto supremo que afecta el Impuesto Selectivo al Consumo. La estrategia de la compañía ha sido la diversificación de la cartera de productos, adaptándose a las nuevas regulaciones, con el objetivo de no perder público consumidor. Las bebidas que tiene la compañía en su cartera de productos cero azúcares o light compensan la subida en precios del ISC aplicado a las presentaciones normales como las botellas de Inca Cola, Coca Cola, Sprite y Fanta.

\subsubsection{Proyección Financiera}

Se ha calculado el promedio de tasa de crecimiento de las ventas del año 2008 al 2017, utilizando el método de regresión lineal, con el propósito de obtener el crecimiento en ventas por los años 2018, 2019 y 2020. Este método es comúnmente utilizado para pronósticos de relaciones entre variables dependientes e independientes. 
Tabla 0.43

Crecimiento Ventas últimos 10 años

\begin{tabular}{|r|r|r|r|}
\hline Años & Variable & Ventas S/ & Crecimiento $\%$ \\
\hline $\mathbf{2 0 0 8}$ & 1 & $1,220,320$ & \\
\hline $\mathbf{2 0 0 9}$ & 2 & $1,389,891$ & $13.9 \%$ \\
\hline $\mathbf{2 0 1 0}$ & 3 & $1,496,563$ & $7.7 \%$ \\
\hline $\mathbf{2 0 1 1}$ & 4 & $1,724,007$ & $15.2 \%$ \\
\hline $\mathbf{2 0 1 2}$ & 5 & $2,003,030$ & $16.2 \%$ \\
\hline $\mathbf{2 0 1 3}$ & 6 & $2,067,251$ & $3.2 \%$ \\
\hline $\mathbf{2 0 1 4}$ & 7 & $2,174,084$ & $5.2 \%$ \\
\hline $\mathbf{2 0 1 5}$ & 8 & $2,330,184$ & $7.2 \%$ \\
\hline $\mathbf{2 0 1 6}$ & 9 & $2,499,003$ & $7.2 \%$ \\
\hline $\mathbf{2 0 1 7}$ & 10 & $2,514,204$ & $0.6 \%$ \\
\hline
\end{tabular}

Fuente: Corporación Lindley (2008 - 2017).

Elaboración propia.

La tendencia histórica aplicada al modelo de regresión resulta en la fórmula que será utilizada para la proyección en ventas donde " $y$ " es el porcentaje de crecimiento anual (variable dependiente) y " $x$ " que representa los años de proyección (variable independiente).

Formula base es $\mathbf{Y}=\mathbf{a X}+\mathbf{b}$, donde "a" es la pendiente de la recta y "b" es el punto donde corta la recta. (Torres, 2015).

$y=151,462.41 x+1,108,810.47$

$\mathbf{R}^{2}=\mathbf{0 . 9 8}$

Figura 0.8

Regresión lineal Ventas

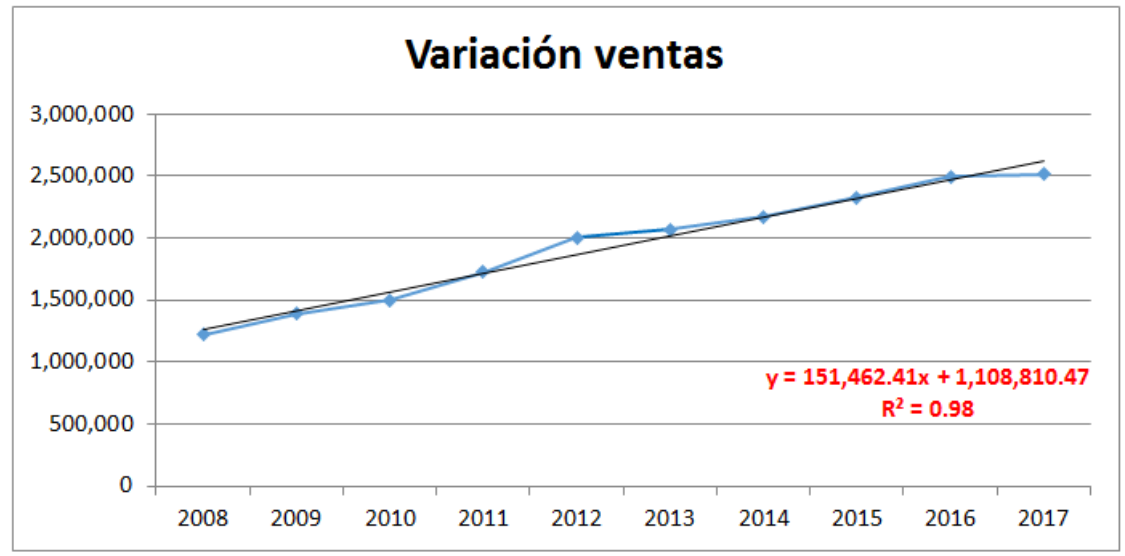

Elaboración propia. 
Tabla 0.44

Proyección ventas 2018, 2019,2020

\begin{tabular}{|r|r|r|r|}
\hline Años & Variable & Ventas S/ & Crecimiento \% \\
\hline 2018 & 11 & $2,635,105$ & $4.81 \%$ \\
\hline 2019 & 12 & $2,790,457$ & $5.90 \%$ \\
\hline 2020 & 13 & $2,945,810$ & $5.57 \%$ \\
\hline
\end{tabular}

Fuente: Corporación Lindley (2017, 2016, 2015).

Elaboración propia.

Los siguientes porcentajes de crecimiento serán multiplicados año a año para calcular las ventas proyectadas y empezar a proyectar las demás partidas de los estados financieros, además, manteniendo el promedio de la estructura de costos se calcula los costos de ventas, gastos operativos y financieros y finalmente la utilidad neta proyectada.

Tabla 0.45

Estados de Resultados Proyectados

ESTADO DE RESULTADOS

\begin{tabular}{|c|c|c|c|c|}
\hline \multirow{3}{*}{$\begin{array}{c}\text { ESTADO DE RESULTADOS } \\
\text { Cuenta }\end{array}$} & \multirow[b]{2}{*}{2017} & \multicolumn{3}{|c|}{ n Financiera } \\
\hline & & 2018 & 2019 & 2020 \\
\hline & $2,514,204$ & $2,635,105$ & $2,790,457$ & $2,945,810$ \\
\hline Costo de Ventas & $-1,590,719$ & $1,677,825$ & $1,776,741$ & $1,875,657$ \\
\hline Ganancia (Pérdida) Bruta & 923,485 & 957,280 & $1,013,717$ & $1,070,153$ \\
\hline Gastos de Ventas y Distribución & $-536,056$ & 567,053 & 600,484 & 633,914 \\
\hline Gastos de Administración & $-96,690$ & 110,482 & 116,996 & 123,509 \\
\hline Otros Ingresos Operativos & 116,035 & 178,201 & 188,707 & 199,213 \\
\hline Otros Gastos Operativos & $-46,163$ & 61,744 & 65,384 & 69,024 \\
\hline Ganancia (Pérdida) Operativa & 360,611 & 396,203 & 419,561 & 442,919 \\
\hline Ingresos Financieros & 2,976 & 11,081 & 11,735 & 12,388 \\
\hline Gastos Financieros & $-147,599$ & 189,420 & 200,587 & 211,754 \\
\hline Diferencias de Cambio Neto & 25,188 & 72,586 & 76,865 & 81,144 \\
\hline Ganancia (Pérdida) antes de Impuestos & 241,176 & 145,279 & 153,844 & 162,409 \\
\hline Ingreso (Gasto) por Impuesto & $-77,520$ & 69,258 & 73,341 & 77,424 \\
\hline Ganancia (Pérdida) Neta de Operaciones Continuadas & 163,656 & 76,021 & 80,503 & 84,985 \\
\hline Ganancia (Pérdida) Neta del Ejercicio & 163,656 & 76,021 & 80,503 & 84,985 \\
\hline
\end{tabular}

Elaboración propia.

En seguida se calculan los activos totales y de acuerdo al promedio del análisis estructural (Análisis Vertical), las cuentas de los activos corrientes y los no corrientes. 
Tabla 0.46

Análisis Vertical Variación - Activos

\begin{tabular}{|c|c|c|c|c|}
\hline Cuenta & $\begin{array}{l}\text { ANALISIS V } \\
2017\end{array}$ & $\begin{array}{c}\text { ANALISIS V } \\
2016\end{array}$ & $\begin{array}{l}\text { ANALISIS V } \\
2015\end{array}$ & Promedio \\
\hline Efectivo y Equivalentes al Efectivo & $1.69 \%$ & $1.29 \%$ & $7.92 \%$ & $3.63 \%$ \\
\hline Otros Activos Financieros & $0.02 \%$ & $0.00 \%$ & & $0.01 \%$ \\
\hline Cuentas por Cobrar Comerciales & $3.10 \%$ & $3.48 \%$ & $4.17 \%$ & $3.58 \%$ \\
\hline Cuentas por Cobrar a Entidades Relacionadas & $3.81 \%$ & $1.74 \%$ & $1.67 \%$ & $2.41 \%$ \\
\hline Otras Cuentas por Cobrar & $1.39 \%$ & $1.74 \%$ & $2.10 \%$ & $1.75 \%$ \\
\hline Anticipos & $0.24 \%$ & $0.30 \%$ & & $0.27 \%$ \\
\hline Inventarios & $6.41 \%$ & $7.90 \%$ & $7.33 \%$ & $7.21 \%$ \\
\hline Activos por Impuestos a las Ganancias & & $0.66 \%$ & $1.00 \%$ & $0.83 \%$ \\
\hline Otros Activos no Financieros & $0.10 \%$ & $0.27 \%$ & $0.32 \%$ & $0.23 \%$ \\
\hline $\begin{array}{l}\text { Activos no Corrientes o Grupos de Activos para su } \\
\text { Disposición Clasificados como Mantenidos para la Venta } \\
\text { o como Mantenidos para Distribuir a los Propietarios }\end{array}$ & $0.43 \%$ & $0.00 \%$ & $0.00 \%$ & $0.14 \%$ \\
\hline Total Activos Corrientes & $17.19 \%$ & $17.38 \%$ & $24.50 \%$ & $19.69 \%$ \\
\hline Otros Activos Financieros & $2.03 \%$ & $2.78 \%$ & $3.13 \%$ & $2.64 \%$ \\
\hline $\begin{array}{l}\text { Inversiones en Subsidiarias, Negocios Conjuntos y } \\
\text { Asociadas }\end{array}$ & $0.35 \%$ & $0.36 \%$ & $0.21 \%$ & $0.31 \%$ \\
\hline Otras Cuentas por Cobrar & $0.77 \%$ & $0.72 \%$ & $0.73 \%$ & $0.74 \%$ \\
\hline Anticipos & $0.04 \%$ & $0.07 \%$ & & $0.05 \%$ \\
\hline Propiedades de Inversión & $0.57 \%$ & $0.60 \%$ & $1.23 \%$ & $0.80 \%$ \\
\hline Propiedades, Planta y Equipo & $69.40 \%$ & $68.29 \%$ & $60.72 \%$ & $66.13 \%$ \\
\hline Activos Intangibles Distintos de la Plusvalia & $0.15 \%$ & $0.17 \%$ & $0.18 \%$ & $0.17 \%$ \\
\hline Activos por Impuestos Diferidos & $0.15 \%$ & & $0.43 \%$ & $0.29 \%$ \\
\hline Plusvalia & $9.35 \%$ & $9.63 \%$ & $8.82 \%$ & $9.27 \%$ \\
\hline Otros Activos no Financieros & & & $0.05 \%$ & $0.05 \%$ \\
\hline Total Activos No Corrientes & $82.81 \%$ & $82.62 \%$ & $75.50 \%$ & $80.31 \%$ \\
\hline TOTAL DE ACTIVOS & $100 \%$ & $100 \%$ & $100 \%$ & $100.0 \%$ \\
\hline
\end{tabular}

Elaboración propia.

A continuación, se calcula el patrimonio, manteniendo constante todas las cuentas, excepto las utilidades acumuladas que irán incrementando de acuerdo con las utilidades obtenidas en los periodos proyectados (Estado de Ganancias y Pérdidas). Finalmente se debe proyectar los pasivos en base al total de activos por la estructura porcentual obtenida del Análisis Vertical.

Tabla 0.47

\section{Análisis Vertical Variación - Pasivos y Patrimonio}

\begin{tabular}{|c|c|c|c|c|}
\hline Cuenta & $\begin{array}{c}\text { ANALISIS V } \\
2017\end{array}$ & $\begin{array}{c}\text { ANALISIS V } \\
2016\end{array}$ & $\begin{array}{c}\text { ANALISIS V } \\
2015\end{array}$ & Promedio \\
\hline Otros Pasivos Financieros & $0.21 \%$ & $0.14 \%$ & $0.13 \%$ & $0.16 \%$ \\
\hline Cuentas por Pagar Comerciales & $14.52 \%$ & $16.42 \%$ & $15.95 \%$ & $15.63 \%$ \\
\hline Cuentas por Pagar a Entidades Relacionadas & $1.99 \%$ & $3.05 \%$ & $2.35 \%$ & $2.46 \%$ \\
\hline Otras Cuentas por Pagar & $2.47 \%$ & $2.65 \%$ & $3.35 \%$ & $2.82 \%$ \\
\hline Otras Provisiones & $0.83 \%$ & $0.80 \%$ & $0.64 \%$ & $0.76 \%$ \\
\hline Pasivos por Impuestos a las Ganancias & $0.85 \%$ & & & $0.85 \%$ \\
\hline Otros Pasivos no Financieros & $1.56 \%$ & $1.47 \%$ & $1.52 \%$ & $1.52 \%$ \\
\hline Total Pasivos Corrientes & $22.42 \%$ & $24.53 \%$ & $23.94 \%$ & $23.63 \%$ \\
\hline Otros Pasivos Financieros & $49.34 \%$ & $50.51 \%$ & $57.04 \%$ & $52.29 \%$ \\
\hline Cuentas por Pagar Comerciales & & & $0.02 \%$ & $0.02 \%$ \\
\hline Cuentas por Pagar a Entidades Relacionadas & & & $2.00 \%$ & $2.00 \%$ \\
\hline Otras Cuentas por Pagar & $0.54 \%$ & $0.40 \%$ & $0.19 \%$ & $0.38 \%$ \\
\hline Pasivos por Impuestos Diferidos & & $0.08 \%$ & & $0.08 \%$ \\
\hline Total Pasivos No Corrientes & $49.88 \%$ & $50.99 \%$ & $59.24 \%$ & $53.37 \%$ \\
\hline Total Pasivos & $72.30 \%$ & $75.52 \%$ & $83.19 \%$ & $77.00 \%$ \\
\hline Capital Emitido & $17.77 \%$ & $18.31 \%$ & $16.78 \%$ & $17.62 \%$ \\
\hline Acciones de Inversión & $2.19 \%$ & $2.25 \%$ & $2.07 \%$ & $2.17 \%$ \\
\hline Otras Reservas de Capital & $1.74 \%$ & $1.27 \%$ & $0.47 \%$ & $1.16 \%$ \\
\hline Resultados Acumulados & $7.88 \%$ & $3.48 \%$ & $-3.06 \%$ & $2.77 \%$ \\
\hline Otras Reservas de Patrimonio & $-1.88 \%$ & $-0.84 \%$ & $0.56 \%$ & $-0.72 \%$ \\
\hline Total $\mathbf{P}$ & $27.70 \%$ & $24.48 \%$ & $16.81 \%$ & $23.00 \%$ \\
\hline TOTAL PASIVO Y PATRIMONIO & $100 \%$ & $100 \%$ & $100 \%$ & $100.00^{\circ}$ \\
\hline
\end{tabular}

Elaboración propia.5 
Los activos totales resultantes de la proyección son de S/ 3,318,260, S/ 3,370,870 y S/ 3,428,075 para los años 2018, 2019 y 2020 respectivamente (valores en miles de soles). Se espera la continua inversión en activo fijo, como se ha venido dando los últimos años como parte de sus políticas de inversión y plan de expansión.

Tabla 0.48

Estados de Situación Financiera Proyectado - Activos

\begin{tabular}{|c|c|c|c|c|}
\hline \multicolumn{2}{|l|}{ ESTADO DE SITUACION FINANCIERA } & \multicolumn{3}{|c|}{ Proyeccion Financiera } \\
\hline Cuenta & 31.12 .2017 & 2018 & 2019 & 2020 \\
\hline Efectivo y Equivalentes al Efectivo & 55,146 & 57,150 & 59,227 & 60,674 \\
\hline Otros Activos Financieros & 491 & 491.04 & 491.08 & 491.11 \\
\hline Cuentas por Cobrar Comerciales & 101,459 & 105,095 & 108,862 & 112,763 \\
\hline Cuentas por Cobrar a Entidades Relacionadas & 124,677 & 127,676 & 130,748 & 133,893 \\
\hline Otras Cuentas por Cobrar & 45,581 & 46,376 & 47,186 & 48,009 \\
\hline Anticipos & 7,765 & 7,786 & 7,807 & 7,828 \\
\hline Inventarios & 209,646 & 224,769 & 240,982 & 258,366 \\
\hline Otros Activos no Financieros & 3,193 & 3,200 & 3,208 & 3,215 \\
\hline Activos no Corrientes o Grupos de Activos para su & & & & \\
\hline $\begin{array}{l}\text { Disposición Clasificados como Mantenidos para la Venta } \\
\text { o como Mantenidos para Distribuir a los Propietarios }\end{array}$ & 13,908 & 13,928 & 13,947 & 13,967 \\
\hline Total Activos Corrientes & 561,866 & 586,472 & 612,457 & 639,206 \\
\hline Activos No Corrientes & & & & \\
\hline Otros Activos Financieros & 66,345 & 68,099 & 69,899 & 71,747 \\
\hline $\begin{array}{l}\text { Inversiones en Subsidiarias, Negocios Conjuntos y } \\
\text { Asociadas }\end{array}$ & 11,401 & 11,436 & 11,471 & 11,506 \\
\hline Otras Cuentas por Cobrar & 25,205 & 25,205 & 25,205 & 25,205 \\
\hline Anticipos & 1,206 & 1,215 & 1,224 & 1,233 \\
\hline Propiedades de Inversión & 18,761 & 18,771 & 18,781 & 18,790 \\
\hline Propiedades, Planta y Equipo & $2,269,016$ & $2,287,243$ & $2,305,617$ & $2,324,138$ \\
\hline Activos Intangibles Distintos de la Plusvalia & 5,000 & 8,307 & 13,800 & 22,927 \\
\hline Activos por Impuestos Diferidos & 5,058 & 5,066 & 5,075 & 5,083 \\
\hline Plusvalia & 305,555 & 306,447 & 307,341 & 308,238 \\
\hline Total Activos No Corrientes & $2,707,547$ & $2,731,789$ & $2,758,413$ & $2,788,868$ \\
\hline TOTAL DE ACTIVOS & $3,269,413$ & $3,318,260$ & $3,370,870$ & $3,428,075$ \\
\hline
\end{tabular}

Elaboración propia.

Para las oblgaciones de la corporación, como se ha analizado previamente, la compañia busca reducir sus pasivos financieros, es por eso, que en la proyeccion se esta estimando una reduccion progresiva de pasivos largo plazo, pues las mayores inversiones que requirieron de grandes fondos ya han sido realizadas. Asi mismo el patrimonio se ve afectado por el resultado del periodo proyectado (creciente), las demás partidas permanecen constantes. 
Tabla 0.49

Estado de Situación Financiera Proyectado - Pasivos y Patrimonio.

\begin{tabular}{|c|c|c|c|c|}
\hline Cuenta & 31.12 .2017 & 2018 & 2019 & 2020 \\
\hline Otros Pasivos Financieros & 6,723 & 5,273 & 5,356 & 5,447 \\
\hline Cuentas por Pagar Comerciales & 474,749 & 518,710 & 526,934 & 535,877 \\
\hline Cuentas por Pagar a Entidades Relacionadas & 65,176 & 81,729 & 83,025 & 84,434 \\
\hline Otras Cuentas por Pagar & 80,599 & 93,657 & 95,142 & 96,757 \\
\hline Otras Provisiones & 27,160 & 25,136 & 25,534 & 25,967 \\
\hline Pasivos por Impuestos a las Ganancias & 27,753 & 28,168 & 28,614 & 29,100 \\
\hline Otros Pasivos no Financieros & 50,980 & 50,324 & 51,122 & 51,990 \\
\hline Total Pasivos Corrientes & 733,140 & 802,997 & 815,728 & 829,571 \\
\hline Otros Pasivos Financieros & $1,613,079$ & $1,521,148$ & $1,480,326$ & $1,438,487$ \\
\hline Otras Cuentas por Pagar & 17,569 & 12,469 & 12,667 & 12,882 \\
\hline Total Pasivos No Corrientes & $1,630,648$ & $1,533,617$ & $1,492,993$ & $1,451,369$ \\
\hline Total Pasivos & $2,363,788$ & $2,336,614$ & $2,308,721$ & $2,280,941$ \\
\hline Capital Emitido & 580,981 & 580,981 & 580,981 & 580,981 \\
\hline Acciones de Inversión & 71,523 & 71,523 & 71,523 & 71,523 \\
\hline Otras Reservas de Capital & 56,842 & 56,842 & 56,842 & 56,842 \\
\hline Resultados Acumulados & 257,644 & 333,665 & 414,168 & 499,153 \\
\hline Otras Reservas de Patrimonio & $-61,365$ & $-61,365$ & $-61,365$ & $-61,365$ \\
\hline Total Patrimonio & 905,625 & 981,646 & $1,062,149$ & $1,147,134$ \\
\hline TOTAL PASIVO Y PATRIMONIO & $3,269,413$ & $3,318,260$ & $3,370,870$ & $3,428,075$ \\
\hline
\end{tabular}

Elaboración propia.

Posteriormente, se calculan las variaciones de las actividades de operación, inversión y financiamiento para construir el Estado de Flujo de Efectivo y realizar el cuadre respectivo con el incremento o disminución de la cuenta Caja Bancos del Estado de Situación Financiera. 
Tabla 0.50

Estado de Resultados Proyectados

\begin{tabular}{|c|c|c|c|c|}
\hline \multicolumn{2}{|l|}{ ESTADO DE FLUJO DE EFECTIVO } & \multicolumn{3}{|c|}{ Proyeccion Financiera } \\
\hline Cuenta & 2017 & 2018 & 2019 & 2020 \\
\hline Ganancia (Pérdida) Neta del Ejercicio & 163,656 & 76,021 & 80,503 & 84,985 \\
\hline Gasto por Intereses & 147,599 & 189,420 & 200,587 & 211,754 \\
\hline Ingreso por Intereses & $-2,976$ & 11,081 & 11,735 & 12,388 \\
\hline Pérdida (Ganancia) por Diferencias de Cambio no Realizadas & $-25,188$ & 72,586 & 76,865 & 81,144 \\
\hline Gasto por Impuestos a las Ganancias & 77,520 & 69,258 & 73,341 & 77,424 \\
\hline Ajustes no Monetarios: & 360,611 & 396,203 & 419,561 & 442,919 \\
\hline Depreciación, Amortización y Agotamiento & 200,659 & 191,150 & 192,686 & 194,234 \\
\hline Cargos y Abonos por Cambios Netos en los Activos y Pasivos & 599,350 & 587,353 & 612,246 & 637,152 \\
\hline (Aumento) Disminución de Cuentas por Cobrar Comerciales & $-3,416$ & 3,636 & 3,766 & 3,901 \\
\hline (Aumento) Disminución de Otras Cuentas por Cobrar & $-78,781$ & 795 & 809 & 823 \\
\hline (Aumento) Disminución en Inventarios & 14,348 & 15,123 & 16,214 & 17,383 \\
\hline (Aumento) Disminución de Otros Activos no Financieros & 8,156 & 7 & - & 7 \\
\hline Aumento (Disminución) de Cuentas por Pagar Comerciales & 39,083 & 43,961 & 8,224 & 8,942 \\
\hline Aumento (Disminución) de Otras Cuentas por Pagar & $-22,668$ & 13,058 & 1,485 & 1,615 \\
\hline $\begin{array}{l}\text { Flujos de Efectivo y Equivalente al Efectivo procedente de } \\
\text { (utilizados en) Operaciones }\end{array}$ & 556,072 & 510,771 & 581,741 & 604,480 \\
\hline $\begin{array}{r}\text { Flujos de Efectivo y Equivalente al Efectivo procedente de } \\
\text { (utilizados en) Actividades de Operación }\end{array}$ & 533,191 & 510,771 & 581,741 & 604,480 \\
\hline Venta de Propiedades, Planta y Equipo & 15,628 & - & - & - \\
\hline Compra de Propiedades, Planta y Equipo & $-305,944$ & 18,227 & 18,373 & 18,521 \\
\hline $\begin{array}{l}\text { Flujos de Efectivo y Equivalente al Efectivo procedente de } \\
\text { (utilizados en) Actividades de Inversión }\end{array}$ & $-293,582$ & 18,227 & 18,373 & 18,521 \\
\hline Amortización o Pago de Préstamos & $-3,482$ & 93,381 & 40,738 & 41,748 \\
\hline Intereses Pagados & $-131,894$ & 189,420 & 200,587 & 211,754 \\
\hline $\begin{array}{l}\text { Flujos de Efectivo y Equivalente al Efectivo procedente de } \\
\text { (utilizados en) Actividades de Financiación }\end{array}$ & $-225,446$ & 96,038 & 159,849 & 170,007 \\
\hline $\begin{array}{l}\text { Aumento (Disminución) Neto de Efectivo y Equivalente al Efectivo, } \\
\text { antes de las Variaciones en las Tasas de Cambio }\end{array}$ & 14,163 & 396,506 & 403,519 & 415,952 \\
\hline Aumento (Disminución) Neto de Efectivo y Equivalente al Efectivo & 14,163 & 2,004 & 2,077 & 1,447 \\
\hline Efectivo y Equivalente al Efectivo al Inicio del Ejercicio & 40,983 & 55,146 & 57,150 & 59,227 \\
\hline Efectivo y Equivalente al Efectivo al Finalizar el Ejercicio & 55,146 & 59,227 & 59,227 & 60,674 \\
\hline
\end{tabular}

Elaboración propia.

Cabe resaltar que no se ha incluido el Estado de Cambios en el patrimonio pues es solo un resumen del movimiento de las cuentas que conforman la parte del patrimonio en el Estado de Situación Financiera

En síntesis, de las proyecciones podemos ver que no hay cambios sustanciales en las cuentas y más bien son un claro reflejo de lo que se espera a nivel macroeconómico y las expectativas que se tiene, de acuerdo con el análisis sobre las políticas, estrategias, y objetivos de Corporación Lindley S.A.

Supuestos de la Proyección.

- Crecimiento Ventas: Promedio de los 10 periodos históricos.

- Crecimiento de Activos: Promedio de los 3 periodos históricos y Análisis Vertical.

- Estructura de Costos: Promedio de los 3 periodos históricos y Análisis Vertical.

- Depreciación: Promedio de los 3 periodos históricos.

- Impuestos: Se mantienen de acuerdo al 2017.

- No hay pago de dividendos

- Las cuentas del patrimonio no cambian: No hay incrementos de Capital Social, reservas, evaluaciones de activos, entre otros, excepto el incremento anual de las utilidades retenidas. 
- Situación macroeconómica estable y continua en base a histórico.

\subsubsection{Proyección financiera con efecto IFRS 16 Arrendamientos}

Dado que la compañía aplicará NIIF 16 desde el 01 de enero del 2019, y considerando las proyecciones de estados financieros realizadas en el presente trabajo del 2018 al 2020, se ha incluido la aplicación y se ha analizado los efectos desde el año 2019 al 2020.

Los valores de arrendamiento operativo al 31 de diciembre del 2017 son alrededor de S/ 3,200 (miles de soles), pero para fines didácticos y con el objetivo de mostrar el efecto de su aplicación en los EEFF, se considerará el valor de S/ 23,000 (miles de soles). En base a los siguientes datos de la Tabla 4.51 se hallará el valor de arrendamiento operativo aplicable desde el 2019, se identificarán los nuevos asientos y valores que se incluirán como partidas en los EEFF para los periodos proyectados 2019 y 2020.

Tabla 0.51

Premisas de Arrendamiento Operativo

\begin{tabular}{|lr}
\hline Premisas: & \\
Renta mensual & 720,000 \\
\hline Plazo contrato & 3 años \\
\hline Tasa de descuento anual & $8.00 \%$ \\
\hline Tasa de descuento mensual & $0.64 \%$ \\
\hline Depreciación & Plazo del contrato \\
\hline
\end{tabular}

Elaboración Propia.

Se halla el valor presente de los pagos utilizando la tasa de descuento anual convertida a meses según la formula $\left[(1+\text { Tasa Descuento Anual })^{\wedge}(1 / 12\right.$ meses $\left.)\right]-1$, y tomando el valor de las rentas mensuales de 36 meses, se obtiene como resultante S/ 23,071,199 que posteriormente sera incluido en el Estado de situacion financiera en miles de soles.

Tabla 0.52

Evolución de Pasivo por arrendamiento 


\begin{tabular}{|c|c|c|c|c|c|}
\hline \multirow[b]{3}{*}{ CUOTAS } & \multirow[b]{3}{*}{ VNA } & \multicolumn{4}{|c|}{ PASIVO POR ARRENDAMIENTO } \\
\hline & & Capital & Amortización & Intereses & Pago \\
\hline & & \multicolumn{2}{|l|}{ 23,071,199 } & \multirow[b]{2}{*}{148,441} & \multirow[b]{2}{*}{720,000} \\
\hline 720,000 & & $22,499,639$ & 571,559 & & \\
\hline 720,000 & & $21,924,403$ & 575,237 & 144,763 & 720,000 \\
\hline 720,000 & & $21,345,465$ & 578,938 & 141,062 & 720,000 \\
\hline 720,000 & & $20,762,802$ & 582,663 & 137,337 & 720,000 \\
\hline 720,000 & & $20,176,391$ & 586,412 & 133,588 & 720,000 \\
\hline 720,000 & & $19,586,206$ & 590,184 & 129,816 & 720,000 \\
\hline 720,000 & & $18,992,225$ & 593,982 & 126,018 & 720,000 \\
\hline 720,000 & & $18,394,421$ & 597,803 & 122,197 & 720,000 \\
\hline 720,000 & & $17,792,771$ & 601,650 & 118,350 & 720,000 \\
\hline 720,000 & & $17,187,251$ & 605,521 & 114,479 & 720,000 \\
\hline 720,000 & & $16,577,834$ & 609,417 & 110,583 & 720,000 \\
\hline \multirow[t]{2}{*}{720,000} & & $15,964,496$ & 613,338 & 106,662 & 720,000 \\
\hline & & $231,203,904.78$ & $7,106,702.38$ & $1,533,297.62$ & $8,640,000.00$ \\
\hline 720,000 & & $15,347,212$ & 617,284 & 102,716 & 720,000 \\
\hline 720,000 & & $14,725,957$ & 621,256 & 98,744 & 720,000 \\
\hline 720,000 & & $14,100,704$ & 625,253 & 94,747 & 720,000 \\
\hline 720,000 & & $13,471,428$ & 629,276 & 90,724 & 720,000 \\
\hline 720,000 & & $12,838,104$ & 633,324 & 86,676 & 720,000 \\
\hline 720,000 & & $12,200,705$ & 637,399 & 82,601 & 720,000 \\
\hline 720,000 & & $11,559,204$ & 641,500 & 78,500 & 720,000 \\
\hline 720,000 & & $10,913,577$ & 645,628 & 74,372 & 720,000 \\
\hline 720,000 & & $10,263,795$ & 649,782 & 70,218 & 720,000 \\
\hline 720,000 & & $9,609,832$ & 653,962 & 66,038 & 720,000 \\
\hline 720,000 & & $8,951,662$ & 658,170 & 61,830 & 720,000 \\
\hline \multirow[t]{2}{*}{720,000} & & $8,289,258$ & 662,405 & 57,595 & 720,000 \\
\hline & & $142,271,438$ & $7,675,239$ & 964,761 & $8,640,000$ \\
\hline 720,000 & & $7,622,591$ & 666,667 & 53,333 & 720,000 \\
\hline 720,000 & & $6,951,635$ & 670,956 & 49,044 & 720,000 \\
\hline 720,000 & & $6,276,362$ & 675,273 & 44,727 & 720,000 \\
\hline 720,000 & & $5,596,744$ & 679,618 & 40,382 & 720,000 \\
\hline 720,000 & & $4,912,754$ & 683,990 & 36,010 & 720,000 \\
\hline 720,000 & & $4,224,363$ & 688,391 & 31,609 & 720,000 \\
\hline 720,000 & & $3,531,542$ & 692,820 & 27,180 & 720,000 \\
\hline 720,000 & & $2,834,264$ & 697,278 & 22,722 & 720,000 \\
\hline 720,000 & & $2,132,500$ & 701,764 & 18,236 & 720,000 \\
\hline 720,000 & & $1,426,221$ & 706,279 & 13,721 & 720,000 \\
\hline 720,000 & & 715,397 & 710,824 & 9,176 & 720,000 \\
\hline \multirow[t]{3}{*}{720,000} & & - & 715,397 & 4,603 & 720,000 \\
\hline & & $46,224,374$ & $8,289,258$ & 350,742 & $8,640,000$ \\
\hline & & $419,699,717$ & $23,071,199$ & $2,848,801$ & $25,920,000$ \\
\hline
\end{tabular}

Elaboración Propia. 
A continuación, se establecen los asientos respectivos a cada ejercicio del arrendamiento. Para el año 2019, periodo de inicio, se registrará como activo por derecho de uso, el valor de medición del pasivo por arrendamiento al valor presente de los pagos no cancelados a la fecha, debidamente descontados usando la tasa de interés implícita o de descuento, más cualquier pago adicional realizado antes o a partir de la fecha de comienzo, en este ejemplo, no hay pagos adicionales. Así mismo, se calcula el valor de la depreciación, en este caso tomando como vida útil el plazo del contrato, ya que no hay certeza de que se ejerza la opción de compra a la culminación del arrendamiento y se utilizará el método de depreciación de línea recta para fines prácticos.

De la misma manera, se registra como activo diferido por intereses el valor total de los intereses (de los 3 periodos), y disminuirá por los pagos que se realicen en cada ejercicio. Esta partida comprende los intereses relacionados al pasivo por arrendamiento que aún no ha sido devengado.

Respecto al pasivo por arrendamiento, se registra inicialmente el valor presente de los pagos futuros no cancelados a la fecha, debidamente descontada usando la tasa de interés implícita o de descuento y posteriormente se incrementará reflejando el interés por el pasivo por arrendamiento total, y disminuirá por los pagos de intereses que se realicen en el ejercicio y por los pagos de amortización del capital.

Tabla 0.53

Asiento Arrendamiento Año 2019

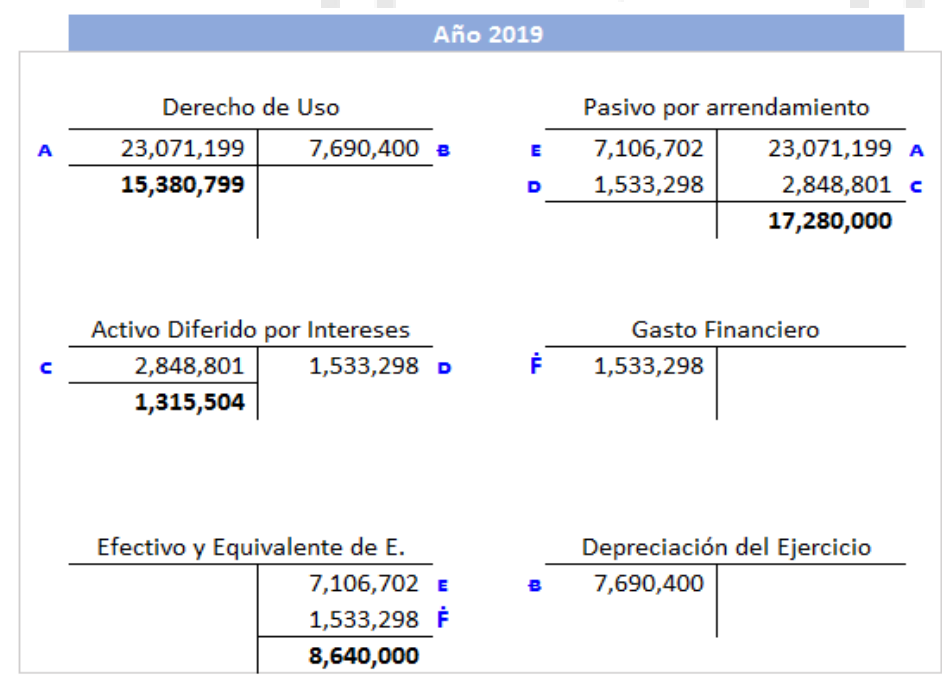

Elaboración Propia. 
De la misma manera, se realizarán los mismos registros para el año 2020, disminuirá el activo por derecho de uso, afectado por la depreciación acumulada, y el pasivo por arrendamiento disminuirá por los pagos que se realicen del interés y la amortización del capital, afectando los gastos financieros y rediciendo los activos diferidos por intereses.

Tabla 0.54

Asiento Arrendamiento Año 2020.

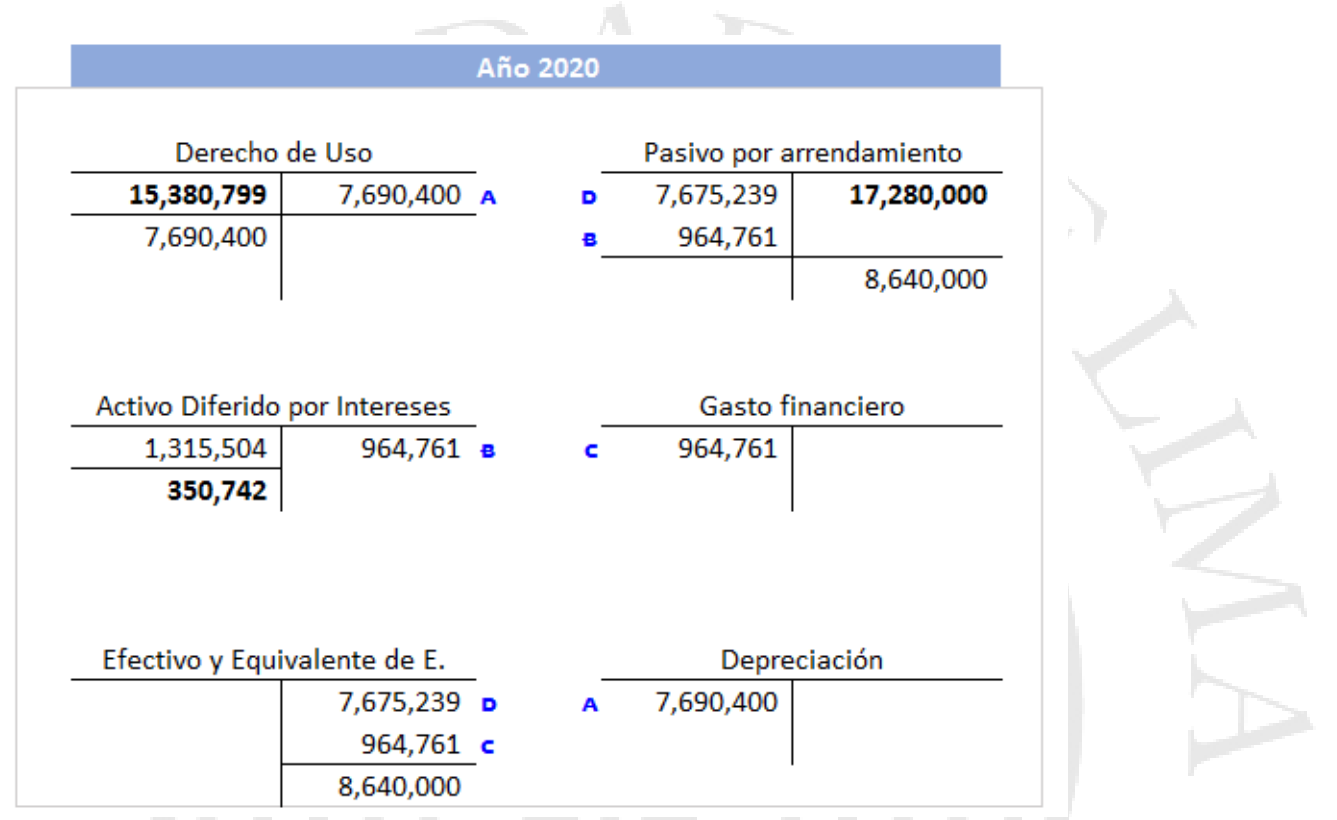

Elaboración Propia.

Finalmente, para el año 2021 (Ver Tabla 4.55), culmina la depreciación y el valor en libros por derecho de uso termina en cero; el pasivo por arrendamiento se cancela con los últimos importes de interés y amortización del capital; y los intereses diferidos terminan de devengarse. Cabe resaltar que los asientos del año 2021 no se incluirán en la comparativa de proyección, dado que el análisis solo es hasta el 2020. 
Tabla 0.55

Asiento Arrendamiento Año 2020.

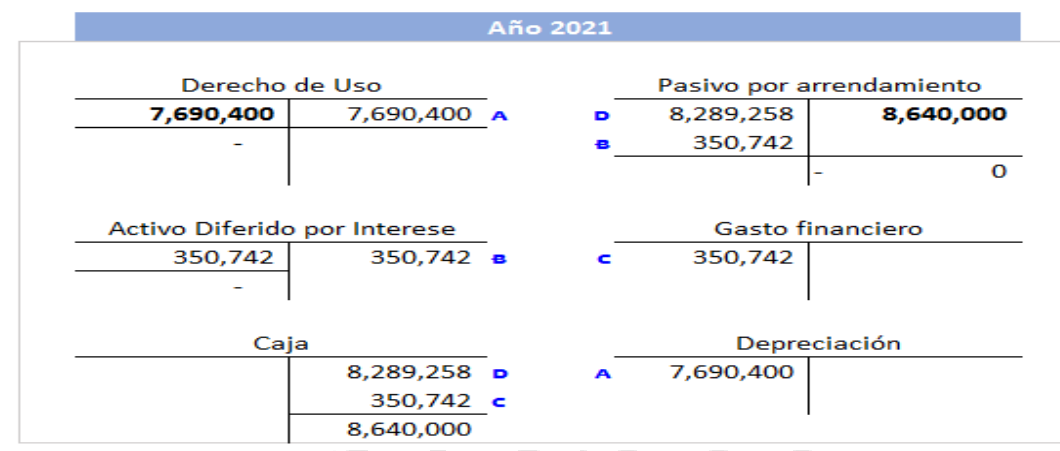

Elaboración Propia.

Se incorporan las partidas por el arredramiento operativo desde el ejercicio 2019, año en que la compañía aplicará la nueva NIIF. Los valores se encuentran presentados en miles de soles para fines comparativos y para el posterior análisis de los ratios financieros.

Tabla 0.56

Estado de Situación Financiera - Activos

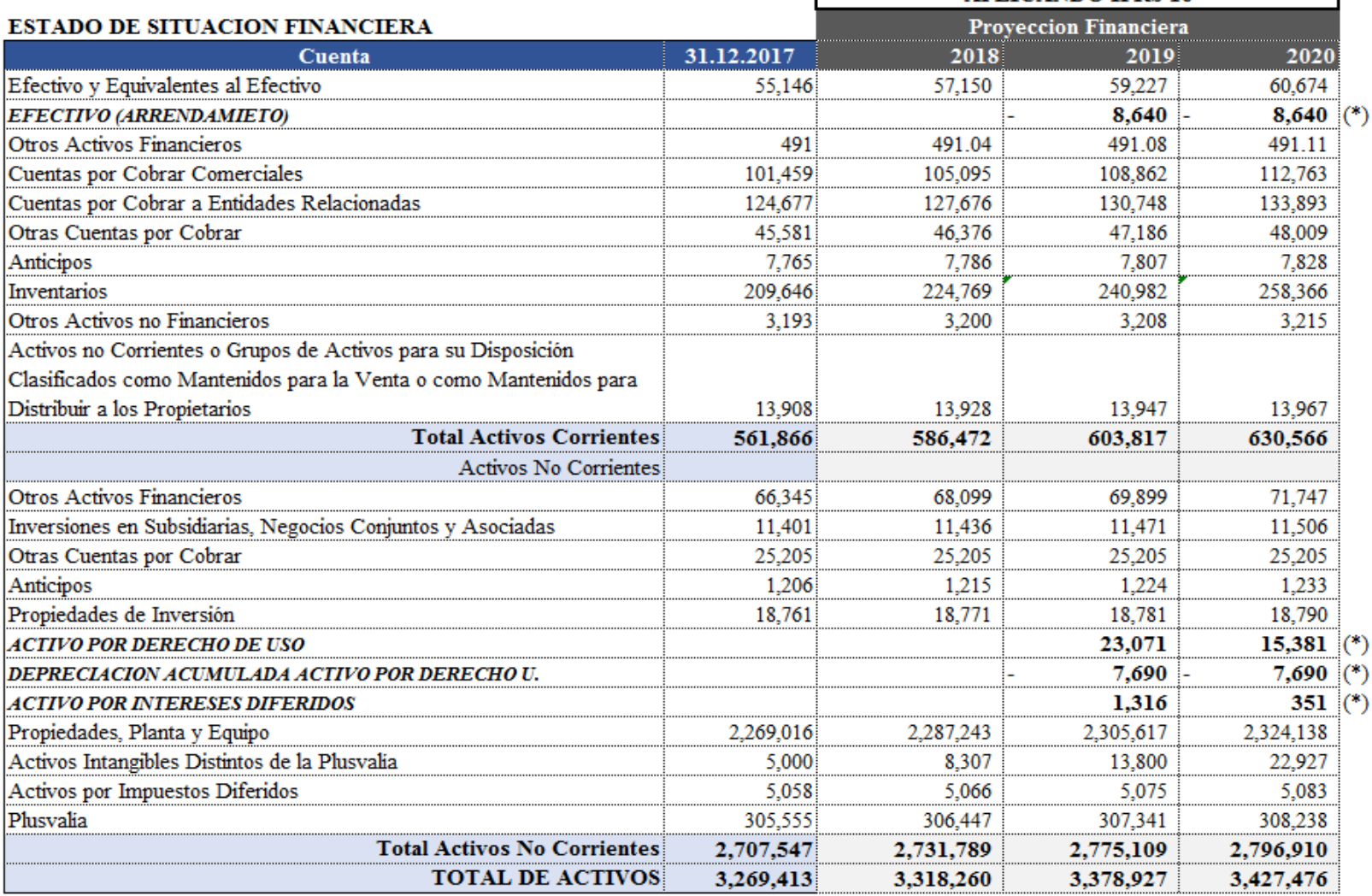

Elaboración Propia. 
Tabla 0.57

Estado de Resultados

\begin{tabular}{|c|c|c|c|c|}
\hline Cuenta & 31.12 .2017 & 2018 & 2019 & 2020 \\
\hline Otros Pasivos Financieros & 6,723 & 5,273 & 5,369 & 5,446 \\
\hline Cuentas por Pagar Comerciales & 474,749 & 518,710 & 528,194 & 535,783 \\
\hline Cuentas por Pagar a Entidades Relacionadas & 65,176 & 81,729 & 83,223 & 84,419 \\
\hline Otras Cuentas por Pagar & 80,599 & 93,657 & 95,370 & 96,740 \\
\hline Otras Provisiones & 27,160 & 25,136 & 25,595 & 25,963 \\
\hline Pasivos por Impuestos a las Ganancias & 27,753 & 28,168 & 28,683 & 29,095 \\
\hline Otros Pasivos no Financieros & 50,980 & 50,324 & 51,244 & 51,981 \\
\hline Total Pasivos Corrientes & 733,140 & 802,997 & 817,678 & 829,427 \\
\hline Otros Pasivos Financieros & $1,613,079$ & $1,521,148$ & $1,478,346$ & $1,447,275$ \\
\hline PASIVO POR ARRENDAMIENTO & & & 17,280 & 8,640 \\
\hline Otras Cuentas por Pagar & 17,569 & 12,469 & 12,697 & 12,880 \\
\hline Total Pasivos No Corrientes & $1,630,648$ & $1,533,617$ & $1,508,323$ & $1,468,794$ \\
\hline Total Pasivos & $2,363,788$ & $2,336,614$ & $2,326,001$ & $2,298,221$ \\
\hline Capital Emitido & 580,981 & 580,981 & 580,981 & 580,981 \\
\hline Acciones de Inversión & 71,523 & 71,523 & 71,523 & 71,523 \\
\hline Otras Reservas de Capital & 56,842 & 56,842 & 56,842 & 56,842 \\
\hline Resultados Acumulados & 257,644 & 333,665 & 404,944 & 481,274 \\
\hline Otras Reservas de Patrimonio & $-61,365$ & $-61,365$ & $-61,365$ & $-61,365$ \\
\hline Total Patrimonio & 905,625 & 981,646 & $1,052,925$ & $1,129,255$ \\
\hline TOTAL PASIVO Y PATRIMONIO & $3,269,413$ & $3,318,260$ & $3,378,927$ & $3,427,476$ \\
\hline
\end{tabular}

Elaboración Propia.

Tabla 0.58

Estado de Situación Financiera - Pasivos y Patrimonio

\begin{tabular}{|c|c|c|c|c|}
\hline ESTADO DE RESULTADOS & & Pro & yeccion Financier & \\
\hline Cuenta & 2017 & 2018 & 2019 & 2020 \\
\hline Ingresos de Actividades Ordinarias & $2,514,204$ & $2,635,105$ & $2,790,457$ & $2,945,810$ \\
\hline Costo de Ventas & $-1,590,719$ & $1,677,825$ & $1,776,741$ & $1,875,657$ \\
\hline Ganancia (Pérdida) Bruta & 923,485 & 957,280 & $1,013,717$ & $1,070,153$ \\
\hline Gastos de Ventas y Distribución & $-536,056$ & 567,053 & 600,484 & 633,914 \\
\hline Gastos de Administración & $-96,690$ & 110,482 & 116,996 & 123,509 \\
\hline Otros Ingresos Operativos & 116,035 & 178,201 & 188,707 & 199,213 \\
\hline Otros Gastos Operativos & $-46,163$ & 61,744 & 65,384 & 69,024 \\
\hline Ganancia (Pérdida) Operativa & 360,611 & 396,203 & 419,561 & 442,919 \\
\hline Ingresos Financieros & 2,976 & 11,081 & 11,735 & 12,388 \\
\hline Gastos Financieros & $-147,599$ & 189,420 & 200,587 & 211,754 \\
\hline GASTOS FINANCIEROS (ARRENDAMIENTO) & & & 1,533 & 965 \\
\hline DEPRECIACIÓN (ARRENDAMIENTO) & & & 7,690 & 7,690 \\
\hline Diferencias de Cambio Neto & 25,188 & 72,586 & 76,865 & 81,144 \\
\hline Ganancia (Pérdida) antes de Impuestos & 241,176 & 145,279 & 144,620 & 153,753 \\
\hline Ingreso (Gasto) por Impuesto & $-77,520$ & 69,258 & 73,341 & 77,424 \\
\hline Ganancia (Pérdida) Neta de Operaciones Continuadas & 163,656 & 76,021 & 71,279 & 76,330 \\
\hline Ganancia (Pérdida) Neta del Ejercicio & 163,656 & 76,021 & 71,279 & 76,330 \\
\hline
\end{tabular}

Elaboración Propia.

\subsubsection{Ratios financieros proyectados con NIIF 16 .}

Como se mencionó en el punto 4.1.6 Arrendamientos - Efectos de aplicación, los ratios financieros se ven afectados por las nuevas partidas que serán incluidas en el Estado de Situación Financiera y Estado de Resultados, debido a que estos indicadores, toman información de las partidas de los Estados Financieros. 
Los ratios de endeudamiento se ven incrementados por el incremento de las cuentas de pasivos por arrendamiento, así como el EBITDA aumenta por las nuevas partidas de gastos por depreciación. Cabe resaltar que los resultados del ejercicio también sufren una variación, sobre todo en los primeros años ya que hay un mayor por los gastos de intereses, que al transcurrir el plazo del contrato irán disminuyendo, que a diferencia de la Norma antecesora (NIC 17), los arrendamientos operativos se cargaban a gastos por los años que durara el contrato de manera lineal y sistemática.

Tabla 0.59

Ratios Financieros - Diferencias

\begin{tabular}{|c|c|c|c|}
\hline & & & \\
\hline & & \multicolumn{2}{|c|}{ APLICACIÓN DE IFRS 16} \\
\hline & & \multicolumn{2}{|c|}{ 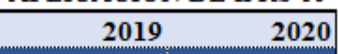 } \\
\hline Grado de Endeudamiento & Pasivo $\mathrm{T} /$ Activo $\mathrm{T}$ & 0.69 & 0.83 \\
\hline Razon Deuda Patrimonio & $\begin{array}{l}\text { Pasivo } \mathrm{T} / \\
\text { Patrimonio } \mathrm{T}\end{array}$ & 2.21 & 2.04 \\
\hline Deuda Largo Plazo - Patrimonio & $\begin{array}{l}\text { Pasivo NC } \\
\text { Patrimonio }\end{array}$ & 1.43 & 1.30 \\
\hline \multirow[t]{2}{*}{ Cobertura de Intereses } & EBIT / Gastos Finan & 2.08 & 2.08 \\
\hline & gasto financiero & 202,120 & 212,719 \\
\hline \multirow[t]{2}{*}{ Multiplicador del capital Contable } & $\begin{array}{l}\text { Activo T / } \\
\text { Patrimonio }\end{array}$ & 3.21 & 3.04 \\
\hline & & \multirow[t]{2}{*}{2019} & 2020 \\
\hline \multicolumn{3}{|l|}{ Ratios de Rentabilidad } & \\
\hline Rendimiento sobre los Activos (ROA) & Utilidad / Activos & $2.11 \%$ & $2.23 \%$ \\
\hline \multirow[t]{2}{*}{ Rendimiento sobre el Patrimonio (ROE) } & Utilidad / Patrimonio & $6.77 \%$ & $6.76 \%$ \\
\hline & & 2019 & 2020 \\
\hline \multicolumn{4}{|l|}{ Otros Indicadores } \\
\hline EBIT & & 419,561 & 442,919 \\
\hline EBITDA & $\begin{array}{l}\text { EBIT }+ \text { DEPREC }+A \\
\text { MORT }\end{array}$ & 619,937 & 644,843 \\
\hline Rentabiliad EBITDA PATRIMONIO & EBITDA/Patrimonio & 0.6 & 0.6 \\
\hline Deuda & & $2,326,001$ & $2,298,221$ \\
\hline Patrimonio & & $1,052,925$ & $1,129,255$ \\
\hline Deuda + Patrimonio & & $3,378,927$ & $3,427,476$ \\
\hline DEUDA/EBITDA & & 3.8 & 3.6 \\
\hline
\end{tabular}

\begin{tabular}{|r|r|}
\hline \multicolumn{2}{|c|}{ SIN IFRS } \\
\hline \multicolumn{2}{|c|}{$\mathbf{2 0 1 9}$} \\
\hline 0.68 & $\mathbf{2 0 2 0}$ \\
\hline 2.17 & 0.67 \\
\hline 1.41 & 1.99 \\
\hline 2.09 & 1.27 \\
\hline 200.587 & 2.09 \\
\hline 3.17 & 211.754 \\
\hline & 2.99 \\
\hline
\end{tabular}

\begin{tabular}{|r|r|}
\hline $\mathbf{2 0 1 9}$ & $\mathbf{2 0 2 0}$ \\
\hline & \\
\hline $2.39 \%$ & $2.48 \%$ \\
\hline $7.58 \%$ & $7.41 \%$ \\
\hline
\end{tabular}

\begin{tabular}{|r|r|}
\hline $\mathbf{2 0 1 9}$ & $\mathbf{2 0 2 0}$ \\
\hline & \\
\hline 419,561 & 442,919 \\
\hline & \\
612,246 & 637,152 \\
\hdashline 0.6 & 0.6 \\
\hdashline $2,308,721$ & $2,280,941$ \\
\hdashline $1,062,149$ & $1,147,134$ \\
\hdashline $3,370,870$ & $3,428,075$ \\
\hline 3.8 & 3.6 \\
\hline
\end{tabular}

Elaboración Propia.

\subsubsection{Aplicación de NIIF 15 Ingreso de Actividades Ordinarias procedentes de contratos con clientes.}

No se ha considerado la aplicación de la NIIF 15 dentro del análisis de este trabajo y las proyecciones ya que no afecta de manera significativa los Estados Financieros de la compañía, tomando como análisis los 5 pasos para identificar las obligaciones de desempeño y principales cambios respecto a la NIC 18. Cabe resaltar que según el informe auditado de Pricewaterhouse Coopers (PWC), indican que "la compañía ha 
efectuado un análisis cualitativo de los impactos de la NIIF 15, como resultado de esta evaluación la Compañía no ha identificado un impacto significativo producto de la adopción de esta norma" (PWC, 2018, p.12).

En este sentido, la base de la NIIF 15 es el reconocimiento de los ingresos a la compañía cuando se haya efectuado la transferencia de los bienes y servicios pactados con el cliente a cambio de una retribución monetaria.

Los 5 pasos que refiere la nueva norma son:

1) Identificar el contrato con el cliente

2) Identificar las obligaciones de desempeño

3) Determinar el precio de transacción

4) Distribuir el precio de transacción a las obligaciones de desempeño

5) Reconocer el ingreso cuando se satisfagan las obligaciones de desempeño

Para el caso de Corporación Lindley, la principal obligación de desempeño es la entrega de las bebidas no alcohólicas, así mismo, los contratos con clientes que tiene la compañía se clasifican por el canal moderno (comercio venta al detalle) y el canal tradicional (a distribuidores).

A) Canal Moderno:

Se ubican las empresas que tienen venta al mayoreo, es decir, empresas de comercialización masiva y las ventas son directas al cliente.

Los contratos con los clientes son en su mayoría autoservicios, instituciones, supermercados, etc., donde la única obligación de desempeño de Lindley hacia ellos es la entrega de las bebidas a cambio de una contraprestación mensual. Así mismo, el precio de la transacción es el valor de las bebidas y descuentos comerciales por compras por volumen o periodos del año. La Compañía reconoce el ingreso cuando la obligación de desempeño se satisface.

B) Canal Tradicional:

Son las empresas distribuidoras de mercadería que llevan las bebidas a bodegas y demás puntos de venta. Existen contratos con empresas distribuidoras en los cuales, al igual que el canal moderno, la única obligación de desempeño es la entrega de bebidas no alcohólicas a cambio de una contraprestación mensual. El precio de la transacción es el valor de las bebidas menos bonificaciones por 
cumplimiento de entrega. Así mismo, se reconoce el ingreso cuando los riesgos y beneficios se trasladan al cliente final.

Para ambos canales, no hay efectos por cambio en el registro debido a la única obligación de desempeño es la entrega del bien y el reconocimiento es en base al devengado. En consecuencia, no hay un cambio en la política contable que tiene la Corporación.

\subsubsection{Aplicación de NIIF 9 Instrumentos Financieros.}

Los principales cambios que presenta esta nueva norma están relacionados a la clasificación y medición de los activos financieros dependiendo del modelo de negocio de la compañía para administrar sus activos financieros los cuales pueden medirse al costo amortizado o valor razonable según las características del instrumento de deuda; y las características de los flujos de efectivo contractuales del activo financiero.

Por otro lado, la NIIF 9 establece nuevos parámetros para la contabilidad de coberturas que asocia el tratamiento contable a las prácticas de gestión de riesgos de la entidad y cambios en el reconocimiento de pérdidas por deterioro de activos financieros, que será basada en la denominada pérdida crediticia esperada, la cual es el promedio ponderado de las perdidas crediticias y sus respectivos riesgos de incumplimiento (IASB, 2014)

No se ha considerado la aplicación de la NIIF 9 en el presente trabajo, puesto que no se ha podido obtener información necesaria para cuantificar los efectos, además de que la compañía todavía sigue evaluando los impactos de la aplicación. Así mismo, mediante el informe auditado de Pricewaterhouse Coopers (PWC) comunican que 'De forma preliminar, no se espera un impacto en los aspectos de clasificación y medición de los activos financieros ni de la contabilidad de cobertura" (PWC 2018, p. 12). Sin embargo, el principal riesgo que tiene la compañía es respecto a la provisión por deterioro de activos financieros, específicamente en sus cuentas por cobrar comerciales a clientes, con los cuales se reconocerá en base a la Perdida Crediticia Esperada usando el enfoque simplificado que es el apropiado para las cuentas por cobrar, activos de contratos y cuentas por cobrar con arrendamientos. 


\section{CAPITULO V: CONCLUSIONES Y RECOMENDACIONES}

\subsection{Conclusiones.}

a) La compañía ha estado en un estado de inversión y expansión en los últimos 3 años debido a la fusión de la misma con la compañía mexicana Arca Continental SAB, en donde unieron recursos económicos, materiales y tecnológicos con el objetivo de ampliar e incrementar las ventas en regiones aun no desarrolladas como provincias y demás regiones del Perú. En consecuencia, ha necesitado financiarse para poder obtener fondos para las adquisiciones de diferentes edificaciones, instalaciones, maquinaria y vehículos de distribución entre otros. Actualmente, Corporación Lindley sigue evaluando inversiones para los siguientes años para explotar el consumo en provincias donde aún no cuenta con penetración de mercado, sin embargo, por el momento se está cancelando las obligaciones financieras incurridas con el objetivo de desapalancarse y reducir el endeudamiento.

b) Las ventas de la compañía van en sentido creciente bajo los Estados de Resultados Recuperados de la SMV por los últimos 10 años. A pesar de los diferentes cambios macroeconómicos en el país, crisis económicas externas, cambios de gobierno, alza de precios, IGV o ISC, la demanda y venta de bebidas no alcohólicas se ha logrado incrementar años a año. Además, se espera una proyección en ventas de $4.81 \%$, 5.90\%, 5.57\% para los años 2018, 2019 y 2020, según el análisis de regresión lineal considerando un panorama macroeconómico del país estable y sin cambios críticos que puedan afectar de manera significativa la economía del país. Así mismo, parte de los incrementos de las ventas anuales se debe también al mejoramiento de la capacidad instalada y nuevas tecnologías que permiten producir, abastecer y satisfacer el incremento de la demanda.

c) Hay una buena gestión de costo y gastos, considerando una mejora en el margen operativo o Ebit de los últimos tres años. Por el lado de los costos de venta, la compañía se ve expuesta a los precios del azúcar y el precio de los envases PET, que son principales en la producción, por lo que ha firmado contratos de swap para el aseguramiento de los precios del commodity y mitigar los riesgos de volatilidad debido a que se compran grandes cantidades de azúcar en toneladas y podría afectar directamente los costos. Así mismo, el precio de los envases retornables y no 
retornables de las botellas PET, se encuentran afectadas por las variaciones del precio del petróleo en el mercado internacional pero no afecta de manera significativa el mercado peruano por lo que los precios de estos envases no se encuentran coberturados.

d) La compañía cuenta con una cartera de productos bastante diversificada, lo cual protege a la empresa de verse afectada por diferentes cambios en el consumo a causa de nuevas modas o tendencias saludables, alza de impuestos como el Impuesto Selectivo al Consumo, y otras situaciones que repercutan y afecten la demanda de bebidas no alcohólicas.

e) Los indicadores financieros muestran altas cifras de endeudamiento que son en parte utilizadas en la adquisición de Propiedad, Planta y Equipo como también en cancelaciones de obligaciones. Cabe resaltar que Corporación Lindley ahora se encuentra respaldada financieramente por la compañía matriz ubicada en México, lo cual también ayuda a mejorar su calificación crediticia. Así mismo, los ratios indican eficiencia en gestión de activos como las rotaciones de inventario y las cobranzas a clientes, que permiten obtener liquidez en menor tiempo.

f) Las nuevas modificaciones en el reconocimiento implementadas por las NIIF 16 arrendamientos, afectan principalmente a la contabilidad de los arrendatarios, debido a que integra dentro del Estado de Situación Financiera los activos y los pasivos correspondientes a los mismos, tratando los arrendamientos financieros y operativos de igual manera, salvo los arrendamientos menores a un año o de bajo valor. Así mismo, también se ven modificados los que bajo por NIC 17 se reconocían como gastos operativos provenientes de los gastos lineales, ahora firmaran parte de los gastos por depreciación y gastos financieros de intereses pagados.

g) La NIIF 16 modificará los ratios o indicadores financieros, como un incremento en el valor del EBITDA, dado que ya no se considerarán entro de los pagos operativos las amortizaciones y los intereses. Así también, otros indicadores financieros que tomen como base los activos o pasivos, se verán afectados por el incremento de los mismos. 


\subsection{Recomendaciones.}

a) Se recomienda una estructura de capital de $60 \%$ deuda y $30 \%$ capital considerando las políticas de inversión y financiamiento que tiene la compañía, para que no aumente el riesgo de sobreendeudamiento.

b) Es recomendable no contraer nuevas obligaciones financieras hasta que exista un incremento significativo en las ventas, pues es la fuente de donde proviene la capacidad de pago de la compañía, y en el último año (2017) solo se obtuvo un crecimiento del $0.61 \%$ respecto al año anterior.

c) El interior del país aún no se encuentra tan explotado como el mercado de la capital, se recomendaría, penetrar más en las regiones y provincias del Perú, dado que en la región Lima, la compañía cubre el 99\% de las bodegas.

d) Mejorar la respuesta de la compañía ante desastres naturales como el Fenómeno del Niño para que no se vean afectadas las ventas, pues es un riesgo latente que año a año afecta el norte del Perú.

e) Mejorar e incrementar las campañas publicitarias, así como descuentos y/o promociones en las bebidas no gasificadas como aguas de bebida, jugos, tés e isotónicos o rehidratantes, debido al incremento del ISC y nuevas tendencias alimenticias saludables que pueden afectar el consumo de bebidas gaseosas. 


\section{REFERENCIAS}

AC Lindley. (2015). EEFF individuales anuales al 31 de Diciembre del 2014. Retrieved from SMV: https://bit.ly/2TOabvm

AC Lindley. (2015, Marzo 31). Memoria Anual 2014 Corporación Lindley S.A. Retrieved Octubre 02, 2018, from SMV: https://bit.ly/2TxA57t

AC Lindley. (2016). EEFF individuales anuales al 31 de Diciembre del 2015. Retrieved from SMV: https://bit.ly/2NYFRZU

AC Lindley. (2017). EEFF individuales anuales al 31 de Diciembre del 2016. Retrieved from SMV: https://bit.ly/2r9sry1

AC Lindley. (2018). EEFF individuales anuales al 31 de Diciembre del 2017. Retrieved from SMV: https://bit.ly/2CjtD9o

AC Lindley. (2018, Marzo 19). Memoria Anual 2017 Corporación Lindley S.A. Retrieved from SMV: http://www.smv.gob.pe/Bp_Memorias?op=bq12

Arellano Marketing. (S. F.). Cuando cambia el sabor. Retrieved Noviembre 15, 2018, from https://bit.ly/2ETlAR9

BCRP. (S.F.). Actividad Productiva y Empleo. Retrieved Octubre 10, 2018, from https://bit.ly/2SgrstK.

Comisión para el Mercado Financiero. (S.F.). Clasificadoras de Riesgo. Retrieved from http://www.svs.cl/educa/600/w3-propertyvalue-1598.html

El Comercio. (2018, Mayo 11). Ránking de las bebidas no alcohólicas más vendidas en el Perú. Retrieved Noviembre 09, 2018, from https://bit.ly/2VNK0Cu

FMCG \& RETAIL. (2010, Octubre 05). El 49\% de los peruanos sigue dietas bajas en grasa, ubicándose en el segundo lugar de latinoamérica. Retrieved from https://bit.ly/2PBPZaM

IASB. (2014, Julio). Norma Internacional de Informacion Financiera $N^{o} 9$ Instrumentos Financieros . Retrieved from https://bit.ly/2IJF2EQ.

IASB. (2016, Enero). Norma Internacional de Informacion Financiera $N^{o} 16$ Arrendamientos. Retrieved from https://bit.ly/2OQ7UOZ 
IASC. (1993). Norma Internacional de Contabilidad $N^{o} 8$ Políticas contables, cambios en las estimaciones contables y errores. Retrieved from MEF: https://bit.ly/2Uynr4s

IASC. (2006, Enero). Norma Internacional de Contabilidad No 17 Arrendamientos. Retrieved from https://bit.ly/2MJHCc8

MEF. (2018, Mayo 10). Se modifica el ISC de productos que más afectan a la salud y el ambiente. Retrieved Noviembre 15, 2018, from https://bit.ly/2IgRoQI

Peru-Retail. (18 de Setiembre de 2015). ¿Cuáles son los planes de Corporación Lindley luego de la alianza con Arca Continental? Recuperado el 20 de Noviembre de 2018, de https://bit.ly/2P32qj4

PWC. (2018). Dictamen de los auditores independientes 2017. Retrieved from SMV: https://bit.ly/2HuyyYL

SMV. (2015, Marzo 31). Memoria Anual 2014 Corporación Lindley S.A. Retrieved from https://bit.ly/2TxA57t

Torres, F. (16 de Diciembre de 2015). Pronóstico a través de una Regresión Lineal. Obtenido de https://bit.ly/2GiOlbv 


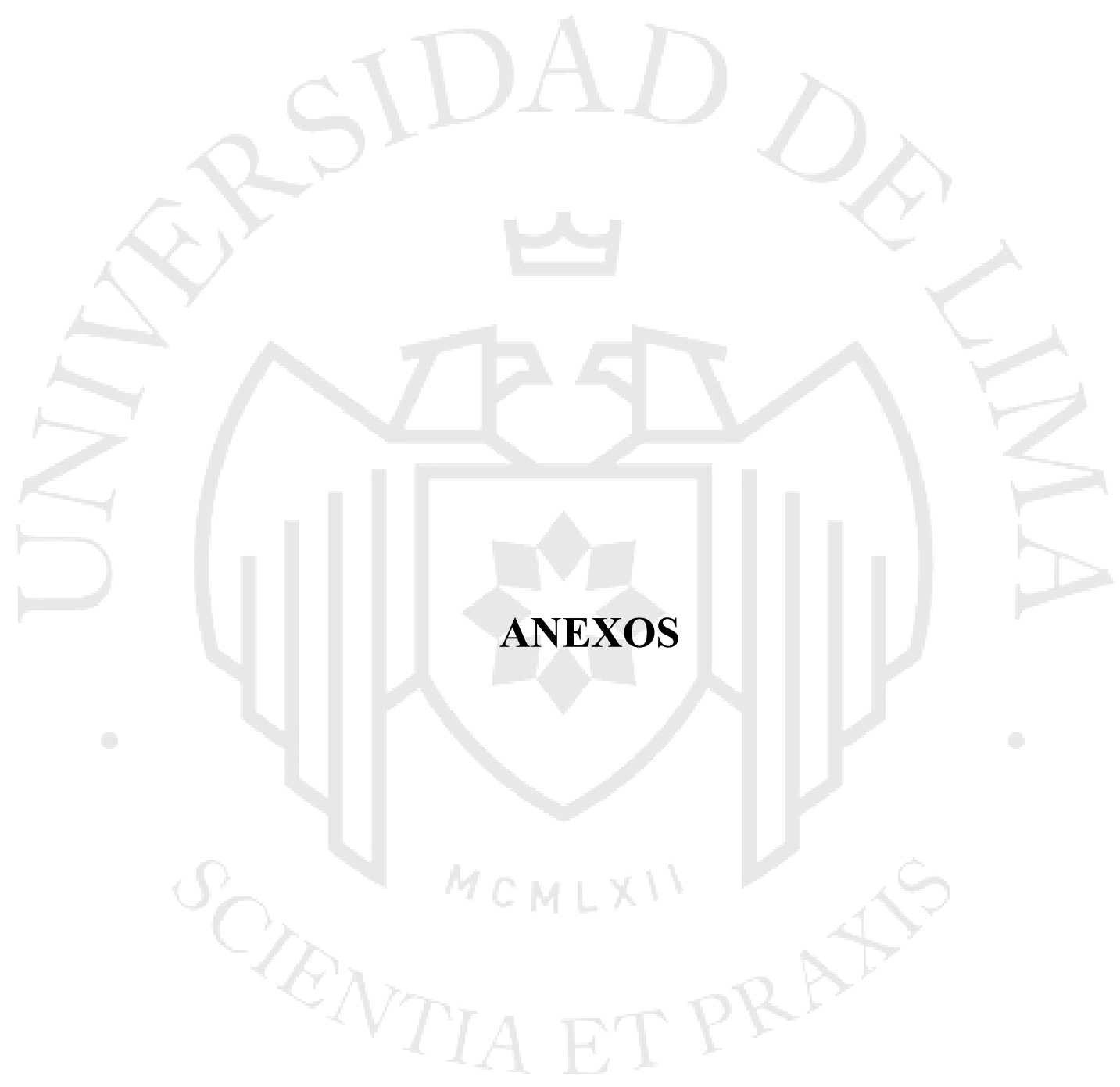




\section{Anexo 1: Indicadores Financieros}

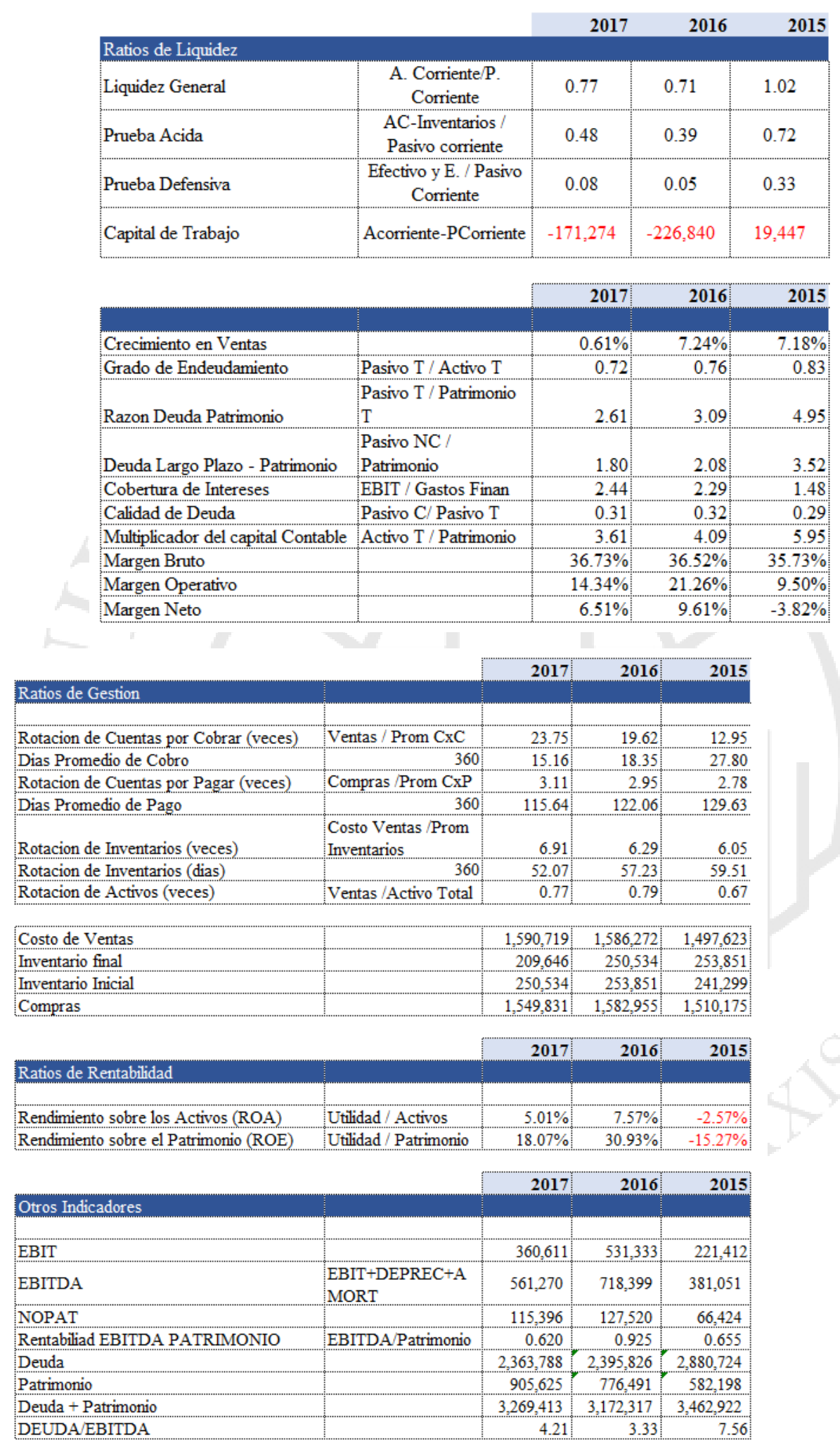

Fuente: AC Lindley (2018, 2017, 2016).

Elaboración propia. 


\section{Anexo 2: Análisis vertical y horizontal de activos}

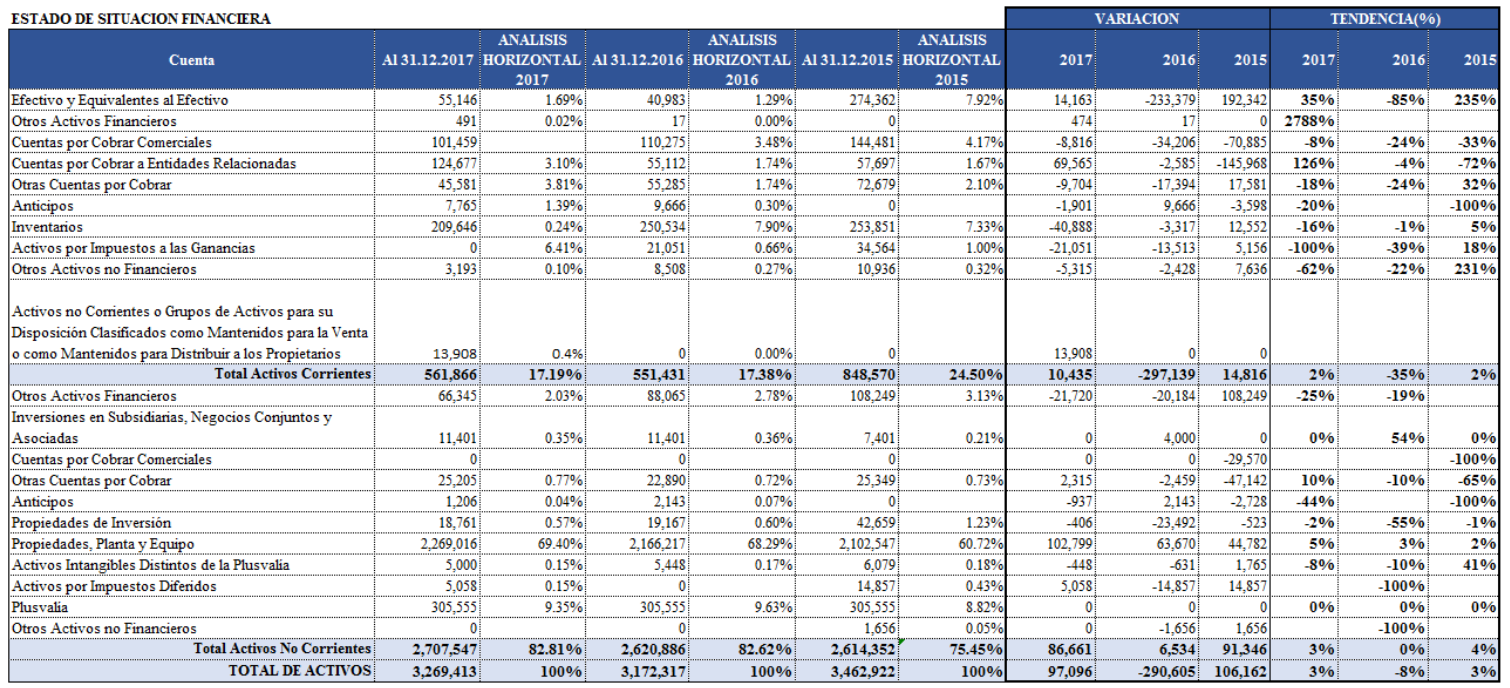

Fuente: AC Lindley (2018, 2017, 2016)

Elaboración propia. 


\section{Anexo 3: Análisis vertical y horizontal pasivos y patrimonio}

\begin{tabular}{|c|c|c|c|c|c|c|c|c|c|c|c|c|}
\hline ESTADO DE SITUACIONFI & & & & & & & & ACION & & & ENCLA(\%) & \\
\hline Cuenta & Al 31.12.2017 & $\begin{array}{c}\text { ANALISIS } \\
\text { HORIZONTAL } \\
2017\end{array}$ & Al 31.12.2016 & $\begin{array}{c}\text { ANAUISIS } \\
\text { HORIZONIAL } \\
2016\end{array}$ & Al 31.12.2015 & $\begin{array}{c}\text { ANALISIS } \\
\text { HORIZONIAL } \\
2015\end{array}$ & 2017 & 2016 & 2015 & 2017 & 2016 & 2015 \\
\hline Otros Pasivos Financieros & 6,723 & $0.21 \%$ & 4,342 & $0.14 \%$ & 4,647] & $0.13 \%$ & 2,381 & -305 & $.75,381$ & $55 \%$ & $.7 \%$ & $-94 \%$ \\
\hline Cuentas por Pagar Comerciales & 474,749 & $14.52 \%$ & 520,909 & $16.42 \%$ & 552,496] & $15.95 \%$ & $-46,160$ & $-31,587$ & 17,418 & $-9 \%$ & $-6 \%$ & $3 \%$ \\
\hline Cuentas por Pagar a Entidades Relacionadas & 65,176] & $1.99 \%$ & 96,732 & $3.05 \%$ & 81,250 & $2.35 \%$ & $-31,556$ & 15,482 & $-42,661$ & $-33 \%$ & $19 \%$ & $-34 \%$ \\
\hline Otras Cuentas por Pagar & 80,599 & $2.47 \%$ & 84,214 & $2.65 \%$ & 115,923 & $3.35 \%$ & $-3,615$ & $-31,709$ & 12,769 & $-4 \%$ & $-27 \%$ & $12 \%$ \\
\hline \begin{tabular}{|l} 
Otras Provisiones \\
\end{tabular} & 27,160 & $0.83 \%$ & 25,462 & $0.80 \%$ & 22,132 & $0.64 \%$ & 1,698 & 3,330 & $-1,005$ & $7 \%$ & $15 \%$ & $-4 \%$ \\
\hline Pasivos por Impuestos a las Ganancias & 27,753 & $0.85 \%$ & 0 & & o] & & 27,753 & 0 & $-11,500$ & & & $-100 \%$ \\
\hline Otros Pasivos no Financieros & 50,980 & $1.56 \%$ & 46,612 & $1.47 \%$ & 52,675 & $1.52 \%$ & 4,368 & $-6,063$ & 52,675 & $9 \%$ & $-12 \%$ & \\
\hline Total Pasiros Corrientes & 733,140 & $22.42 \%$ & 778,271 & $24.53 \%$ & 829,123 & $23.94 \%$ & $-45,131$ & $-50,852$ & $-47,685$ & $-6 \%$ & $-6 \%$ & $-5 \%$ \\
\hline Otros Pasivos Financieros & $1,613,079$ & $49.34 \%$ & $1,602,321$ & $50.51 \%$ & $1,975,097]$ & $57.04 \%$ & 10,758 & $-372,776$ & 235,897 & $1 \%$ & $-19 \%$ & $14 \%$ \\
\hline Cuentas por Pagar Comerciales & 0 & & 0 & & 607 & $0.02 \%$ & 0 & -607 & 607 & & $-100 \%$ & \\
\hline Cuentas por Pagar a Entidades Relacionadas & 0 & & 0 & & 69,401 & $2.00 \%$ & 0 & $-69,401$ & 52,339 & & $-100 \%$ & $307 \%$ \\
\hline Otras Cuentas por Pagar & 17,569 & $0.54 \%$ & 12,764 & $0.40 \%$ & 6,496 & $0.19 \%$ & 4,805 & 6,268 & $-70,914$ & $38 \%$ & $96 \%$ & $-92 \%$ \\
\hline Pasivos por Impuestos Diferidos & o] & & 2,470 & $0.08 \%$ & o] & & $-2,470$ & 2,470 & $-11,600$ & $-100 \%$ & & $-100 \%$ \\
\hline Total Pasivos No Corrientes & $1,630,648$ & $49.88 \%$ & $1,617,555$ & $50.99 \%$ & $2,051,601$ & $59.24 \%$ & 13,093 & $-434,046$ & 206,329 & $1 \%$ & $-21 \%$ & $11 \%$ \\
\hline Total Pasiros & $2,363,788$ & $72.30 \%$ & $2,395,826$ & $75.52 \%$ & $2,880,724$ & $83.19 \%$ & $-32,038$ & $-484,898$ & 158,644 & $-1 \%$ & $-17 \%$ & $6 \%$ \\
\hline Capital Emitido & 580,981 & $17.77 \%$ & 580,981 & $18.31 \%$ & 580,981 & $16.78 \%$ & o & 0 & 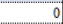 & $0 \%$ & $0 \%$ & $0 \%$ \\
\hline Acciones de Inversión & 71,523 & $2.19 \%$ & 71,523 & $2.25 \%$ & 71,523 & $2.07 \%$ & $0_{0}$ & 0 & 0 & $0 \%$ & $0 \%$ & $0 \%$ \\
\hline Otras Reservas de Capital & 56,842 & $1.74 \%$ & 40,187 & $1.27 \%$ & 16,168 & $0.47 \%$ & 16,655 & 24,019 & 0 & $41 \%$ & $149 \%$ & $0 \%$ \\
\hline Resultados Acumulados & 257,644 & $7.88 \%$ & 110,353 & $3.48 \%$ & $-105,824$ & $-3.06 \%$ & 147,291 & 216,177 & $-88,909$ & $133 \%$ & $-204 \%$ & $526 \%$ \\
\hline Otras Reservas de Patrimonio & $-61,365$ & $-1.88 \%$ & $-26,553$ & $-0.54 \%$ & 19,350 & $0.56 \%$ & $-34,812$ & $-45,903$ & 36,427 & $131 \%$ & $-237 \%$ & $-213 \%$ \\
\hline Total Pa & 905,625 & $27.70 \%$ & 776,491 & $24.48 \%$ & 582,198 & $16.81 \%$ & 129,134 & 194,293 & $-52,482$ & $17 \%$ & $33 \%$ & $-8 \%$ \\
\hline TOTAL PASIVO Y PATRIMONIO & $3,269,413$ & $100 \%$ & $3,172,317$ & $100 \%$ & $3,462,922$ & $100 \%$ & 97,096 & $-290,605$ & 106,162 & $3 \%$ & $-8 \%$ & $3 \%$ \\
\hline
\end{tabular}

Fuente: AC Lindley (2018, 2017, 2016)

Elaboración propia. 


\section{Anexo 4: Análisis vertical y horizontal de estado de resultados}

\begin{tabular}{|c|c|c|c|c|c|c|c|c|c|c|c|c|}
\hline \multirow{2}{*}{\multicolumn{7}{|c|}{ ADO DE R }} & \multicolumn{6}{|c|}{ ANALISIS HORIZONTAL } \\
\hline & & & & & & & & IACION & & & ENCIA $(\%$ & \\
\hline Cuenta & Al 31.12.2017 & $\begin{array}{c}\text { ANALISIS } \\
\text { VERTICAL } \\
2017\end{array}$ & Al 31.12.2016 & $\begin{array}{c}\text { ANALISIS } \\
\text { VERTICAL } \\
2016\end{array}$ & Al 31.12.2015 & $\begin{array}{c}\text { ANALISIS } \\
\text { VERTICAL } \\
2015\end{array}$ & 2017 & 2016 & 2015 & 2017 & 2016 & 20 \\
\hline Ingresos de Actividades Ordinarias & $2,514,204$ & $100 \%$ & $2,499,003$ & $100 \%$ & $2,330,184$ & $100 \%$ & 15,201 & 168,819 & 156,100 & $1 \%$ & $7 \%$ & \\
\hline Costo de Ventas & $-1,590,719$ & $63.27 \%$ & $-1,586,272$ & $63.48 \%$ & $-1,497,623$ & $64.27 \%$ & $-4,447$ & $-88,649$ & $-47,796$ & $0 \%$ & $6 \%$ & $3 \%$ \\
\hline Ganancia (Pérdida) Bruta & 923,485 & $36.73 \%$ & & $36.52 \%$ & & $35.73 \%$ & 10,754 & 80,170 & 108,304 & $1 \%$ & $10 \%$ & $\%$ \\
\hline Gastos de Ventas y Distribución & $-536,056$ & $21.32 \%$ & $-532,279$ & $21.30 \%$ & $-511,168$ & $21.94 \%$ & $-3,777$ & $-21,111$ & $-91,700$ & $1 \%$ & $4 \%$ & $22 \%$ \\
\hline Gastos de Administración & $-96,690$ & $3.85 \% \mathrm{~m}$ & $-101,135$ & $4.05 \%$ & $-109,177 \mid$ & $4.69 \%$ & 4,445 & 8,042 & $-6,110$ & $-4 \%$ & $-7 \%$ & \\
\hline Otros Ingresos Operativos & 116,035 & $4.62 \%$ ! & 295,779 & $11.84 \%$ : & 89,402 & $3.84 \%$ & $-179,744$ & 206,377 & $-109,191$ & $-61 \%$ & $231 \%$ & $-55 \%$ \\
\hline Otros Gastos Operativos & $-46,163$ & $1.84 \%$ & $-43,763$ & $1.75 \%$ & $-80,206$ & $3.44 \%$ & $-2,400$ & 36,443 & 151,236 & $5.48 \%$ & $-45 \%$ & $\%$ \\
\hline Ganancia (Pérdida) Operativa & 360,611 & $14.34 \%$ & 531,333 & $21.26 \%$ & 221,412 & $9.50 \%$ & $-170,722$ & 309,921 & 52,539 & $-32 \%$ & $140 \%$ & $31 \%$ \\
\hline Ingresos Financieros & 2,976 & $0.12 \%$ & 2,360 & $-0.09 \%$ & $28,840:$ & $1.24 \%$ & 616 & $-26,480$ & 25,724 & $26 \%$ & $-92 \%$ & $826 \%$ \\
\hline Ingresos por Intereses calculados usando el Metodo de & 0 & & 0 & & 0 & & 0 & 0 & 02427 & & & \\
\hline $\begin{array}{l}\text { Ginteres strecturo } \\
\text { Gastos Financieros }\end{array}$ & -147,599: & $5.87 \%$ & $-232,265$ & $9.29 \%$ & 9,133 & $6.40 \%$ & 84,666 & $-83,132$ & $-45,817$ & $-36 \%$ & $56 \%$ & \\
\hline Diferencias de Cambio Neto & 25,188 & $1.00 \%$ & 15,504 & $0.62 \%$ & $-230,360$ & $-9.89 \%$ & 9,684 & 245,864 & $-230,360$ & $62 \%$ & $-107 \%$ & \\
\hline Ganancia (Pérdida) antes de Impuestos & 241,176 & $9.59 \%$ & 316,932 & $12.68 \%$ & $-129,241$ & $-5.55 \%$ & $-75,756$ & 446,173 & $-107,487$ & $-24 \%$ & $-345 \%$ & $494 \%$ \\
\hline Ingreso (Gasto) por Impuesto & $-77,520$ & $3.08 \%$ & $-76,736$ & $3.07 \%$ & & $1.73 \%$ & -784 & $-117,068$ & 16,574 & $1 \%$ & $-290 \%$ & \\
\hline Ganancia (Pérdida) Neta de Operaciones Continuadas & & & & & & 3.8 & 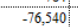 & 329 & -90, & $-32 \%$ & $-370 \%$ & \\
\hline Ganancia (Pérdida) Neta del Ejercicio & 163,656 & $6.51 \%$ & 240,196 & $9.61 \%$ & $-88,909$ & $-3.82 \%$ & $-76,540$ & 329,105 & $-86,905$ & $-32 \%$ & $-370 \%$ & $4337 \%$ \\
\hline
\end{tabular}

Fuente: AC Lindley (2018, 2017, 2016).

Elaboración propia. 


\section{Anexo 5: Propiedad, planta y equipo}

PROPIEDADES, PLANTA Y EQUIPO, NETO

(a) Composición del saldo:

El movimiento de la cuenta propiedades, planta y equipo y el de su correspondiente depreciación acumulada, por el año terminado el 31 de diciembre de 2017 y 2016, es el siguiente:

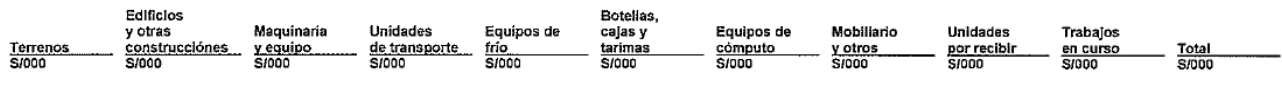

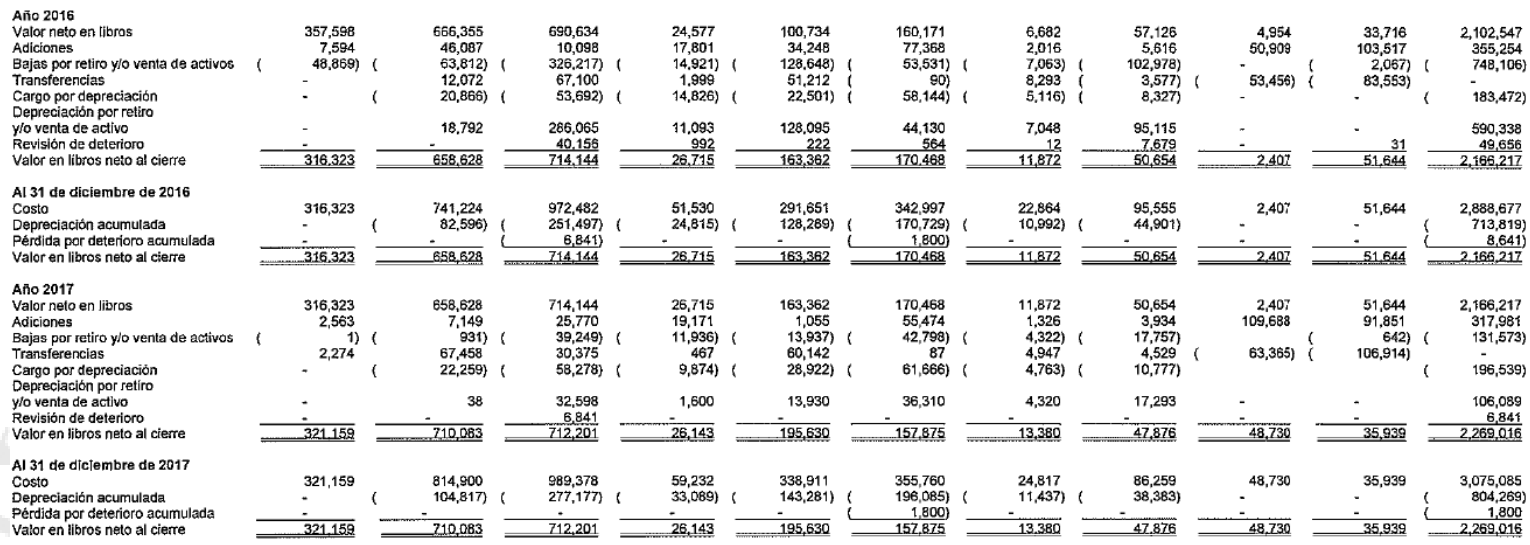

Fuente: PWC (2018) 


\section{Anexo 6: ESF Proyectado con NIIF 16 - Activos}

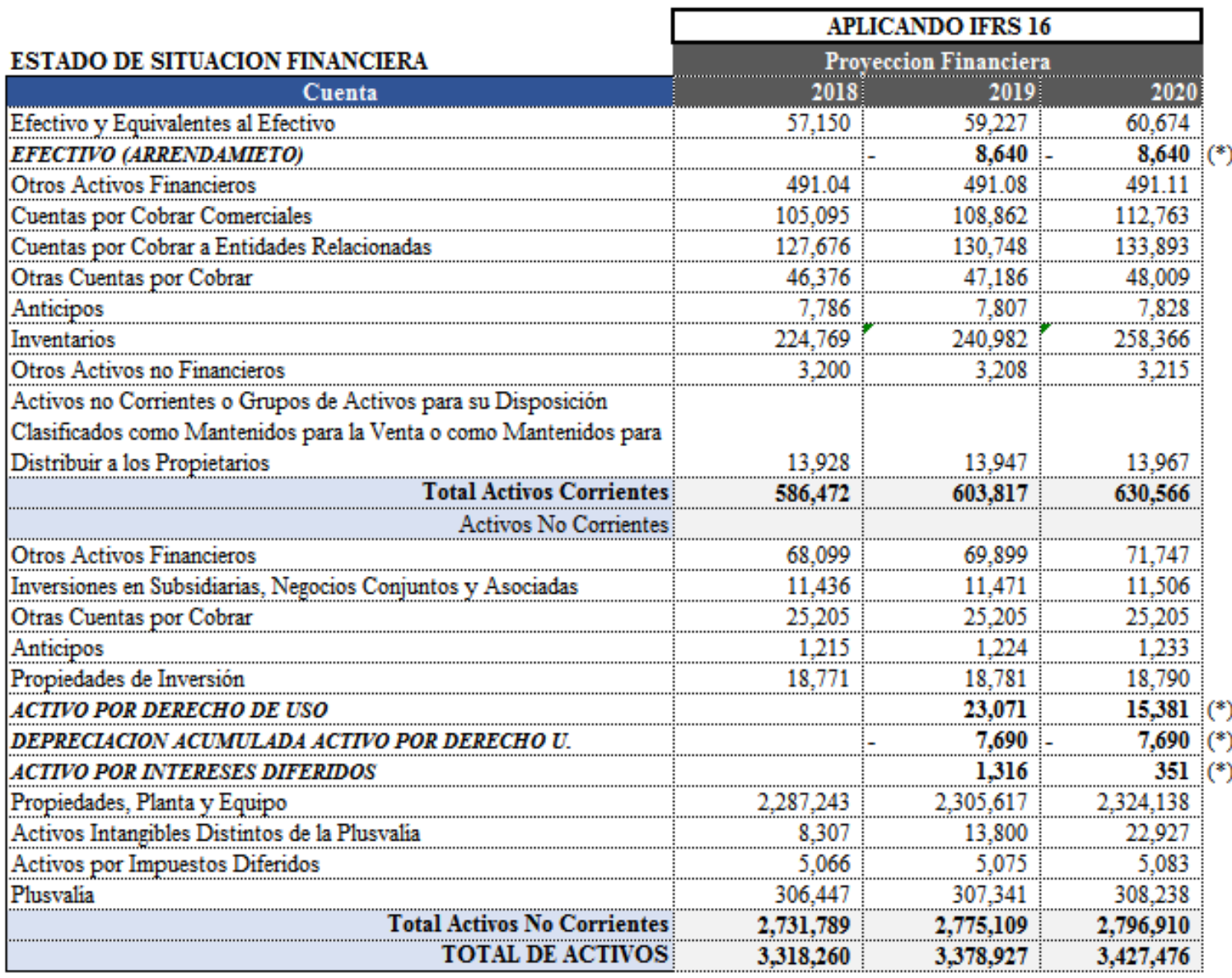

Fuente: AC Lindley (2018)

Elaboración propia. 


\section{Anexo 7: Estado de Situación Financiera Proyectado con NIIF 16 - Pasivos y Patrimonio}

\begin{tabular}{|c|c|c|c|}
\hline Cuenta & 2018 & 2019 & 2020 \\
\hline Otros Pasivos Financieros & 5,273 & 5,369 & 5,446 \\
\hline Cuentas por Pagar Comerciales & 518,710 & 528,194 & 535,783 \\
\hline Cuentas por Pagar a Entidades Relacionadas & 81,729 & 83,223 & 84,419 \\
\hline Otras Cuentas por Pagar & 93,657 & 95,370 & 96,740 \\
\hline Otras Provisiones & 25,136 & 25,595 & 25,963 \\
\hline Pasivos por Impuestos a las Ganancias & 28,168 & 28,683 & 29,095 \\
\hline Otros Pasivos no Financieros & 50,324 & 51,244 & 51,981 \\
\hline Total Pasivos Corrientes & 802,997 & 817,678 & 829,427 \\
\hline Otros Pasivos Financieros & $1,521,148$ & $1,478,346$ & $1,447,275$ \\
\hline PASIVO POR ARRENDAMIENTO & & 17,280 & 8,640 \\
\hline Otras Cuentas por Pagar & 12,469 & 12,697 & 12,880 \\
\hline Total Pasivos No Corrientes & $1,533,617$ & $1,508,323$ & $1,468,794$ \\
\hline Total Pasivos & $2,336,614$ & $2,326,001$ & $2,298,221$ \\
\hline Capital Emitido & 580,981 & 580,981 & 580,981 \\
\hline Acciones de Inversión & 71,523 & 71,523 & 71,523 \\
\hline Otras Reservas de Capital & 56,842 & 56,842 & 56,842 \\
\hline Resultados Acumulados & 333,665 & 404,944 & 481,274 \\
\hline Otras Reservas de Patrimonio & $-61,365$ & $-61,365$ & $-61,365$ \\
\hline Total Patrimonio & 981,646 & $1,052,925$ & $1,129,255$ \\
\hline TOTAL PASIVO Y PATRIMONIO & $3,318,260$ & $3,378,927$ & $3,427,476$ \\
\hline
\end{tabular}

Fuente: AC Lindley (2018).

Elaboración propia. 


\section{Anexo 8: Estado de Resultados Proyectado con NIIF 16}

\begin{tabular}{|c|c|c|c|}
\hline \multirow[b]{2}{*}{ ESTADO DE RESULTADOS } & \multicolumn{3}{|c|}{ APLICANDO IFRS 16} \\
\hline & \multicolumn{3}{|c|}{ Proyeccion Financiera } \\
\hline Cuenta" & 2018 & 2019 & 2020 \\
\hline Ingresos de Actividades Ordinarias & $2,635,105$ & $2,790,457$ & $2,945,810$ \\
\hline Costo de Ventas & $1,677,825$ & $1,776,741$ & $1,875,657$ \\
\hline Ganancia (Pérdida) Bruta & 957,280 & $1,013,717$ & $1,070,153$ \\
\hline Gastos de Ventas y Distribución & 567,053 & 600,484 & 633,914 \\
\hline Gastos de Administración & 110,482 & 116,996 & 123,509 \\
\hline Otros Ingresos Operativos & 178,201 & 188,707 & 199,213 \\
\hline Otros Gastos Operativos & 61,744 & 65,384 & 69,024 \\
\hline Ganancia (Pérdida) Operativa & 396,203 & 419,561 & 442,919 \\
\hline Ingresos Financieros & 11,081 & 11,735 & 12,388 \\
\hline Gastos Financieros & 189,420 & 200,587 & 211,754 \\
\hline GASTOS FINANCIEROS (ARRENDAMIENTO) & & 1,533 & 965 \\
\hline$D E P R E C L A C I O N(A R R E N D A M I E N T O)$ & & 7,690 & 7,690 \\
\hline Diferencias de Cambio Neto & 72,586 & 76,865 & 81,144 \\
\hline Ganancia (Pérdida) antes de Impuestos & 145,279 & 144,620 & 153,753 \\
\hline Ingreso (Gasto) por Impuesto & 69,258 & 73,341 & 77,424 \\
\hline Ganancia (Pérdida) Neta de Operaciones Continuadas & 76,021 & 71,279 & 76,330 \\
\hline Ganancia (Pérdida) Neta del Ejercicio & 76,021 & 71,279 & 76,330 \\
\hline
\end{tabular}

Fuente: AC Lindley (2018)

Elaboración propia 